\title{
SICUT EXPLORATOR ET SPOLIORUM CUPIDUS: ZU METHODE UND FUNKTION DER ANTIKENREZEPTION BEI NIKOLAUS VON VERDUN
}

\author{
VON SAMUEL VITALI
}

„Hin und wieder weht in diesen Bildern noch der unendlich schöpferische Geist griechischer Kunst, wie er sich in den Werken des Phidias aussprach ..." ${ }^{\text {"1 }}$ Mit diesem enthusiastischen Vergleich begründete Joseph Arneth bereits 1844, in der allerersten Publikation zum Klosterneuburger Altar, ein Paradigma, das die Fachliteratur über Nikolaus von Verdun bis heute prägt. So eng jedoch der Name des Goldschmieds mit dem Problem des Antikenstudiums im Mittelalter verknüpft ist: Der Umfang der Arbeiten, die sich ernsthaft mit dieser Frage auseinandersetzen, erweist sich bei näherem Hinsehen als überraschend bescheiden. Lange Zeit gab sich nämlich die Forschung mit unverbindlichen Formulierungen im Stile Arneths zufrieden ${ }^{2}$. Von einigen tastenden Versuchen abgesehen ${ }^{3}$, begann die Suche nach den konkreten Verbindungslinien zur antiken Kunst erst in der Nachkriegszeit. Dabei stand interessanterweise die Vermittlung klassischen Formenguts durch byzantinische oder karolingische Werke zunächst im Vordergrund"; immer wieder wurden Zweifel laut, ob Nikolaus überhaupt direkte Kenntnis der

\footnotetext{
* Der vorliegende Aufsatz stellt einen Extrakt meiner Lizentiatsarbeit „Antikenrezeption und Naturnähe: Zur Kunst des Nikolaus von Verdun" dar, welche 1995/96 bei Professor Claussen an der Universität Zürich entstanden ist. Für wertvolle Anregungen und konstruktive Kritik bin ich Peter Cornelius Claussen, Ferdinand Dohna, Björn Christian Ewald, Tobias Kämpf, Daniela Mondini, Dagmar Schumacher, Robert Suckale und nicht zuletzt meiner Frau Evelyne Vitali zu besonderem Dank verpflichtet.
}

Abgekürzt zitierte Literatur:

ASR I-V = Die antiken Sarkophag-Reliefs, hg. von C. ROBERT/G. RODENWALDT/F. MATZ, Berlin 1890ff.

1) A. CAMEsINa/J. ARNETH, Das Niello-Antipendium zu Klosterneuburg in Österreich, verfertigt im zwölften Jahrhunderte von Nikolaus aus Verdun, Wien 1844, S. 6.

$\left.{ }^{2}\right)$ Ähnlich vage Verweise auf die Antike finden sich bei F. Kugler, Handbuch der Kunstgeschichte, Bd. II, Stuttgart 1859, S. 187; C. SCHNAASE, Geschichte der bildenden Künste, Bd. V, Düsseldorf 1875, S. 621; O. von Falke/H. FraUBERGER, Deutsche Schmelzarbeiten des Mittelalters, Frankfurt 1904, S. 89; V. GrIESSMAIER, Der Emailaltar des Nikolaus von Verdun im Stifte Klosterneuburg bei Wien (Diss. Wien), Wien 1931, S. 208; S. GeVAert, L'orfèvrerie mosane au Moyen Age, Brüssel 1943, S. 28; L. RÉAU, Lambon en émail de Nicolas de Verdun à Klosterneuburg, in: Monuments et mémoires, Fondation Piot, 39, 1943, S. 119f., 122.

3) H. SchNirzler, Die Goldschmiedeplastik der Aachener Schreinswerkstatt (Diss. Bonn), Düren 1934, S. 60; A. WeISGERBER, Studien zu Nikolaus von Verdun und der rheinischen Goldschmiedekunst des 12. Jahrhunderts (Diss. Bonn = Kunstgeschichtliche Forschungen des Rheinischen Heimatbundes, 6), Bonn 1940, S. 122-26.

4) H. SCHNITZLER, Der Schrein des heiligen Heribert, Mönchengladbach 1962, S. 60; DERS., Nikolaus von Verdun, in: Kat. Der Meister des Dreikönigen-Schreins, in: Kölner Domblatt, 23/24, 1964, S. 422; E. KITZINGER, The Byzantine Contribution to Western Art of the Twelfth and Thirteenth Centuries, in: Dumbarton Oaks Papers, 20, 1966, S. 39-41; DERS., Byzantium and the West in the Second Half of the Twelfth Century: Problems of Stylistic Relationships, in: Gesta, 9/2, 1970, S. 49f.; O. Demus, Byzantine Art and the West: The Wrightsman Lectures, New York 1970, S. 180-187; V. GriEssmaIER, Nikolaus von Verdun: Überlieferung und Wirklichkeitserlebnis, in: Wiener Jahrbuch für Kunstgeschichte, 25, 1972, S. 35. 
griechisch-römischen Kunst hatte ${ }^{5}$. Neue Impulse gaben in den siebziger Jahren Hermann Fillitz und Peter Cornelius Claussen, die die klassische Komponente im Stil des Nikolaus zur Hauptsache aus dem unmittelbaren Studium antiker Werke - Schatzkunst, aber auch Porträtskulptur - zu erklären suchten ${ }^{6}$. Mit dem Diptychon der Nicomachi und Symmachi aus dem 4. Jahrhundert, das im Mittelalter nachweislich bekannt war, konnten sie zum erstenmal auch ein mutmaßliches Vorbild für den Goldschmied nennen.

Die nicht zuletzt durch die großen Ausstellungen der sechziger bis achtziger Jahre ausgelöste Welle von Publikationen zu Nikolaus von Verdun ${ }^{7}$ ist inzwischen verebbt. Statt die Ansätze von Fillitz und Claussen zu vertiefen, hat sich die Forschung weitgehend mit deren punktuellen Erkenntnissen begnügt ${ }^{8}$. Der Vergleich mit dem Nicomacher-Symmacher-Diptychon ist zu einer Art Passepartout für die Frage der Antikenrezeption am Klosterneuburger Ambo geworden, der zusammen mit den erwähnten Hinweisen auf byzantinische und karolingische Quellen alles zu erklären scheint.

Dabei bietet das Werk des Nikolaus ideale Voraussetzungen, um den Umgang eines hochmittelalterlichen Künstlers mit antiken Vorbildern zu studieren: Nirgendwo sonst in dieser Epoche können wir ein so großes CEuvre mit einem Namen verbinden, unabhängig davon, wie man die Frage nach der Zusammenarbeit innerhalb seiner Werkstatt beantwortet ${ }^{9}$. Der Umfang des Materials - Klosterneuburger Ambo, Marienschrein in Tournai sowie große Teile des Kölner Dreikönigenschreins - sollte es ermöglichen, nicht nur isolierte Beispiele von Antikenrezep-

5) W. SAUERLÄNDER, Gotische Skulptur in Frankreich 1130-1270, München 1970, S. 52; D. Kötzsche, Nikolaus von Verdun und die Kölner Goldschmiedekunst, in: Kat. Rhein und Maas: Kunst und Kultur 800-1400, Köln 1972-73, Bd. I, S. 314; GrIEsSmaIER, Nikolaus von Verdun (zit. Anm. 4), S. 35, 39. - Sauerländer hat seine Ansicht später revidiert (siehe unten, Anm. 113).

$\left.{ }^{6}\right)$ H. Filurrz, Zu Nikolaus von Verdun: Die Frage seiner antiken Anregungen, in: Kat. Rhein und Maas (zit. Anm. 5), Bd. II, S. 279-282; DERs., Nicolaus von Verdun, in: Kat. Die Zeit der Staufer: Geschichte, Kunst, Kultur, Bd. V Supplement, Stuttgart 1979, S. 279-290; P. C. Claussen, Zum Stil der Plastik am Dreikönigenschrein: Rezeptionen und Reflexionen, in: Kölner Domblatt, 42, 1977, S. 7-42; DERS., Nikolaus von Verdun: Über Antiken- und Naturstudium am Dreikönigenschrein, in: Kat. Ornamenta Ecclesiae: Kunst und Künstler der Romanik in Köln, Köln 1985, Bd. II, S. 447-455 (ergänzte Neufassung des Aufsatzes von 1977).

7) Der Meister des Dreikönigen-Schreins (Köln, Erzbischöfliches Diözesanmuseum, 1964); The Year 1200 (New York, Metropolitan Museum of Art, 1971); Rhein und Maas: Kunst und Kultur 800-1400 (Kunsthalle Köln und Brüssel, Musées royaux d'Art et d'Histoire, 1972); Monumenta Annonis: Köln und Siegburg: Weltbild und Kunst im hohen Mittelalter (Köln, Schnütgen-Museum, 1975); Die Zeit der Staufer: Geschichte, Kunst, Kultur (Stuttgart, Württembergisches Landesmuseum, 1977); Ornamenta Ecclesiae: Kunst und Künstler der Romanik in Köln (Köln, Josef-Haubrich-Kunsthalle, 1985).

$\left.{ }^{8}\right)$ Neues haben lediglich zwei Dissertationen über den Klosterneuburger Ambo beigetragen, welche sich allerdings in erster Linie mit ikonographischen Fragen auseinandersetzen: M. SHIKIDA, Das Bilddenken am „Verduner Altar“: Ein Beitrag zum „Nikolaus-Problem“ (Diss. Bonn), Bonn 1988; F. DAHM, Studien zur Ikonographie des Klosterneuburger Emailwerkes des Nicolaus von Verdun (Dissertationen der Universität Wien, 197), Wien 1989. Der Aufsatz von F. RöHrig, Nikolaus von Verdun und die Antike, in: Kat. Sehnsucht nach der Antike, Klosterneuburg 1992, S. 5-13, beschränkt sich hingegen im wesentlichen darauf, die Thesen von Fillitz zusammenzufassen. In der jüngsten Publikation zum Thema kamen O. DauterT/C. LIND, Der Dreikönigenschrein des Kölner Doms: Die Propheten des Nikolaus von Verdun als Beispiele antikisierender Skulpturenauffassung um 1200, in: Kat. Meisterwerke mittelalterlicher Skulptur, hg. von H. КROHM, Berlin 1996, S. 89, gar zum Schluß, es werde „kaum möglich sein, bestimmte [antike] Vorbilder für diesen Künstler nachzuweisen ${ }^{\star}$.

9) Es soll an dieser Stelle unterstrichen werden, daß wir weder über die Person des Nikolaus von Verdun noch über die Beteiligung von Gehilfen oder Mitarbeitern an den signierten bzw. zugeschriebenen Arbeiten etwas Genaueres wissen. Wenn in der Folge vom Künstler oder seiner Werkstatt die Rede ist, so ist dies also cum grano salis zu verstehen. Das heikle Problem der Händescheidung kann in diesem Rahmen nicht diskutiert werden. 
tion zu identifizieren, sondern sie auch im Zusammenhang zu untersuchen: Bei welcher Gelegenheit rekurriert Nikolaus von Verdun auf antike Vorlagen, welche Intentionen stehen dahinter und in welcher Weise wurden einmal übernommene Motive in der Werkstatt weiterverarbeitet?

Der meist wenig reflektierte Begriff „Antikenstudium“ deckt in der bildenden Kunst ein weites Feld sehr unterschiedlicher Phänomene ab. Wenn wir uns einmal auf den formalen Aspekt beschränken - die Übernahme antiker Themen kommt im Werk des Nikolaus nicht vor -, so muß zum einen zwischen der Aneignung klassischer Elemente durch die Vermittlung z. B. byzantinischer oder karolingischer Werke und dem direkten Studium antiker Kunst unterschieden werden. Zum anderen sind ganz verschiedene Spielarten von Rezeption möglich. Die Skala reicht von der allgemein stilbildenden Funktion der Vorbilder bis zur eigentlichen Antikenkopie, bei der eine bestimmte Vorlage oder ein Teil davon mehr oder weniger getreu in einen neuen Zusammenhang transferiert wird ${ }^{10}$. Das Ergebnis, d. h. die Nähe zum Modell, kann dabei stark divergieren, je nachdem, ob nur das Motiv, z. B. eine bestimmte Körperhaltung, oder auch Figuren- und Gewandstil übernommen werden ${ }^{11}$.

So bedeutend etwa die Imitation klassischer Gewandmodellierung für das Erscheinungsbild der Kunst des Nikolaus ist, so sind doch für unsere Fragestellung Beispiele von Antikenkopien sehr viel aufschlußreicher. Denn was ein Künstler in der Antike suchte, kann nur rekonstruiert werden, wenn es gelingt, seine Auswahl der Modelle zu analysieren - wobei es ebenso aufschlußreich ist festzustellen, was aus dem potentiellen Angebot an „verfügbarer“ Antike nicht berücksichtigt wurde ${ }^{12}$. Daher soll hier nicht einfach mit Hilfe der üblichen assoziativen Bildvergleiche illustriert werden, welcher Art die möglichen Vorlagen des Goldschmieds gewesen sein dürften; vielmehr gilt es antike Stücke zu identifizieren, die im 12. Jahrhundert erwiesenermaßen zugänglich waren und mit einiger Wahrscheinlichkeit der Werkstatt des Nikolaus als Vorbilder dienten - nur auf diesem Weg sind Aussagen über dessen Rezeption der griechischrömischen Kunst möglich.

Ausgangspunkt für eine solche Untersuchung muß fast zwangsläufig der Klosterneuburger Ambo sein - nicht nur, weil diese im 14. Jahrhundert zu einem Altarretabel umgearbeitete Kanzelverkleidung in der chronologischen Abfolge des Nikolaus-Euvres am Anfang steht, sondern auch weil sie mit ihrem typologischen System von ursprünglich 45 biblischen Szenen eine große Vielfalt an Figurentypen und Bildthemen bietet und daher die Suche nach Antikenkopien die besten Aussichten auf Erfolg hat ${ }^{13}$.

$\left.{ }^{10}\right)$ Der nächste Schritt wäre dann die Spolie, also die materielle Integration von Antike. Vgl. R. HAMANNMacLeAn, Antikenstudium in der Kunst des Mittelalters, in: Marburger Jahrbuch für Kunstwissenschaft, 15, 1949/50, S. 160-200, der seinen Abschnitt über die stilistische Bedeutung der antiken Kunst in die Kapitel „Spolienwesen“, „Kopien" und „Imitation, Rezepte" gliedert.

11) Vgl. zur Unterscheidung von Motiv und Stil auch FiLırrz, Nicolaus von Verdun (zit. Anm. 6), S. 282.

${ }^{12}$ ) Zum Problem der Selektion eines antiken Vorbilds vgl. die Überlegungen von S. SETTIS, Verbreitung und Wiederverwertung antiker Modelle, in: H. BECK/K. Hengevoss-DürKop (Hg.), Studien zur Geschichte der europäischen Skulptur im 12./13. Jahrhundert, Frankfurt a. M. 1994, Bd. I, S. $358 f$.

${ }^{13}$ ) Für eine umfassende Bibliographie zum Klosterneuburger Ambo vgl. H. Frl.rrz/M. PIPPAL, Schatzkunst: Die Goldschmiede- und Elfenbeinarbeiten aus österreichischen Schatzkammern des Hochmittelalters, Salzburg/Wien 1987, S. 206f. An seither erschienener Literatur ist neben den in Anm. 8 aufgeführten Arbeiten zu nennen: M. PIPPAL, Inhalt und Form bei Nicolaus von Verdun: Bemerkungen zum Klosterneuburger Ambo, in: BECK/HeNGEvoss-DüRKOP, Studien (zit. Anm. 12), Bd. I, S. 367-380; A. ArnulF, Studien zum Klosterneuburger Ambo und den theologischen Quel- 
Es ist hier vor allem eine an sich kleine Zahl von weiblichen Figuren, die jeweils als Kronzeugen für den antikisierenden Stil des Werks herangezogen werden: die Maria in der Geburt Christi (II/2) ${ }^{14}$ und in der Kreuzigung (Abb. 16) sowie die Königin von Saba bei der Begegnung mit Salomon (Abb. 13) ${ }^{15}$. Immer wieder hat auch die nackte Gestalt Christi in der Taufe (Abb. 19) ihre Betrachter an antike Kunst gemahnt ${ }^{16}$. Daneben haben eine Reihe von Rückenfiguren das Interesse der Forschung auf sich gezogen, d.h. jene Gestalten, deren Körper ganz oder teilweise von hinten gesehen ist und dabei oft eine ganz organisch wirkende Drehbewegung beschreibt (vgl. Abb. 5, 8, 22). Der allgemeine Eindruck von Antikennähe hängt aber vor allem mit dem für sämtliche Figuren charakteristischen Gewandstil zusammen, der in der Regel mit dem etwas unscharf gewordenen Etikett „Muldenfaltenstil“ versehen wird ${ }^{17}$. Kennzeichnend ist dafür neben der differenzierten, raumhaltigen Faltenzeichnung die Unterscheidung zwischen Körper und Gewand. Am gelungensten erscheint sie dort, wo die Stoffbahnen durch die Bewegung der Figur so gerafft sind, daß sie an Rücken, Gesäß und Beinen eng anliegen und das Volumen des Körpers von den Konturen her gleichsam herausmodellieren (vgl. Abb. 2, 7 , $5,8,10,22)$.

Gleichzeitig sind aber, was die Rolle antiker Vorbilder betrifft, drei grundsätzliche Einschränkungen zu machen.

Erstens bildet Formengut der zeitgenössischen abendländischen Kunst zweifellos die Grundlage des Figurenstils am Klosterneuburger Ambo ${ }^{18}$. Diese Verankerung in der Tradition ist besonders augenfällig im Bereich der Stand- und Sitzmotive: Die überwiegende Mehrheit der Figuren zeigt für das 12. Jahrhundert typische Haltungen. So nimmt Johannes in der Szene der Kreuzigung (Abb. 16) mit leicht gebeugten Knien und nach vorne geneigtem Oberkörper eine unentschiedene Pose zwischen Stehen und Schreiten ein, die in dieser oder ähnlicher Form am Klosterneuburger Ambo wie in der romanischen Kunst insgesamt allgegenwärtig ist. Unter den Sitzfiguren finden sich gar keine spezifisch antiken Typen ${ }^{19}$. Selbst die immer wieder als

len bildlicher Typologien von der Spätantike bis 1200, in: Wiener Jahrbuch für Kunstgeschichte, 48, 1995, S. 9-41; G. Pоснат, Bild - Zeit: Zeitgestalt und Erzählstruktur in der bildenden Kunst von den Anfängen bis zur frühen Neuzeit, Wien 1996, Kap. XIV, S. 187-201.

$\left.{ }^{14}\right)$ Die Numerierung der hier nicht reproduzierten Szenen bezieht sich auf H. BUSCHHAUSEN, Der Verduner Altar, Wien 1980, wo alle Platten in Farbreproduktionen abgebildet sind.

15) Schon von Falke/Frauberger, Deutsche Schmelzarbeiten (zit. Anm. 2), S. 89, weisen auf diese drei Figuren hin.

16) Erstmals Griessmaier, Emailaltar (zit. Anm. 2), S. 208.

17) Über diesen Begriff scheint selbst im Kreis der Fachleute keine Einigkeit zu bestehen. Entgegen der traditionellen Lehrmeinung, wonach der Klosterneuburger Ambo die „Geburtsstunde“ der Muldenfalten markiert (vgl. P. LASKO, Ars sacra 800-1200 [The Pelican History of Art, 36], Harmondsworth 1972, S. 248, mit genauer Begriffsbestimmung), äußerte Anton von Euw in einem Vortrag am Wiener C.I.H.A.-Kolloquium über Nikolaus von Verdun (1995) die Ansicht, die Grubenschmelzplatten zeigten noch keinen Muldenfaltenstil - allerdings ohne den Terminus neu zu definieren.

${ }^{18}$ ) Die Forschung hat Voraussetzungen und Parallelen nicht nur im maasländischen und kölnischen, sondern auch im nordfranzösisch-südenglischen Kunstkreis festgestellt; vgl. dazu BusCHHAUSEN, Verduner Altar (zit. Anm. 14), S. 104 f., und insbesondere SHIKIDA, Bilddenken (zit. Anm. 8), S. 16-43.

${ }^{19}$ ) Die Darstellungen von Abraham (I/2), Manoah (III/2) und Jakob (I/12) sind mit alttestamentarischen Gestalten auf den etwa gleichzeitig entstandenen Glasfenstern von Canterbury verglichen worden (M. H. CAVINEss, The Early Stained Glass of Canterbury Cathedral, Princeton 1977, S. 73; BuschHausEN, Verduner Altar [zit. Anm. 14], S. 105), welche zum Teil auch gewisse Parallelen in der Faltenbildung aufweisen: Vgl. beispielsweise das Faltengeschlinge der Gewänder von Christus beim Einzug in Jerusalem (II/6) und von Lamech in Canterbury (CAvINEss, Early Stained 
besonders klassisch bezeichneten thronenden Christusfiguren auf den Weltgerichtsplatten (I/16; II/17) bedürfen keiner Ableitung aus antiken Quellen. Was hier an die Antike erinnert, etwa die Hängefalten oder die diagonalen Zerrfalten zwischen den Beinen, ist Allgemeingut des Mittelalters aus dem griechisch-römischen Erbe, das erst durch den neuen Gewandstil seinen klassischen Charakter erhält.

Doch auch der Faltenwurf entspricht nicht immer der antiken Formensprache. Oft werden Formeln verwendet, die aus dem Musterkatalog der maasländischen oder rheinischen Tradition stammen und einfach in den neuen Stil übertragen werden. Ein Beispiel ist das Motiv der parallel untereinandergesetzten V-förmigen Schüsselfalten zwischen den Beinen von stehenden Figuren (vgl. Abraham in der Isaaksverkündigung, Abb. 4; noch ausgeprägter auf den Platten $\mathrm{II} / 3, \mathrm{I} / 16, \mathrm{II} / 16)$, das beispielsweise auch am Maurinusschrein vorkommt ${ }^{20}$. Obwohl Hängefalten unterhalb der Knie dem natürlichen Fall des Gewandes widersprechen, hat das Motiv vermutlich dennoch einen "naturalistischen " Zweck, nämlich die plastische Hervorhebung der Beine durch die angrenzende glatte Fläche. In diesem Sinne wird es gleichberechtigt neben den antikennahen und "richtigeren“ Vertikal- oder Diagonalfalten eingesetzt; die Variationsmöglichkeiten, die sich daraus ergeben, erhöhen den Abwechslungsreichtum, die varietas, der Darstellung ${ }^{21}$.

Zweitens ist der direkte Kontakt mit Mustern aus dem byzantinischen Bereich nicht zu unterschätzen. Auf die Rezeption zeitgenössischer byzantinischer Werke, wie sie in der westlichen Kunst gegen Ende des 12. Jahrhunderts oft begegnet, hat besonders Kitzinger aufmerksam gemacht ${ }^{22}$. Es soll hier genügen, auf die Gestaltung des nackten Körpers, beispielsweise beim Gekreuzigten (Abb. 16) hinzuweisen: Während das Prinzip der Binnenzeichnung mit doppelt geführten Linien typisch ist für die maasländische Emailkunst, basiert die Gliederung der Bauchmuskulatur auf dem byzantinischen „Doppel-M-Schema“23.

Mehrfach wurde darüber hinaus angenommen, daß Nikolaus von Verdun auch Kenntnis früherer Stilstufen der östlichen Kunst hatte. Richard Hamann-MacLean vermutete eine der Hauptquellen für die expressiven Tendenzen am Klosterneuburger Ambo in der Miniaturmalerei des 10. und 11. Jahrhunderts, insbesondere im sogenannten Menologium Basileios' II. (Vat. gr. 1613), und stellte zur Illustration dem Samson aus der Löwenkampfszene die Gestalt

Glass, Abb. 13). Die Draperien in den Glasmalereien zeigen teilweise sogar Ansätze zu Muldenfalten (z. B. beim Pharao in der Szene des Roten Meeres, ebenda, Abb. 30).

${ }^{20}$ ) In der Szene der Steinigung des heiligen Stephanus, abgebildet bei H. ScHNTTZLER, Rheinische Schatzkammer, Bd. 2: Die Romanik, Düsseldorf 1959, Taf. 98.

${ }^{21}$ ) Zum Konzept der varietas, das aus der antiken Rhetoriktheorie stammt, siehe B. BRENK, Spolien und ihre Wirkung auf die Ästhetik der „varietas“, in: J. POESCHKE (Hg.), Antike Spolien in der Architektur des Mittelalters und der Renaissance, München 1996, S. 76.

${ }^{22}$ ) KrtZINGER, Byzantine Contribution (zit. Anm. 4), S. 39; ähnlich Demus, Byzantine Art (zit. Anm. 4), S. 180f. SHIKIDA, Bilddenken (zit. Anm. 8), S. 93f., hat gegen Kitzingers Vergleich zwischen dem Engel in der Verkündigung Christi (II/1) und jenem in der Vertreibung aus dem Paradies in der Cappella Palatina richtig eingewendet, daß das byzantinische Schrittmotiv, bei dem das nähere statt wie üblich das hintere Bein nach vorne gesetzt ist, auch durch westliche Werke vermittelt worden sein kann; doch ein für die mittelbyzantinische Kunst charakteristisches Detail wie die ganz graphische Fältelung über dem rechten Knie legt doch die direkte Kenntnis eines (möglicherweise plastischen) byzantinischen Modells nahe (vgl. z. B. die Maria Platytera in S. Maria Mater Domini in Venedig, abgebildet bei R. LANGE, Die byzantinische Reliefikone, Recklinghausen 1964, Abb. 6).

${ }^{23)}$ In der französischen und maasländischen Kunst wurde sonst bis ins 13. Jahrhundert in der Regel ein stärker abstrahierendes dreieckförmiges Muster verwendet (vgl. J. WerrzmAnN-FiEDLER, Die Aktdarstellung in der Malerei, Straßburg 1934, S. 82f.). 
eines Schlächters aus dieser Handschrift gegenüber ${ }^{24}$. Signifikanter ist meines Erachtens die Übereinstimmung zwischen der Figur eines anderen Schergen aus demselben Codex (Abb. 1) und jener des Samson mit den Toren von Gaza (Abb. 2), die das Haltungsmotiv mit den weit ausschreitenden Beinen und den erhobenen Armen ziemlich genau reproduziert ${ }^{25}$. Diese Parallele ist aber innerhalb des umfangreichen Bildmaterials des Basileios-Menologiums zu isoliert, um einen direkten Zusammenhang zwischen dem Original oder einer Kopie der Handschrift und dem Klosterneuburger Emailwerk bezeugen zu können. Für die Bedeutung der spätmakedonischen Buchmalerei für Nikolaus von Verdun lassen sich jedoch weitere Indizien finden. Ein schönes Beispiel liefert die Miniatur des betenden Propheten aus einer Jesaias-Handschrift (Vat. gr. 755) des frühen 11. Jahrhunderts (Abb. 3) ${ }^{26}$. Die Gestalt des Jesaias zeigt frappierende Ähnlichkeiten zum Abraham auf der ersten Platte in Klosterneuburg (Abb. 4); besonders eng ist die Verwandtschaft im Bereich der oberen Körperhälfte: Kopftypus sowie Haltung und Draperie der Arme sind, wenn wir von den durch Medium und Stil bedingten Differenzen abstrahieren, beinahe identisch. Einzig in der (vom ikonographischen Kontext vorgegebenen) gebückteren Postur und in der Gewandbildung an den Beinen weicht die Figur des Abraham von der Miniatur ab. Die beiden übrigen Illustrationen der Handschrift bieten aber wiederum keine weiteren Berührungspunkte zum Emailwerk, und gleichzeitig weist keine andere Fassung des Jesaias-Gebets innerhalb der byzantinischen Buchmalerei des 10. und 11. Jahrhunderts denselben Figurentyp auf ${ }^{27}$. All dies legt den Schluß nahe, daß Nikolaus von Verdun Gelegenheit hatte, einen verlorenen Kodex oder vielleicht noch eher ein Musterbuch spätmakedonischer Zeit zu studieren.

Diese Rezeption byzantinischer Miniaturen betrifft nur die Figurenschemata, nicht den Stil der Darstellung, d. h. Proportionen und Körperlichkeit der Figuren sowie Details der Ge-

24) R. Hamann-MacLean, Byzantinisches und Spätantikes in der Werkstatt des Nikolaus von Verdun, in: Kölner Domblatt, 42, 1977, besonders S. 253-255. Bei dieser Prachthandschrift, die für Kaiser Basileios II. um 986 in Konstantinopel angefertigt wurde, handelt es sich eigentlich um ein Synaxar (vollständig publiziert in: Il menologio di Basilio II, Torino 1907). - Die Ähnlichkeit zwischen den beiden Figuren ist auf den ersten Blick evident. Bei näherem Hinsehen zeigt sich allerdings, daß weder die Haltung des Oberkörpers noch die Beinstellung, noch die Gewandstruktur genau übereinstimmen; jene Merkmale, die Hamann-MacLean hervorhebt - die „etwas manierierte Bewegung“, der „leicht karikierte Profilkopf“ und die Muskelzeichnung - sind aber in der byzantinischen Kunst weit verbreitet und deshalb zuwenig aussagekräftig.

${ }^{25}$ ) Filurrz, Nicolaus von Verdun (zit. Anm. 6), S. 277, vergleicht die Samson-Platte mit einem spätantiken Elfenbeinrelief im Bayerischen Nationalmuseum, bei dem sich die Übereinstimmung aber auf die Schrittstellung beschränkt. - M. PIPPAL, Beobachtungen zur „Zweiten“ Ostermorgenplatte am Klosterneuburger Ambo des Nicolaus von Verdun, in: Wiener Jahrbuch für Kunstgeschichte, 35, 1982, S. 118, weist darauf hin, daß sich die Samson-Darstellung in Klosterneuburg von der älteren Bildtradition durch den Realismus unterscheidet, mit dem das kraftvolle Emporschreiten und das Tragen der schweren Türflügel geschildert sind. Genau in diesem Bemühen um eine naturnähere Wiedergabe der Szene dürfte die Motivation dafür zu suchen sein, daß der Goldschmied auf eine Vorlage aus einem anderen Kunstkreis und einem völlig anderen ikonographischen Kontext rekurrierte.

$\left.{ }^{26}\right) \mathrm{Zu}$ diesem Kodex vgl. J. LowDEN, Illuminated Prophet Books: A Study of Byzantine Manuscripts of the Major and Minor Prophets, University Park/London 1988, S. 22-25, 65-69.

$\left.{ }^{27}\right)$ Die übrigen Versionen dieses Darstellungstypus, der auf eine Illustration im Pariser Psalter gr. 139 zurückgeht, sind aufgelistet bei LowDEN, Prophet Books (zit. Anm. 26), S. 67. - Interessanterweise zeigt der Knabe neben dem Propheten, welcher die Morgendämmerung verkörpert, im Bewegungsmotiv auffällige Parallelen zum vorderen Kundschafter mit der Traube aus dem gelobten Land (III/9). Da für diesen aber auch eine unmittelbare Vorstufe auf den Emailtafeln im Wiener Diözesanmuseum existiert (BuschHAusEN, Verduner Altar [zit. Anm. 14], Abb. 16e), mag die Übereinstimmung zufällig sein. 
wandbildung ${ }^{28}$. Mit der gleichen Einschränkung zeigt sich die Übernahme östlicher Muster am Klosterneuburger Ambo vielleicht noch deutlicher bei den Kopftypen ${ }^{29}$. Wie Birgit Bänsch festgestellt hat, ist in diesem Bereich von einem relativ begrenzten Repertoire an festgelegten Schemata Gebrauch gemacht worden, die je nach Bedarf durch die Hinzufügung von Falten oder durch unterschiedliche Haar- und Barttracht variiert wurden ${ }^{30}$. Während die jugendlichen Gesichter glatt bleiben, werden zur Andeutung des Alters bzw. von körperlicher oder seelischer Anspannung eine Reihe von im Prinzip gleichbleibenden Binnenlinien eingesetzt: Typisch sind die Zeichnung der Stirnfalten - einfach oder doppelt geführte Bogen über den Augenbrauen, darüber horizontale Wellenlinien (vgl. z. B. Abb. 2) - sowie die beim Nasenflügel ansetzende Falte entlang dem Oberlippenbart. Am augenfälligsten ist die Rezeption byzantinischer Vorlagen bei den Engeln sowie bei den frontal gegebenen Christusfiguren, für die die Künstler dem sogenannten Drei-Kreise-Schema gefolgt sind ${ }^{31}$. Doch auch die meisten übrigen Köpfe sind auf östliche Prototypen zurückzuführen; wieder liefern spätmakedonische Handschriften die besten Parallelen. Schon der obige Vergleich des Klosterneuburger Abraham mit dem Jesaias der vatikanischen Handschrift offenbart enge Übereinstimmungen auch in den Gesichtszügen. Noch überzeugender veranschaulicht den Sachverhalt der Kopf des Jeremias aus einem anderen Prophetenbuch des späten 10. Jahrhunderts (Abb. 18) ${ }^{32}$, welcher einen bestimmten langbärtigen Typus des Ambos (zu sehen beispielsweise bei Johannes dem Täufer, Abb. 19) in allen Details vorwegnimmt - bis hin zu den Haarlocken auf den Schultern und den bogenförmigen Falten über den Augenbrauen. Der Profilkopf des Schergen aus dem Basileios-Menologium mit halblangem, in Stirn und Nacken gelocktem Haar (Abb. 1) kehrt unter anderem beim jüngsten König in der Anbetungsszene (II/4) oder bei den Auferstehenden im Jüngsten Gericht (III/16) wieder. In den Grundzügen, besonders der Partie um Nase, Mund und Augen, gilt diese Ty-

${ }^{28}$ ) Auch für die Entstehung des Muldenfaltenstils wurden aber immer wieder östliche Vorbilder verantwortlich gemacht. Vergleiche mit georgischen Silberikonen, stellvertretend für die weitgehend verlorene Goldschmiedekunst Konstantinopels aus dem 11. und 12. Jahrhundert, (SCHNITZLER, Schrein [zit. Anm. 4], S. 60; DERS., Nikolaus von Verdun [zit. Anm. 4], S. 422) oder mit den - praktisch zeitgleich entstandenen - Mosaiken in Monreale und Inkrustationen in Esztergom (H. BuschHAusen, The Klosterneuburg Altar of Nicholas of Verdun: Art, Theology and Politics, in: Journal of the Warburg and Courtauld Institutes, 37, 1974, S. 2f, 6) vermögen diese These nicht überzeugend zu belegen (vgl. Hamann-MacLean, Byzantinisches und Spätantikes [zit. Anm. 24], S. 252f, und Fillitz, Nicolaus von Verdun [zit. Anm. 6], S. 280f). Eher könnten dafür frühbyzantinische Elfenbeinarbeiten in Frage kommen, eine These, die KrrzINGER, Byzantine Contribution (zit. Anm. 4), S. 171, und Demus, Byzantine Art (zit. Anm. 4), S. 185, aufgebracht hatten, v. a. in bezug auf Dreikönigenschrein und Marienschrein (s. unten, Anm. 99). SHIKIDA, Bilddenken (zit. Anm. 8), S. 57, hat den Ansatz aufgegriffen und vermutet, daß die Erzengelplatte des British Museum der Nikolaus-Werkstatt bekannt. gewesen sein muß, da sie die Vorlage für das Motiv des Gewandes, das Elias dem Elisäus über die Schulter geworfen hat, geliefert habe. Die vergleichbare Faltenpartie ist jedoch zu klein und die Übereinstimmung zuwenig exakt, um einen direkten Zusammenhang schlüssig zu belegen. Solange wir die Bedeutung der frühbyzantinischen Elfenbeinreliefs für Nikolaus von Verdun aber an keinem konkreten Beispiel festmachen können, bleibt sie eine reine Hypothese.

${ }^{29}$ ) Darauf hat zuerst LASKO, Ars sacra (zit. Anm. 17), S. 248, hingewiesen.

$\left.{ }^{30}\right)$ B. BÅNsCH, Kölner Goldschmiedekunst um 1200 - Muster und Modelle (Diss. Münster), Münster (Westfalen) 1984, S. 87-95. Diese Muster wurden offenbar, so Bänsch, mittels Pausen auf die Platten übertragen, was daran zu erkennen ist, daß die entsprechenden Köpfe exakt dieselben Maße und Proportionen aufweisen. Auch bei Frisuren und Bärten gibt es eine Reihe von mehrfach wiederkehrenden Schemata.

$\left.{ }^{31}\right)$ Ebenda, S. 90. Zum Drei-Kreise-Schema, bei dem die Umrisse von Gesicht, Haaren und Nimbus mit Hilfe von drei konzentrischen Kreisen konstruiert werden, vgl. E. PANOFSKY, Sinn und Deutung in der bildenden Kunst, Köln 1975 , S. 82-86.

$\left.{ }^{32}\right) \mathrm{Zu}$ diesem Kodex, der nur noch diese eine Illustration enthält, vgl. LowDEN, Prophet Books (zit. Anm. 26), S. $14-22$. 
penverwandtschaft für praktisch alle Köpfe auf dem Emailwerk; die fast karikaturhafte Überspanntheit und asketische Spiritualität, die die byzantinischen Gesichter zuweilen auszeichnet, ist aber einem ruhigeren, klassischeren Gesamteindruck gewichen ${ }^{33}$.

Drittens wird in der Diskussion um den stilistischen „Pedigree“ des Klosterneuburger Ambo immer wieder auf die karolingische und ottonische Kunst hingewiesen, die Nikolaus von Verdun unter anderem auch antikes Formengut und Körperverständnis vermittelt habe - sei es in Ergänzung zu antiken Vorbildern oder als Ersatz dafür ${ }^{34}$. In der Tat haben besonders die Elfenbeinarbeiten der großen karolingischen und ottonischen Werkstätten der Forschung eine ganze Reihe von Vergleichsbeispielen geliefert, und zwar gerade für die oben erwähnten Rückenfiguren. Als Beispiel sei die Himmelfahrtsplatte im Wiener Kunsthistorischen Museum (Abb. 7) erwähnt, auf die Fillitz hingewiesen hat ${ }^{35}$. Der Apostel rechts von Maria weist mit den in weitem Schwung die Beine umziehenden Faltenbahnen große Ähnlichkeit zur Marienfigur in der Himmelfahrt Christi am Ambo (Abb. 5) auf; beim zweiten Apostel von links ist das Schrittmotiv des Elisäus zu beobachten (Abb. 8). Für diese besonders bewunderte Emailfigur existieren allerdings noch bessere Pendants, beispielsweise der Verkündigungsengel auf einem einst in Berlin aufbewahrten Täfelchen (Abb. 9). In beiden Fällen stellen sich aber ähnliche Probleme ein wie bei den Vergleichen mit byzantinischen Werken: Wohl stimmen die Figuren- und manchmal sogar die Faltenschemata überein; doch die klassisch anmutenden, ausgewogenen Proportionen und die feine Differenzierung der Gewänder, die die Klosterneuburger Emails auszeichnen, sucht man in den karolingischen Arbeiten meist vergeblich. Rückenfiguren mit vergleichbaren Bewegungsmotiven kommen zudem bei näherem Hinsehen quer durch die europäische Kunstgeschichte vor ${ }^{36}$ : ausgehend von der griechischen Kunst in spätantiken Elfenbeinwerken ${ }^{37}$ ebenso wie in der ottonischen Buchmalerei ${ }^{38}$ oder am Heribertschrein (Abb. 6).

33) SHIKIDA, Bilddenken (zit. Anm. 8), S. 33f, hat beobachtet, daß die Köpfe von Klosterneuburg auch jenen in Teilen der Winchester-Bibel sehr ähnlich sind - und zwar handelt es sich um die byzantinisierenden Stilrichtungen des „Genesis Master" und des „Master of the Morgan Leaf“. Es ist deshalb denkbar, daß byzantinisches Formengut auch durch Vermittlung über England aufgenommen wurde. Da aber die genaue Datierung der Miniaturen des Morgan- und des Genesis-Meisters umstritten ist (W. OAKeshotт, The Two Winchester Bibles, Oxford 1981, S. 114, datiert sie in die siebziger Jahre, L. M. AYrES, The Work of the Morgan Master at Winchester and English Painting of the Early Gothic Period, in: The Art Bulletin, 56, 1974, bes. S. 217-221, in die Zeit nach 1180), ist hier Vorsicht geboten.

${ }^{34}$ ) Weisgerber, Studien zu Nikolaus von Verdun (zit. Anm. 3), S. 123-126; Schnitzler, Schrein (zit. Anm. 4), S. 60-63; Griessmaier, Nikolaus von Verdun (zit. Anm. 4), S. 36-39; Filurtz, Nicolaus von Verdun (zit. Anm. 6), S. 281; DERS., Zu Nikolaus von Verdun (zit. Anm. 6), S. 285; DAHM, Studien zur Ikonographie (zit. Anm. 8), S. 12f., 18. - H. SwARZENSKI, The Style of Nicholas of Verdun: Saint Amand and Reims, in: Gatherings in Honor of Dorothy E. Miner, Baltimore 1974, S. 111-114, dachte gar an eine doppelt gebrochene Antikenrezeption, indem er als eine entscheidende Quelle für den Nikolaus-Stil die Evangelistenporträts aus der Schule von Saint-Amand in der Diözese Tournai bezeichnete, welche ihrerseits Kopien von Reimser Miniaturen der karolingischen Renaissance sind.

${ }^{35}$ ) Filırtz, Zu Nikolaus von Verdun (zit. Anm. 6), S. 281. Zum Problem der Datierung dieser Arbeit (karolingisch oder ottonisch?) vgl. zuletzt U. SurmanN, Studien zur ottonischen Elfenbeinplastik in Metz und Trier: Nordenfalks Sakramentar- und Evangeliargruppe (Diss. Bonn 1989), Witterschlick/Bonn 1990, S. 183-189, 253-288.

36) Daнm, Studien zur Ikonographie (zit. Anm. 8), S. 39. Vgl. M. Koch, Die Rückenfigur im Bild von der Antike bis zu Giotto, Recklinghausen 1965.

${ }^{37}$ ) Vgl. z. B. die akklamierende Figur links unten auf der Vorderseite des Probianus-Diptychons in der Berliner Staatsbibliothek (W. F. VolBaCH, Elfenbeinarbeiten der Spätantike und des frühen Mittelalters, Mainz 19763 ${ }^{3}$ Nr. 62, Taf. 34) oder die rechte Muse auf dem Fragment einer Pyxis (?) im Rheinischen Landesmuseum Trier (ebenda, Nr. 89, Taf. 49).

${ }^{38}$ ) So die zentrale Apostelfigur in der Szene des Pfingstwunders im Codex Egberti (Staatsbibliothek Trier) und im Perikopenbuch Ms. b21 der Bremer Stadtbibliothek [KocH, Rückenfigur (zit. Anm. 36), Abb. 27, 28]. 
Mit der zeitlichen Nähe wächst dabei tendenziell auch die formale Entfernung zum Klosterneuburger Ambo: Die Darstellung des Propheten Amos am Heribertschrein nimmt zwar das Bewegungsmotiv des Elisäus in den Grundzügen vorweg ${ }^{39}$, doch ist der Körper dabei als in die Fläche eingebundenes, fast schwereloses Gebilde aufgefaßt.

Ähnlich verhält es sich mit jenen Figuren, deren Gewand sich durch die Haltung der Arme eng um Rücken und Beine spannt und so radial ausstrahlende Faltenkonfigurationen bildet; seine schönste Ausprägung findet dieses Motiv am Mantel des Aaron, der das Manna in die Bundeslade stellt (Abb. 10). Vergleichbare Gewandmuster sind in der karolingischen Kunst ${ }^{40}$ oder, um ein zeitlich näherliegendes Beispiel zu nennen, am Lütticher Taufbecken anzutreffen ${ }^{41}$. Bessere Parallelen zur Aaron-Figur bieten aber Greisendarstellungen der antiken Kunst. Die Gestalt des alten Thestius auf der Vorderseite eines Leda-Sarkophags in Aix-en-Provence (Abb. 11) zeigt nicht nur dieselbe gebückte Haltung mit gekrümmtem Rücken und vorgestrecktem Arm, sondern auch die gleiche Auffassung von Körper und Gewand: Im Bereich zwischen Oberschenkel- und Armkontur ist die plastische Masse der Glieder deutlich von dem nur vom dünnen Gewand überspannten Raum dazwischen abgesetzt, was die transparente Wirkung des Stoffes erzeugt, die der Johannes-Figur am Lütticher Taufbecken fehlt $t^{42}$.

Letztlich läuft also die Untersuchung der Stilbildung bei Nikolaus von Verdun auf die alte Frage survival oder revival hinaus: Beruhen diese Figuren, die uns so beharrlich an die klassische Kunst erinnern, auf vereinzelten Antikenkopien oder auf jenen Formeln, die das Mittelalter aus dem Altertum ererbt und beständig weitertradiert hatte und die nun durch ein neues, an der Antike geschärftes Interesse am menschlichen Körper wieder zum Leben erweckt wurden? Die Methode des Bildvergleiches stößt hier an ihre Grenzen; solange wir nicht in der Lage sind, zumindest in einem Fall aufgrund eindeutiger Indizien ein direktes Abhängigkeitsverhältnis zu rekonstruieren, kann über die Antwort auf diese Frage nur spekuliert werden. Aufgrund der besseren Zugänglichkeit zeitgenössischer Vorlagen, aber auch der Routine, mit der auf den Klosterneuburger Emails rein mittelalterliche Figurentypen durch antikennahen Gewandstil und Körperlichkeit transformiert wurden, sollte im Zweifelsfall der zweiten Option, d. h. der These des survival oder des revival aus zweiter Hand (nach karolingischen Werken), als lectio facilior zunächst der Vorzug gegeben werden ${ }^{43}$.

Wenn man sich nicht auf den Standpunkt stellen will, daß der Goldschmied gleichsam in einem Akt sokratischer Anamnesis aus eigener Kraft von den schattenhaften Abbildern in der jüngeren Kunst zu den „Ideen“, dem Stil der Klassik, zurückfand ${ }^{44}$, so stellt sich die Frage, wel-

${ }^{39}$ ) Vgl. BuschHausen, Verduner Altar (zit. Anm. 14), S. 104.

${ }^{40}$ ) Z. B. bei der Figur der Ecclesia auf einem Buchdeckel im Kathedralschatz von Tournai (A. GoLDSCHMIDT, Die Elfenbeinskulpturen, Berlin 1914-1926, Bd. I, Nr. 160, Taf. LXXI).

${ }^{41}$ ) Griessmaier, Nikolaus von Verdun (zit. Anm. 2), S. 49. Abb. Kat. Rhein und Maas (zit. Anm. 5), Bd. I, S. 239.

${ }^{42}$ ) Das ins 3. Jahrhundert datierte Sarkophagfragment war bis Ende des 16. Jahrhunderts in die Wand einer Kapelle der Kathedrale von Aix-en-Provence vermauert (C. ROBERT, ASR II: Mythologische Zyklen, Berlin 1890, Nr. 2, S.6f).

${ }^{43}$ ) Relativ eindeutig scheint mir dieser Sachverhalt im Falle der Maria in der Geburtsszene, die immer wieder mit den „Tauschwestern“ vom Ostgiebel des Parthenon verglichen wurde; zuletzt hat noch SHIKIDA, Bilddenken (zit. Anm. 8), S. 101, eine antike Vorlage angenommen. Die Figur dürfte aber auf einen karolingischen Typus zurückgehen: Die Maria in der Geburtsdarstellung auf einem elfenbeinernen Buchdeckel des 9. Jahrhunderts im British Museum (GoLDSCHMIDT, Elfenbeinskulpturen [zit. Anm. 40], Bd. I, Nr. 24, Taf. XIII) zeigt genau die gleiche Körperhaltung mit den im Gegensatz zu entsprechenden antiken Darstellungen (vgl. dazu H. WREDE, Stadtrömische Monumente, Urnen und Sarkophage des Klinentypus in den beiden ersten Jahrhunderten n. Chr., in: Archäologischer Anzeiger, 1977, S. 395-431) fast durchgestreckten Beinen.

${ }^{44}$ ) Explizit wurde eine solche These selbstverständlich nie formuliert; sie wäre aber die logische Konsequenz aus 
che konkreten antiken Vorbilder bei einem solchen Wiederbelebungsprozess als Katalysatoren wirkten. Diese sind jedoch wiederum nur dann zu fassen, wenn sie an irgendeiner Stelle möglichst genau imitiert wurden. Eigentliche Antikenkopien bleiben also der einzige Schlüssel zum Verständnis der Antikenrezeption des Nikolaus von Verdun.

Der bislang erfolgreichste Versuch in diese Richtung geht auf Hermann Fillitz und Peter Cornelius Claussen zurück. Fillitz sah in der Figur der Priesterin auf der Rückseite des Diptychons der Nicomacher und Symmacher (Abb. 12), das Claussen in die Diskussion um das Antikenstudium im Mittelalter eingebracht hatte ${ }^{45}$, das unmittelbare Vorbild für die Königin von Saba am Klosterneuburger Ambo (Abb. 13) ${ }^{46}$. Die These ist deshalb besonders suggestiv, weil sich das Elfenbeindiptychon, ein klassizistisches Werk aus dem Umkreis der heidnischen Reaktion des ausgehenden 4. Jahrhunderts ${ }^{47}$, im Mittelalter im Schatz der Benediktinerabtei Montier-enDer befand, nur knapp 90 Kilometer von Verdun entfernt ${ }^{48}$. Fillitz' Vorschlag wurde daher von der Forschung mit seltener Einmütigkeit angenommen, und der Vergleich ist geradezu emblematisch geworden für das Antikenstudium des Nikolaus von Verdun. Einzig Claussen äußerte sich etwas vorsichtiger, indem er feststellte, daß ,man keinesfalls von Nachahmung oder gar Kopie sprechen kann" und wohl ein „Erinnerungsbild“ genügt haben dürfte ${ }^{49}$. Tatsächlich beschränkt sich die Übereinstimmung zwischen den beiden Figuren auf die Haltung und einen Teil der Faltenzüge, namentlich jene lange, leicht geschwungene Diagonalfalte zwischen den Beinen und die ungefähre Linienführung am unteren Ende des Gewandes; verwandt ist auch die Art, wie sich das dünne Kleid an Spielbein und Brust den Körperformen anpaßt. Abgesehen von manchen Divergenzen in den Details der Faltenzeichnung unterscheidet sich aber die Gewandung der Priesterin (ärmelloser Chiton und Himation) grundsätzlich von jener der Königin von Saba. Deren oberhalb der Hüfte mit viel Überhang gegürtetes Kleid entspricht auch sonst keinem im Altertum geläufigen Typus. Der Gewandbausch über dem Gürtel mag Assoziationen an klassische Werke wecken; er kann aber ebensogut aus zeitgenössischen Mustern abgeleitet $\operatorname{sein}^{50}$. Auch die Kombination von Hänge- und Diagonalfalten kommt in der mittelalterlichen Kunst recht häufig, in der antiken dagegen äusserst selten vor ${ }^{51}$. Wenn die Königin

der Feststellung der Antikennähe einerseits und der oft geäußerten Vermutung andererseits, daß der Künstler vor allem oder gar ausschließlich byzantinische oder frühmittelalterliche Vorlagen verarbeitet habe (s. oben, Anm. 4, 5).

${ }^{45}$ ) P. C. Claussen, Antike und gotische Skulptur in Frankreich um 1200, in: Wallraf-Richartz-Jahrbuch, 35, 1973, S. 83-108.

${ }^{46}$ ) Filurtz, Zu Nikolaus von Verdun (zit. Anm. 6), S. 280f.; DERs., Nicolaus von Verdun (zit. Anm. 6), S. 283; FILLITZ/PIPPAL, Schatzkunst (zit. Anm. 13), S. 205.

$\left.{ }^{47}\right)$ Zum Diptychon zuletzt: D. KINNEY, The Iconography of the Ivory Diptych Nicomachorum-Symmachorum, in: Jahrbuch für Archäologie und Christentum, 37, 1994, S. 64-96; DIES., A Late Antique Ivory Plaque and Modern Response, in: American Journal of Archeology, 98, 1994, S. 437-480 (mit Angabe der älteren Literatur).

${ }^{48}$ ) Es galt dort als Geschenk des Abteigründers, des hl. Bercharius; die Tafeln hatten daher den Status von Reliquien und wurden um 1200 als Türflügel eines Reliquiars verwendet, das in einem Stich aus dem frühen 18. Jahrhundert überliefert ist. Siehe dazu P. C. Claussen, Das Reliquiar von Montier-en-Der: Ein spätantikes Diptychon und seine mittelalterliche Fassung, in: Pantheon, 36, 1978, S. 308-319.

49) Claussen, Zum Stil der Plastik (zit. Anm. 6), S. 26.

$\left.{ }^{50}\right)$ Vgl. z. B. die Figur des disputierenden Paulus auf einem um 1160 entstandenen Grubenschmelzplättchen im Victoria and Albert Museum, London (H. SwarZENSKI, Monuments of Romanesque Art: The Art of Church Treasures in North-Western Europe, London 1954, Abb. 445).

${ }^{51)}$ Vgl. besonders karolingische Werke, so die Figur der Bathseba auf dem Einband zum Psalter Karls des Kahlen (GolDSCHMidT, Elfenbeinskulpturen [zit. Anm. 40], Bd. I, Nr. 40, Taf. XIX), die schon GrIEssmaIER, Nikolaus von Verdun (zit. Anm. 4), S. 37, der Königin von Saba gegenübergestellt hat. Vgl. aber auch den Engel im Relief der Berufung 
von Saba also direkt von einem antiken Vorbild inspiriert ist, dann kann sich der Künstler nur sehr vage daran angelehnt haben; und daß das Vorbild die Figur auf der Nicomacher-Tafel war, ist allein durch diesen Bildvergleich nicht zu belegen.

Wenn man von den flüchtigen Bemerkungen in der älteren Literatur absieht, ist die Maria in der Kreuzigung Christi (Abb. 16) bisher kaum in den Antikendiskurs einbezogen worden - erstaunlicherweise, denn die physische Präsenz der sorgfältig ponderierte Figur und die elegante Drapierung des Gewandes, das ihre Körperrundungen in fast unpassend sinnlicher Weise zur Geltung bringt, wirken mindestens ebenso antikisch wie bei der Königin von Saba. Mit Ausnahme des Kopftuches könnte die Bekleidung - langes Untergewand und ein um den Körper geschlungener weiter Mantel - in diesem Fall tatsächlich einen römischen Gewandtyp reflektieren (vgl. Abb. 14 - man beachte die vom Stoff umhüllte Hand, die das Mantelende festhält). Die Suche nach einem antiken Prototyp drängt sich also hier geradezu auf. Masako Shikida meinte diesen in der bisher vernachlässigten Vorderseite des Diptychons aus Montier-en-Der (Abb. 13) gefunden zu haben: Sowohl die Maria als auch der Johannes der Kreuzigungsszene seien in Gewandung und Positur von der Priesterin der Symmacher-Tafel abhängig52. In der Anlage der Figuren sehe ich keinen Zusammenhang; erstaunliche Übereinstimmungen bestehen aber in der Tat im Faltenduktus: Allen drei Figuren gemeinsam sind die senkrechten Falten des Obergewandes, die in die mäandernde Zickzacklinie des Saums münden; am rechten Unterschenkel der Maria finden sich die in diagonale Furchen übergehenden, teils eckig gebrochenen, teils runden Querfalten vom hinteren Oberschenkel der Priesterin wieder, und auch die schmalen Falten des Untergewandes mit darin eingeschlossenen langgezogenen Mulden sind bei der Maria sehr ähnlich. Wenn man die untere Hälfte der zwei Frauenfiguren nebeneinanderhält, so kann man sich dem Eindruck kaum entziehen, daß zwischen ihnen ein unmittelbarer Zusammenhang besteht: Die Formensprache ist fast identisch, auch wenn die einzelnen Elemente unterschiedlich angeordnet sind.

Für die Pose der Maria kann jedoch die Symmacher-Tafel nicht das Vorbild abgegeben haben. Ein solches müßte man sich eher in der Art der trauernden Frauengestalt am MeleagerSarkophag der Villa Albani (Abb. 17) vorstellen ${ }^{53}$; doch abgesehen von der bescheidenen Qualität und der ganz anderen Gewandung fehlt hier die eigentümliche Haltung des linken Armes, der waagrecht unterhalb der Brust an den Körper gelegt ist, wobei die Hand den rechten Unterarm umfaßt. Bei diesem dem heutigen Betrachter nicht mehr ohne weiteres verständlichen Motiv handelt es sich um einen in der mittelalterlichen Kunst geläufigen Trauergestus, durch den ein Mensch seinen ohnmächtigen Schmerz angesichts eines unabänderlichen Ereignisses (insbesondere des Todes) zum Ausdruck bringt ${ }^{54}$. Es scheint also, daß der Goldschmied hier

Davids an der Fassade von Saint-Gilles (W. S. STODDARD, The Facade of Saint-Gilles-du-Gard, Middletown [Connecticut] 1973, Abb. 68) oder die in Anm. 50 erwähnte Figur. Aus der Antike kann eine Frauenfigur am sogenannten Plotin-Sarkophag im Vatikan (M. WEGNER, ASR V 3 : Die Musensarkophage, Berlin 1966, Nr. 133, Taf. 60) genannt werden.

52) SHIKIDA, Bilddenken (zit. Anm. 8), S. 56.

${ }^{53}$ ) Man beachte die Übereinstimmung in Fuß- und Beinstellung. Was Bekleidung und Faltenschemata im Bereich der Beine betrifft, so kommt die Braut vom Hochzeitssarkophag in der St. Petersburger Eremitage (abgebildet bei C. REINSBERG, Das Hochzeitsopfer - eine Fiktion: Zur Ikonographie der Hochzeitssarkophage, in: Jahrbuch des Deutschen Archäologischen Instituts, 99, 1984, S. 294, Abb. 1) der Maria noch näher, weicht von dieser aber in der Haltung des Oberkörpers ab.

${ }^{54)}$ Vgl. F. Garnier, Le langage de l'image au Moyen Âge, Bd. I: Signification et symbolique, Paris 1982, S. 198-201 und Abb. 102, sowie Bd. II: La grammaire des gestes, S. 102f. Auffällig ist, daß die Klosterneuburger Maria im Vergleich 
kein antikes Muster als Ganzes übernommen hat, sondern einen bestimmten antiken Frauentyp mit der vom ikonographischen Kontext geforderten mittelalterlichen Verzweiflungsgeste sowie Gewandformeln der Symmacher-Tafel kombinierte. Der Anteil direkt rezipierten antiken Formenguts ist aber offensichtlich größer als bei der Königin von Saba.

Reflexe der Symmacher-Tafel sind auch auf anderen Platten des Klosterneuburger Ambos sichtbar. Dem Studium des antiken Elfenbeins dürfte es unter anderem zu verdanken sein, daß das Stilmittel des entlang der Körperkontur gestrafften Gewandes hier sehr viel subtiler als zuvor in der mittelalterlichen Kunst eingesetzt ist ${ }^{55}$. So kehren die um Bein oder Gesäß herumgedrehten feinen Falten, die sich dann in diagonalen Rinnen fortsetzen, bei der Gestalt des schreibenden Juden in der Szene „Percussio Egipti“ (I/12) oder bei der Maria in der Himmelfahrt Christi (Abb. 5) in ganz ähnlicher Form wieder; an zahlreichen anderen Figuren ist dasselbe Prinzip in freier Variation angewandt worden.

Während sich also einerseits die These verdichtet, daß Nikolaus das Diptychon tatsächlich studiert hat, so ist andererseits festzustellen, daß er in diesem Fall das Gesehene bemerkenswert souverän und eigenständig in seine Arbeit umgesetzt hat. Die Formensprache der Elfenbeinreliefs hat den neuen Faltenstil des Goldschmieds mitgeprägt und sicherlich auch zum Verständnis des menschlichen Körpers in seiner Dreidimensionalität beigetragen; eigentliche Kopien der Figuren sind aber nicht auszumachen. Während wir die Gestalt der Königin von Saba immerhin noch als Reflex der Priesterin auf dem Nicomacher-Flügel ansehen können, so ist der Figurentypus der Symmacher-Priesterin als ganzer in keinem der drei erhaltenen Werke wiederzufinden.

Mehrfach ist darauf hingewiesen worden, daß die auch im Norden des ehemaligen Römischen Reiches in großen Mengen hergestellten antiken Kleinbronzen eine Rolle bei der Stilbildung des Nikolaus gespielt haben könnten ${ }^{56}$; Versuche, diese These zu untermauern, wurden aber kaum unternommen ${ }^{57}$. So ist der Forschung das offenkundigste Beispiel für die Adaptation einer solchen Bronzestatuette in die Emailtechnik entgangen: Die fast übertrieben kon-

zu den von Garnier gezeigten Figuren, welche sich als Zeichen ihrer Ohnmacht d. h. Handlungsunfähigkeit meist die Hand oder das Handgelenk festhalten, den Unterarm weit oben faßt, beinahe beim Ellbogen. Ich halte es nicht für ausgeschlossen, daß diese Lösung von einem antiken Vorbild beeinflußt ist: $\mathrm{Zu}$ vergleichen wäre etwa die Gestalt der Phaedra an der linken Schmalseite eines Hyppolitos-Sarkophages im Museum von Arles (C. ROBERT, ASR III: Einzelmythen, 2. Abt.: Hippolytos-Meleagros, Berlin 1904, Nr. 160, Fig. 160a), welche den linken Unterarm ebenfalls unterhalb der kräftig hervortretenden Brust waagrecht an den Körper gelegt hat, so daß die Hand sich auf der Höhe des Ellbogens des nach oben angewinkelten rechten Arms befindet; siehe auch den nahe verwandten Pudicitia-Gestus der Frau in Abb. 14.

${ }^{55)}$ Vgl. SHIKIDA, Bilddenken (zit. Anm. 8), S. $56 f$.

56) Solche Stücke sind sicherlich auch im 12. Jahrhundert ans Tageslicht gekommen und, sei es auch nur zur Einschmelzung, durch die Hände von Goldschmieden gewandert. Antike Bronzestatuetten vermutete man bereits als Vorbilder für die Figuren des Lütticher Taufbeckens (W. OAKESHOTT, Classical Inspiration in Mediaeval Art, London 1959, S. 88; A. LeGner, Die Rinderherde des Reiner von Huy, in: Kat. Rhein und Maas [zit. Anm. 5], Bd. II, S. 249), des Prager Leuchterfußes, des Trivulzio-Kandelabers sowie des Giebelkamms am Anno-Schrein (CLAussen, Zum Stil der Plastik [zit. Anm. 6], S. 22-24; DERS., Antikisierende Kleinplastik im Vorfeld und Umkreis des Nikolaus von Verdun, in: Römische Historische Mitteilungen, 41, 1999 [= Festschrift Hermann Fillitz], S. 95-116); überzeugend sind auch die Vergleiche von H. R. HAHnLOSER, Villard de Honnecourt: Kritische Gesamtausgabe des Bauhüttenbuches ms. fr 19093 der Pariser Nationalbibliothek, Wien 1972², Abb. 139-139a, und J. AdHÉMAR, Influences antiques dans l'art du Moyen Âge français: Recherches sur les sources et les thèmes d'inspiration, London 1939, S. 279f, Abb. 106-111, die eine Reihe der Aktdarstellungen Villards de Honnecourt mit solchen Bronzefigürchen in Verbindung bringen.

${ }^{57}$ ) Hamann-MacLean, Byzantinisches und Spätantikes (zit. Anm. 24), S. 248f, bildet eine Minerva-Statuette des Römisch-Germanischen Museums in Köln neben der Isaaksverkündigung von Klosterneuburg ab, um die Bedeutung antiker Muster für den Gewandstil des Nikolaus zu verdeutlichen; die Ähnlichkeit bleibt aber relativ vage. 
trapostische Haltung des Christus in der Taufe (Abb. 19) entspricht genau dem Muster der nackten Götterfigur, das in unzähligen Beispielen überliefert ist. Beim Typus einer Marsfigur aus Reims (Abb. 20), der fast ausschließlich in der Gallia Belgica und in den angrenzenden Gebieten verbreitet war $^{58}$, erstreckt sich die Übereinstimmung sogar auf die Haltung des linken Armes $^{59}$. Dabei ist es zu einer eigentümlichen Fusion zwischen dem antiken Akttypus und den zeitgenössischen (maasländisch-byzantinischen) Darstellungsgewohnheiten gekommen. Während die Beine übermäßig lang und die Taille sehr schmal geraten ist, verraten die kräftige Muskulatur der Arm- und Schulterpartie und ein Überrest des charakteristischen Muskelwulstes an den Hüften noch deutlich das antike Vorbild. Das byzantinische Muster der Bauchmuskulatur und die schematische Angabe der Rippen des Brustkorbes entsprechen wiederum ganz dem Stil der Zeit. Die Wirkung der Aktfiguren auf dem Email ist durch die parzellierende Technik der energischen Doppellinien ohnehin eine ganz andere („byzantinischere“) als in der antiken Skulptur, in der die weiche Modellierung in der Binnenzeichnung nur wenige scharfe Konturen entstehen läßt. Interessanterweise schlagen die antiken Muster vor allem bei manchen zweitrangigen und deshalb weniger von Darstellungskonventionen geprägten Figuren, etwa beim in den Brunnen gestürzten Joseph (I/11) oder bei den Seligen im himmlischen Jerusalem (I/17) stärker durch, wo der Thorax muskulöser, ohne Andeutung der Rippen und mit einfachen Linien gezeichnet ist.

Friedrich Dahm hat bei der Suche nach den ikonographischen Wurzeln der Szene des Auszugs aus Ägypten (Abb. 22) die Vorlagen der Goldschmiede erstmals auf heidnischen Sarkophagen vermutet: Für jedes der drei auf den Schultern beziehungsweise im Arm getragenen Kinder, deren Nacktheit in den frühchristlichen und mittelalterlichen Fassungen des Themas ohne Parallele ist, konnte er ein analoges Beispiel auf römischen Sarkophagen mit der Darstellung des Triumph- oder Hochzeitszugs des Dionysos finden ${ }^{60}$. Dahms Bildvergleiche sind optisch unmittelbar einleuchtend; die Frage allerdings, auf welchem Weg diese Typenübertragung zustande kam bzw. wo die Künstler solche Sarkophage überhaupt sehen konnten, klammerte er aus. In dieser Hinsicht sind durchaus präzisere Aussagen möglich.

Das Motiv des Satyrn, der einen kleinen Satyrisken auf Schulter oder Arm trägt, ist tatsächlich sehr verbreitet auf den dionysischen Sarkophagen. ${ }^{61}$ Von den auf dem Email wiederkehrenden Typen ist die Variante des seitlich im Arm getragenen Kindes, das sich mit beiden Händen an seinem Träger festhält, recht häufig anzutreffen, wobei sich aber keiner der erhaltenen Sarkophage als Vorlage aufdrängt ${ }^{62}$. Der Sonderfall des huckepack auf den Schultern sitzenden

${ }^{58)}$ Vgl. S. BOUCHER, Recherches sur les bronzes figurés de Gaule pré-romaine et romaine, Roma 1976, S. 88 und Karte Nr. XII, S. 386.

${ }^{59}$ ) Beide Arme in dieser Stellung haben Bronzestatuetten mit adoratio-Gestus (vgl. z. B. G. M. A. RicHTER, The Metropolitan Museum of Art: Greek, Etruscan and Roman Bronzes, New York 1915, Nr. 89); es ist mir jedoch nicht gelungen, ein Beispiel zu finden, das auch die gleiche Körperhaltung wie der Taufchristus zeigt.

${ }^{60}$ ) DAHM, Studien zur Ikonographie (zit. Anm. 8), S. 24-27.

$\left.{ }^{61}\right)$ F. MATZ, ASR IV: Die dionysischen Sarkophage, Berlin 1968-75, Bd. 1, S. 48-50, weist es in seinem Typenkatalog auf 50 Exemplaren nach.

${ }^{62}$ ) Am nächsten kommt der Emailfigur der Satyrisk auf dem Sarkophag von Pozzuoli (DAHM, Studien zur Ikonographie [zit. Anm. 8], Abb. 12), welcher auch das charakteristische Element des abgewandten Kopfes zeigt; über die Provenienz dieses Stücks ist aber offenbar nichts Näheres bekannt (zumindest keine Angaben in MaTz, ASR IV [zit. Anm. 51], Bd. 1, Nr. 58A, S. 166). Die übrigen Beispiele sind dem Email weniger ähnlich und sind zudem meist erst in neuerer Zeit entdeckt worden, so auch der von Dahm angeführte Sarkophag im Louvre, der 1804 bei St-Médard-d'Eyran ausgegraben wurde (E. ESPÉRANDIEU, Recueil général des bas-reliefs (statues et bustes) de la Gaule romaine, Paris 
Knaben, der auf der Klosterneuburger Platte zweimal vorkommt, ist dagegen äußerst selten: Im erhaltenen Denkmälerbestand ist er nur noch auf zwei Sarkophagen in Cambridge und London nachzuweisen ${ }^{63}$, welche Dahm denn auch als mögliche Vorbilder für die Klosterneuburger Platte heranzieht. Das Exemplar in Cambridge kommt aber dafür nicht in Frage, da es erst im 19. Jahrhundert in Südkreta gefunden worden ist ${ }^{64}$. Das von einer Frau getragene hintere Kind auf dem Email, welches Dahm mit dem Sarkophag in Verbindung bringt, bedarf dieser Ableitung ohnehin nicht, denn gerade das charakteristische Motiv des Reliefs - der Satyr hält den Kleinen am ausgestreckten Ärmchen fest - fehlt in Klosterneuburg; viel einfacher ist die Figur als Umformung des schon beim vorderen Knaben verwendeten Schemas zu erklären. Letzterer sitzt ebenfalls rittlings auf den Schultern des bärtigen Mannes und hält sich mit den Händen an dessen Kopf fest - die Analogie zum Satyrisken auf dem von Dahm erwähnten Dionysos-Sarkophag im British Museum (Abb. 23) ist evident. Dieser Typ ist nun aber in der gesamten griechisch-römischen Kunst völlig einmalig65, so daß wir die Existenz verlorener Sarkophage mit dem gleichen Motiv zumindest nicht voraussetzen können. Der Londoner Sarkophag befand sich spätestens seit dem frühen 15. Jahrhundert in S. Maria Maggiore in Rom, wo er unter anderem schon von Lorenzo Ghiberti studiert wurde ${ }^{66}$; die Chancen stehen gut, daß er dort bereits im 12. Jahrhundert zu sehen war und daher möglicherweise selbst das Vorbild für die Klosterneuburger Figur lieferte. Wir hätten in diesem Fall erstmals ein Indiz für die oft postulierte Italienreise des Nikolaus ${ }^{67}$ - nicht mehr als ein Indiz allerdings, denn eine direkte Beziehung zwischen Sarkophag und Email ist, auch angesichts des schlechten Zustands des Reliefs, schwer zu belegen. Die Sitzhaltung und der füllige Körperbau mit den ausladenden Gesäßbacken würden dafür sprechen; das Kind auf dem Sarkophag streckt jedoch den hinteren Arm nach einer Traube in der Hand des Satyrn aus und wird von diesem am Unterschenkel statt am Knie festgehalten. Da auf den Platten des Klosterneuburger Ambos sonst keine eindeutigen Spuren des Sarkophagreliefs auszumachen sind, muß die Frage nach dem Zusammenhang zwischen den beiden Werken wenigstens vorläufig offen bleiben.

Die römische Sarkophagplastik ist als „Musterkatalog “ für Nikolaus von Verdun bisher zweifellos zuwenig in Betracht gezogen worden. Christliche wie heidnische Sarkophage waren, als Grablegen für Heilige und Fürsten begehrt oder in Bruchstücken für Kirchenausstattungen verwendet und in Fassaden vermauert, im 12. Jahrhundert vermutlich der am besten bekannte und öffentlich sichtbare Bereich der antiken.Kunstproduktion ${ }^{68}$. Einem solchen reimpiego verdankt

1907-1938, Bd. II, Nr. 1240, 1242, S. 214, 220). Daß das Muster, das übrigens am Ambo gleich noch zweimal eingesetzt wurde (in den Szenen II/3 und - ohne Kopfwendung - I/2), von einem verschollenen dionysischen Sarkophag stammt, erscheint mir dennoch plausibel.

${ }^{63}$ ) Matz, ASR IV (zit. Anm. 51), Bd. 1, S. 48.

${ }^{64)}$ Ebenda, Bd. 3, S. 263, Nr. 129.

$\left.{ }^{65}\right)$ Ebenda, Bd. 1, S. 48.

${ }^{66)}$ Ebenda, Bd. 2, Nr. 88, S. 204f. Vgl. B. DegenharT, Michele di Giovanni di Bartolo: Disegni dall'Antico e il camino „della Iole“, in: Bolletino d'Arte, 35, 1950, S. 208-215; R. KraUTHEIMER, Lorenzo Ghiberti, Princeton 1970, II, S. 344, Nr. 26, 27.

67) Zuletzt von Griessmaier, Nikolaus von Verdun (zit. Anm. 4), S. 50; Hamann-MacLean, Byzantinisches und Spätantikes (zit. Anm. 24), S. 264.

$\left.{ }^{68}\right)$ Vgl. dazu: I. RAguSA, The Re-use and public exhibition of Roman sarcophagi during the middle ages and the early Renaissance, Diss. New York 1961; B. ANDREAE /S. SeTris (Hg.), Colloquio sul reimpiego dei sarcofagi romani nel medioevo, Marburg/Lahn 1984; M. Greenhalgh, The Survival of Roman Antiquities in the Middle Ages, London 1989, S. 189-201. 
auch das Fragment eines ursprünglich dreijochigen Säulensarkophags aus der Mitte des 3. Jahrhunderts mit der Darstellung eines älteren Ehepaares und einem Philosophen in der Ny Carlsberg Glyptothek Kopenhagen (Abb. 21) seine Erhaltung: Wie das Flachrelief auf der Rückseite mit der stilisierten Darstellung von Vögeln mit Weintrauben zwischen Flechtbändern bezeugt, wurde die Platte vermutlich in langobardischer Zeit als Altarfront oder Teil einer Schrankenanlage wiederverwertet ${ }^{69}$. Dies ist deshalb von Interesse, weil die Frau auf dem Relief frappierende Ähnlichkeiten mit der hintersten Figur im Auszug aus Ägypten (Abb. 22) aufweist. Beide sind in einen weiten, über den Kopf gezogenen Mantel gehüllt und zeigen dasselbe Bewegungsmotiv: Die rechte Seite ist nach vorne geschoben, so daß der Körper schräg von hinten zu sehen ist, der Kopf aber ins Profil gedreht. Die Übereinstimmungen reichen bis in die Details der Gewandfalten, die auf dem Rücken und um die Beine langgezogene Kurven beschreiben, während sich dazwischen das Gesäß deutlich abzeichnet. Nur ist auf dem Email die über den linken Arm herabhängende Stoffmasse reduziert und das Gewand an Rücken und Beinen gestrafft - als hätte der Künstler die stärkere Hebung des rechten Armes einkalkuliert. Da Provenienz ${ }^{70}$ und Rückseitenbearbeitung der Kopenhagener Platte nach Italien weisen und nicht sicher ist, ob das antike Relief in der mittelalterlichen Anordnung überhaupt sichtbar war, ist auch bei der Deutung dieses Zusammenhangs Vorsicht geboten. Die Verwandtschaft ist aber so eng, daß wir zumindest ein Sarkophagrelief dieser Art als Muster für den Goldschmied annehmen dürfen ${ }^{71}$.

Wenigstens in einem Fall ist also eine Rückenfigur wohl nicht aus einem frühmittelalterlichen, sondern direkt aus einem antiken Werk abzuleiten. Ob dann etwa die Maria in der Szene von Christi Himmelfahrt (Abb. 5), deren Kleid bei etwas anderer Körperhaltung fast noch bessere Übereinstimmung in der Faltenstruktur zeigt, einer eigenen Vorlage bedurfte, sei dahingestellt; als Ausgangspunkt mag dieselbe römische Relieffigur ausgereicht haben. Generell dürfte ein Werk wie die Kopenhagener Platte eine wichtige Quelle für den Klosterneuburger Gewandstil gewesen sein - man vergleiche beispielsweise, auf derselben Platte der Himmelfahrt, die Falten an Rücken und rechtem Arm des Petrus.

Bis jetzt ist die angestrebte Rekonstruktion der konkreten Muster des Goldschmieds hypothetisch geblieben. In der weiteren Umgebung seiner Heimatstadt befindet sich aber noch heute ein antiker Sarkophag, der sämtliche Bedingungen erfüllt. Erstens war er im Mittelalter nachweislich sichtbar und zweitens hat die Auseinandersetzung mit seinem Relief am Klosterneuburger Ambo eindeutige Spuren hinterlassen - und zwar an einer eher überraschenden Stelle:

${ }^{69}$ ) Zum Sarkophagrelief vgl. J. S. ØstergaARD, Catalogue Imperial Rome - Ny Carlsberg Glyptotek, Kopenhagen 1996, Nr. 31, S. 74 f (mit Angabe der älteren Literatur und Abb. der Rückseite); DERS., Metropolitan Roman Sarcophagi in the Ny Carlsberg Glyptotek, Copenhagen, in: Akten des Symposiums „125 Jahre Sarkophag-Corpus “ (Marburg, 4.-7. 10. 1995), hg. von G. Koch, Mainz 1998, S. 101-103, Taf. 471-3; B. C. EwaLD, Bildungswelt und Bürgerbild: Ikonographische Elemente magistratischer und bürgerlicher Repräsentation auf den römischen Musen-Philosophensarkophagen, ebenda, S. 50.

70) Das Fragment wurde 1895 in der Villa Borghese gekauft (ØstERGAARD, Catalogue [zit. Anm. 69], S. 74).

$\left.{ }_{71}\right)$ Einschränkend ist allerdings zu sagen, daß dieser Figurentyp nicht sehr verbreitet gewesen sein kann: Im erhaltenen Bestand römischer Ehepaardarstellungen mit dextrarum iunctio ist das Beispiel, soweit ich sehe, ein Einzelstück (vgl. das Abbildungsmaterial bei L. REEKMANS, La „dextrarum iunctio “ dans l'iconographie romaine et paléochrétienne, in: Bulletin de l'Institut historique belge de Rome, 31, 1958, S. 23-95). In der Regel sind beide Personen in Vorderansicht gegeben; nur auf einem Sarkophag im Vatikan ist die Frau ebenfalls von hinten dargestellt. Der Fall ist also ganz ähnlich gelagert wie jener des Kinderträgers vom Londoner Sarkophag und könnte damit ein Mosaiksteinchen mehr für die These der Italienreise darstellen. 
Der Kopf des hinteren Kundschafters mit der Traube aus dem gelobten Land (Abb. 26, III/9) ist eine erstaunlich präzise Kopie nach dem Kopf des zu Boden gestürzten Jägers auf dem sogenannten Jovinus-Sarkophag in Reims (Abb. 24, 25). Nicht nur sind die Kopfwendung nach oben, der geöffnete Mund und die höchst eigentümliche Barttracht - Schnurrbart, Kinnbärtchen und ein Haarbüschel auf der Wange - ziemlich exakt wiederholt, der Goldschmied hat sich auch für die Gestaltung der nach hinten geworfenen welligen Haare, die im Nacken Löckchen bilden, eng an das Sarkophagrelief angelehnt. Die Zeichnung der Falten im Gesicht entspricht zwar ebenfalls weitgehend dem Reliefkopf, aber auch dem allgemeinen Formenkanon der Werkstatt; die Querfalte über der Nasenwurzel und die konkave Stirn dürften jedoch auf das antike Vorbild zurückgehen. Einzig auf die Wölbung des Nasenrückens hat der Künstler verzichtet.

Der Jovinus-Sarkophag gehört zu einer Gruppe von Löwenjagdsarkophagen des 3. Jahrhunderts n. Chr. und ist mit Sicherheit eine stadtrömische Arbeit; mit Ausnahme der erst in konstantinischer Zeit ausgeführten Köpfe des Feldherrn und Jagdführers entstand sie um $260^{72}$. Die Jagdgehilfen mit langem, wildem Haar und den eigentümlichen Bartbüscheln stellen offenbar Barbaren vor - die Darstellungen von Germanen und Dakern auf Schlachtsarkophagen, Triumphsäulen und in der Großplastik weisen ähnliche Köpfe auf ${ }^{73}$. Die Einzelheiten der Gesichts- und Haarbildung und die Überlieferungsgeschichte des Reimser Sarkophages lassen jedoch keinen Zweifel daran, daß genau dieses Werk das Vorbild für den Emailkopf lieferte. Wohl um die Mitte des 13. Jahrhunderts wurde er auf rund 1,5 Meter hohen Säulchen im Neubau der Abteikirche Saint-Nicaise aufgestellt, wo er als Grabmal des Christen Flavius Jovinus, Konsul von 367 , galt ${ }^{74}$. Die Forschung nimmt aber an, daß der Sarkophag schon in der Antike nach Reims gebracht worden war; auf jeden Fall war er hier schon zu Beginn des 13. Jahrhunderts zu sehen, wie Panofskys Vergleich mit einem Kapitell im Chor der Kathedrale (Abb. 28) beweist $^{75}$. Das seltsame Fabelwesen, das dort gegen ein harpyienartiges Monster kämpft, ist offensichtlich eine freie Adaptation des gestürzten Jagdgehilfen auf dem Sarkophag, wobei sich der gotische Bildhauer auf die Übernahme einzelner Motive - Mantel, Schild, wehendes Haar - und Elemente der Bildstruktur konzentriert hat.

Peter Cornelius Claussen hat darauf aufmerksam gemacht, daß die Haar- und Barttracht der Reimser Sarkophagfiguren auch an einer Kopfkonsole in Castel del Monte, dem sogenannten Faunkopf, auftauchen (Abb. 29). ${ }^{76}$ Dies ist deshalb interessant, weil in Frankreich (und beson-

72) Zum Jovinus-Sarkophag siehe B. ANDREAE, ASR I 2 : Die römischen Jagdsarkophage, Berlin 1980, S. 46-49 und Kat. 75, S. $157 \mathrm{f}$ (mit Angabe der älteren Literatur); R. HAMANN-MacLean, Reimser Denkmale des französischen Königtums im 12. Jahrhundert: Saint-Remi als Grabkirche im frühen und hohen Mittelalter, in: Nationes, 4: Beiträge zur Bildung der französischen Nation im Früh- und Hochmittelalter, hg. von H. BEumanN, Sigmaringen 1983, S. $129-134$.

${ }^{73}$ ) Vgl. z. B. den Ludovisischen Schlachtsarkophag, auf dem in der Mitte ein solcher Barbarenkopf sogar in der gleichen nach oben gewandten Haltung zu sehen ist (T. Kraus, Propyläen Kunstgeschichte 2: Das römische Weltreich, Berlin 1990, Abb. 244).

74) Hamann-MacLean, Reimser Denkmale (zit. Anm. 72), S. 131-134, der diese Tradition für glaubwürdig hält; es hätte sich dabei in jedem Fall um eine Zweitverwendung gehandelt. - In der Abteikirche von Saint-Remi befand sich ein weiterer Löwenjagdsarkophag, der ähnlich ausgesehen haben soll wie der Jovinus-Sarkophag, aber etwas kleiner und künstlerisch schwächer war; im 17. Jahrhundert sah man ihn als Grabmal Karlmanns an (vgl. dazu ebenda, S. 126-138).

75) E. PANOFSKY, Über die Reihenfolge der vier Meister von Reims, in: Jahrbuch für Kunstwissenschaft, 4, 1927, S. 70, Anm. 2. Hamann-Maclean, Reimser Denkmale (zit. Anm. 72), S. 133, datiert die durch Stiche überlieferten Kapitelle der Säulchen, die bis ins 18. Jahrhundert den Sarkophag trugen, ins 12. oder gar 11. Jahrhundert und vermutet deshalb, daß dieser schon in der alten Nikasiuskirche ähnlich präsentiert war.

76) P. C. Claussen, Scultura figurativa federiciana, in: Kat. Federico II e l'Italia: Percorsi, Luoghi, Segni e Strumenti, Roma 1995, S. 102. 
ders in Reims) geschulte Bildhauer immer wieder für die gotischen Tendenzen in der süditalienischen Skulptur unter Friedrich II. verantwortlich gemacht wurden ${ }^{77}$. Das Vorbild scheint hier allerdings eher der Kopf des berittenen Jagdgehilfen vom Jovinus-Sarkophag geliefert zu haben, dessen Backenbart ebenfalls in mehrere Büschel zerfällt ${ }^{78}$. Die Nachahmung ist aber zu frei, um einen anderen römischen Barbarenkopf als Vorlage auszuschließen. Bemerkenswert ist auf jeden Fall, wie sehr sich trotz enger motivischer Übereinstimmung der Ausdruck des Kopfes durch die Übertragung in die fein ziselierende Formensprache der frühen Hochgotik verändert hat.

Der Vergleich mit diesen späteren Rezeptionen macht deutlich, wie genau der Sarkophagkopf am Klosterneuburger Ambo kopiert ist, obwohl damit noch die Umsetzung in ein zweidimensionales Medium verbunden war. Nicht nur einzelne charakteristische Motive, sondern der Kopf als Ganzes wurde samt seinem Ausdrucksgehalt sorgfältig in einen neuen Zusammenhang übertragen, wobei die organische Verschmelzung der verschiedenen Komponenten bemerkenswert gut geglückt ist - ein Vorgang, der vor Nicola Pisano sonst kaum anzutreffen ist. Diese Sensibilität für das antike Kunstwerk läßt die theoretisch gegebene Möglichkeit, daß die Vorlage für die Emailfigur aus zweiter Hand stammt, abwegig erscheinen; es ist anzunehmen, daß Nikolaus von Verdun selbst in Reims war und die Zeichnung nach dem Original ausführte. Ein Aufenthalt im damaligen „Vorort des Antikenstudiums“79, von dessen Bedeutung als römische Stadt im Hochmittelalter noch eine ganze Reihe von heute verschwundenen antiken Monumenten zeugten ${ }^{80}$, paßt zweifellos ausgezeichnet ins Phantombild des Künstlers.

Wer nun aber im CEuvre des Nikolaus eine Fülle von weiteren Motiven nach dem JovinusSarkophag erwartet, wird enttäuscht. Wohl boten dessen Figuren Nikolaus ausreichend Anschauungsmaterial für die Entwicklung seines Gewandstils. Obwohl keines der Faltenschemata wörtlich imitiert ist, sind die Draperien des Reliefs mit den tief eingeschnittenen und reich varïierten Falten jenen am Klosterneuburger Ambo doch nahe verwandt ${ }^{81}$. Auch zum Verständnis der organischen Körperbildung konnte der Sarkophag beitragen. Eindeutige Kopien ganzer Figuren oder wenigstens größerer Teile davon sucht man in den Werken des Goldschmieds jedoch vergeblich; es sind nur noch vereinzelte Analogien auszumachen, bei denen der unmit-

${ }^{77)}$ J. POESCHKE, Zum Einfluß der Gotik in Süditalien, in: Jahrbuch der Berliner Museen, 22, 1980, bes. S. 110-118; C. GNUDI, Considerazioni sul gotico francese, l'arte imperiale e la formazione di Nicola Pisano, in: Federico II e l'arte del Duecento italiano (Atti della III settimana di studi di storia dell'arte medievale, 1978), Galatina 1978, Bd. I, S. 2-4; P. C. Claussen, Die Statue Friedrichs II. vom Brückentor in Capua (1234-1239), in: Festschrift Hartmut Biermann, hg. von C. Andreas/M. Bückling/R. Dorn, Weinheim 1990, S. 28f. - V. PACE, Scultura „federiciana“ in Italia meridionale e scultura dell'Italia meridionale di età federiciana, in: W. Tronzo (Hg.), Intellectual Life at the Court of Frederick II (Studies in the History of Art, 44), Washington 1994, S. 161, spricht sich im Falle des Faunkopfes gegen diese französische Wurzel aus und verweist dabei auf den „patetismo espressivo analogo a quello della scultura romana di età antonina, di cui (l'artista) forse fu in grado di studiare opere“; als Beispiel nennt er die Einzeichnung der Iris in den Augen. Gerade dieses Element könnte der Bildhauer aber auch am Jovinus-Sarkophag gesehen haben, und zwar an den Köpfen des Feldherrn.

${ }^{78}$ ) Vgl. die Detailaufnahme des Kopfes in AndreaE, ASR I 2 (zit. Anm. 72), Taf. 17, Abb. 5-6.

79) Hamann-Maclean, Antikenstudium (zit. Anm. 10), S. 152.

${ }^{80)}$ Vgl. die Beschreibungen aus dem 12. Jahrhundert bei ADHÉMAR, Influences antiques (zit. Anm. 56), S. 58f. Davon hat sich über der Erde einzig die Porte de Mars erhalten; von ihren arg verwitterten Reliefs ist jedoch nichts in eine engere Beziehung zu Nikolaus von Verdun zu bringen.

${ }^{81}$ ) Am besten sind die über die Brust geschwungenen Mantelteile der Relieffiguren mit entsprechenden Draperien in den Emails zu vergleichen (z. B. bei der Verkündigungsmaria [II/1], bei Abraham in der Szene der Isaaksgeburt [I/2], oder bei Manoah in den Darstellungen von Geburt und Beschneidung Samsons [III/2, III/3]). 
telbare Zusammenhang mit dem antiken Relief allerdings unsicher ist. So zeigt der Kopf der weiblichen Virtus-Figur links des reitenden Feldherrn auffallende Ähnlichkeit zum jugendlichen Gesichtstypus am Ambo (z.B. beim Apostel ganz rechts in der Szene des Abendmahls, Abb. 40) - man vergleiche die ausgeprägten unteren Augenlider. Weil aber diese Gesichter sich gerade durch ihre Ebenmäßigkeit auszeichnen und charakteristische Merkmale fehlen, sind daraus keine sicheren Schlüsse zu ziehen. Möglicherweise hat der kleine Putto auf der linken Seite des Sarkophags die Darstellung des gehenden nackten Knaben ganz links im Auszug aus Ägypten (Abb. 22) angeregt. Die Schrittstellung, die feiste Statur und das füllige Gesicht stimmen überein, doch die Binnenzeichnung entspricht nur teilweise (vor allem in Bauch- und Leistengegend) der Anatomie des Eroten. Auch die Gestaltung des Löwen auf der Samson-Platte (III/12) könnte vom Vorbild des Sarkophagreliefs beeinflußt worden sein, besonders wenn man die ausgestreckten Vorderpranken mit den kurzen Haarzotteln vergleicht; doch schon Kopf und Mähne sind in den Details anders gebildet. Die Muskelzeichnung des Klosterneuburger Löwen ist nur zum Teil anatomisch motiviert und soll offensichtlich gleichzeitig durch abstrakte Linien die gespannte Kraft des Löwen visualisieren ${ }^{82}$.

Gemessen am gesamten Figurenrepertoire des Jovinus-Sarkophags sind diese Anleihen, wenn es denn solche sind, nur Marginalien. Das große Angebot an Ganzfigurenschemata bleibt völlig ungenutzt; auch in der Darstellung des nackten Körpers ist kaum ein spezifischer Einfluß des Reliefs festzustellen ${ }^{83}$. Die Auseinandersetzung mit dem Jovinus-Sarkophag illustriert also noch besser als der Fall des Nicomacher-Symmacher-Diptychons die selektive Haltung und Souveränität der Nikolaus-Werkstatt auch gegenüber qualitativ erstklassigen antiken Werken.

Das Muster des Barbarenkopfes ist dafür, einmal kopiert, in der Werkstatt eifrig weiterverwertet worden: zunächst mit anderer Frisur und ohne Bart beim Judas im Abendmahl (Abb. 40 - man beachte die Horizontalfalte über der Nasenwurzel), wobei aber der Künstler wohl nicht von der ursprünglichen Vorlage, sondern vom Kopf des Kundschafters ausging; dann beim dritten Kopf von oben auf der Kopfleiste des Dreikönigenschreins (Abb. 51), wo zwar wieder der Bart fehlt und der Kopf deutlich verjüngt ist, aber dafür die gebogene Nase des Originals zurückkehrt; schließlich, wieder in die Dreidimensionalität der Plastik zurückübersetzt, an der Langseite des Schreins beim Propheten Habakuk (Abb. 27).

Daß es ausgerechnet ein Kopf war, der Nikolaus von Verdun am Jovinus-Sarkophag faszinierte, ist kein Zufall. Erstens ließ die Werkstatt der Darstellung der Köpfe offenbar besondere Aufmerksamkeit angedeihen; zweitens ist in diesem Bereich das Gewicht nicht nur der byzantinischen, sondern auch der antiken Komponente höher als bei den Figurentypen. Inwiefern die asketische Strenge der byzantinischen Muster auch unter dem Eindruck von antiker Kunst gemildert wurde, ist bei den Köpfen in Dreiviertelprofil schwer abzuschätzen. Einige der Profilansichten verraten aber deutlich das Studium von antiken Werken: Gemmen und Kameen, im Mittelalter als Schmuckstücke hochgeschätzt ${ }^{84}$, aber auch Münzen und Medaillen boten den Künstlern der Zeit ein schier unerschöpfliches Repertoire von unterschiedlichsten Physiogno-

82) Vgl. Griessmaier, Emailaltar (zit. Anm. 2), S. 258.

$\left.{ }^{83}\right)$ Ein Reflex der antiken Plastik wäre am ehesten in jener Abfolge von halbkreisförmigen Linien seitlich über der Hüfte des Adam in der Anastasis (II/12) zu erkennen, welche die hervortretenden Adern des nackten Jagdgehilfen ganz rechts nachzuahmen scheinen.

$\left.{ }^{84}\right)$ G. A. S. SnIJDER, Antique and Mediaeval Gems on Bookcovers at Utrecht, in: The Art Bulletin, 14, 1932, S. 5-52; H. WentzeL, Portraits à l'antique on French Medieval Gems and Seals, in: Journal of the Warburg and Courtauld Institutes, 16, 1953, S. 342f.; GreENHALGH, Survival (zit. Anm. 68), S. 229-232. 
mien, das immer wieder genutzt wurde ${ }^{85}$. Ein Beispiel für die Rezeption solcher Stücke dürfte der Kopf des vorderen Juden sein, der beim Einzug Christi in Jerusalem seinen Mantel ausbreitet (Abb. 31); die prägnante Hakennase und das schräg abfallende Kinn, vor allem aber die eigentümlichen Stirnfransen deuten auf eine spätrepublikanische oder frühkaiserzeitliche Porträtgemme als Vorbild hin (Abb. 30). Analogien zu antiker Glyptik (Abb. 32) zeigt auch das Profil der Maria in der Himmelfahrt Christi (Abb. 5): Man beachte die fast gerade verlaufende Nasen-Stirn-Linie und die schräg abfallende, parallel zur Brauenlinie verlaufende Kontur des Kinns. Einige der bärtigen Köpfe, insbesondere jener im Pfingstwunder (II/15) mit der ungewöhnlichen Kombination von langem, gewelltem Haupthaar und gelocktem Bart, könnten ebenfalls von Münzen oder Gemmen angeregt worden sein ${ }^{86}$.

Auch die Sarkophagplastik wird der Nikolaus-Werkstatt Vorlagen für Kopftypen geliefert haben; das Beispiel des Jovinus-Sarkophags war vermutlich kein Einzelfall. Für die bejahrte Hebamme in der Geburtsszene Samsons (Abb. 33), der der Künstler mit einer besonderen Strichführung das Aussehen einer ausgezehrten Greisin zu verleihen suchte, könnte der Kopf der alten Amme Phaedras von einem Hippolytos-Sarkophag wie jenem im Louvre (Abb. 34) vorbildlich gewesen sein. Auch wenn der Vergleich gewisse Unterschiede offenbart (etwa im Bereich der Wangen), so sind doch die Form des Unterkiefers, des verkniffenen Mundes und der schräggestellten Augen mit abfallenden Augenwinkeln sowie das unter dem Kopftuch hervorschauende Haarbüschel klare Indizien für ein Muster dieser Art ${ }^{87}$.

Daneben dürften für die Haar- und Bartbildung antike Quellen eine Rolle gespielt haben. Dies gilt vor allem für die stark gerollten, plastisch differenzierten Locken mit „Bohrlöchern“ in der Mitte, die auffällig viele Klosterneuburger Köpfe zieren. Zwar tauchen etwa in der provenzalischen Plastik des 12. Jahrhunderts und in den Glasmalereien von Canterbury ${ }^{88}$ gelegentlich ähnliche Frisuren auf; die Lockenköpfe auf dem Klosterneuburger Ambo sind aber in ihrer Vielfalt und Differenziertheit im Detail kaum ohne direkten Rückgriff auf römische Skulptur denkbar.

Gründete der Ruhm des Nikolaus von Verdun in der Kunstwissenschaft zunächst lange Zeit hauptsächlich auf den Platten des Klosterneuburger Ambos ${ }^{89}$, so hat dafür die Plastik des Drei-

85) So am sogenannten Sarkophag des Arnulf in der Kathedrale von Lisieux (um 1180), an der Brunnenschale mit der Darstellung von antiken Göttern aus Saint-Denis (um 1200) oder am Fragment eines Grabmals in Chartres (um 1220-25; vgl. zu allen drei Werken W. SAUERLÄNDER, Art antique et sculpture autour de 1200: Saint-Denis-LisieuxChartres, in: Art de France, 1, 1961, S. 47-56). Zum Einfluß antiker Stücke auf die mittelalterlichen Gemmen und Siegelstempel des 13. Jahrhunderts siehe WeNTZEL, Portraits à l'antique (zit. Anm. 84). Für die Nachahmung von Münzbildnissen in oft antikisierender Manier in der karolingischen und ottonischen Buchmalerei siehe R. KAHSNIrz, Ein Bildnis der Theophanu? Zur Tradition der Münz- und Medaillon-Bildnisse in der karolingischen und ottonischen Buchmalerei, in: A. von Euw/P. SchreIner (Hg.), Kaiserin Theophanu, Köln 1991, Bd. II, bes. S. 110-124.

86) Ein gutes Vergleichsbeispiel bietet ein Stater des Arkadischen Bundes mit dem Kopf des Zeus Lykaios im British Museum, um 370-363 v. Chr. (P. R. Franke/M. Hirmer, Die griechische Münze, München 1972², Taf. 159, Abb. 512).

$\left.{ }^{87}\right)$ Das Exemplar des Louvre kommt dafür allerdings nicht in Frage, da es erst 1853 in einem Grab an der Via Aurelia gefunden wurde (ROBERT, ASR $\mathrm{III}_{2}$ [zit. Anm. 54] Nr. 161, S. 198). Im erhaltenen Bestand von Hyppolitos-Sarkophagen zeigt z. B. der Kopf der Amme auf einem Kasten im Vatikan (Museo Gregoriano Profano; vgl. ebenda, Nr. 167, S. 208f) eine ähnliche Wangenbildung und Unterkieferkontur wie der Emailkopf.

${ }^{88}$ ) CAvinEss, Early Stained Glass (zit. Anm. 19), Abb. 44, 85; vgl. auch SwARZENSKI, Monuments (zit. Anm. 50), Abb. 393.

${ }^{89}$ ) Claussen, Zum Stil der Plastik (zit. Anm. 6), S. 8-11. Der Rückstand in der Rezeption des Dreikönigenschreins dürfte wohl auch mit den unterschiedlichen Abbildungsmöglichkeiten von zweidimensionalem, graphischem Email 
königenschreins in der neueren Forschung die meisten Superlative auf sich vereinigt. Vor allem angesichts der Prophetenreihen an den unteren Langseiten (Abb. 35, 39) pflegt die kunsthistorische Zunft jede vornehme Zurückhaltung abzulegen: Die Assoziierung des Goldschmieds mit Künstlern der Neuzeit - von Donatello über Michelangelo bis Rodin - zieht sich wie ein roter Faden durch die Fachliteratur ${ }^{90}$. Sie ist symptomatisch für das Fehlen jeglichen Vergleichsmaßstabs in der Kunst des 12. Jahrhunderts - die Antikennähe und zugleich vollkommene Natürlichkeit von Gewandstil und Physiognomie, auf die kein Bewunderer dieser Figuren hinzuweisen versäumt, erwarten wir in diesem Ausmaß nur in neuzeitlicher Kunst ${ }^{91}$.

Anders als am Klosterneuburger Ambo sind diese Qualitäten tatsächlich bei allen Figuren, die im allgemeinen der Hand des Nikolaus selbst zugeschrieben werden (die Propheten sowie die Apostel Bartholomäus, Philippus, Simon ${ }^{92}$ ), mehr oder weniger gleich stark ausgeprägt.

und dreidimensionaler Treibarbeit zusammenhängen: Während die Platten des Klosterneuburger Ambos schon 1844 in relativ präzisen Kupferstichen von Albert Camesina publiziert wurden (CAMESINA/ARNETH, Niello-Antipendium, zit. Anm. 1), taten sich die Stecher mit der Umsetzung der komplexen Oberfläche der Goldschmiedeplastik naturgemäß schwerer. Erst die Photographie schuf hier gleich lange Spieße, und so erhielt der Dreikönigenschrein seine erste adäquate Reproduktion (O. vON FALKE, Der Dreikönigenschrein des Nikolaus von Verdun im Cölner Domschatz, Mönchengladbach 1911) fast siebzig Jahre später als der Klosterneuburger Ambo. Wenn von den Propheten und anderen Figuren des Schreins schon um 1860 Gipsabgüsse angefertigt wurden, so stellt das nicht, wie DAUTERT/ LIND, Dreikönigenschrein (zit. Anm. 8), S. 91, Anm. 21, meinen, die Rolle der Photographie bei der ästhetischen Rezeption der Schreinsplastik (CLAussen, Zum Stil der Plastik [zit. Anm. 6], S. 7) in Frage, sondern unterstreicht sie letztlich: Mitte des 19. Jahrhunderts waren Abgüsse die gängige Methode, um Plastik rasch und einfach zu reproduzieren; nur konnte man sie im Gegensatz zu Stichen nicht zwischen Buchdeckeln publizieren - und so blieben denn die Exemplare der Berliner Sammlung auch ohne Breitenwirkung.

${ }^{90}$ ) Von FaLKe, Dreikönigenschrein (zit. Anm. 89), S. 8; M. CReUTZ, Die Goldschmiedekunst des Rhein-Maas-Gebietes, in: P. Clemen (Hg.), Belgische Kunstdenkmäler, München 1923, Bd. I, S. 142; F. WrTtE, Tausend Jahre deutscher Kunst am Rhein: Die Denkmäler der Plastik und des Kunstgewerbes auf der Jahrtausend-Ausstellung in Köln, Berlin 1932, S. 68; SCHNITZIER, Goldschmiedeplastik (zit. Anm. 3), S. 63; GEVAERT, L'orfèvrerie mosane (zit. Anm. 2), S. 30; O. Demus, Nicola da Verdun, in: Enciclopedia Universale dell'Arte, Bd. 9, Venezia/Roma 1963, Sp. 919; L. GroDECKI, Le „Maitre de la châsse des Rois Mages“, in: Bulletin Monumental, 12, 1965, S. 137. - Für die Bibliographie zum Dreikönigenschrein siehe Kat. Ornamenta Ecclesiae (zit. Anm. 6), Bd. II, Nr. E 18, S. 224. Nachzutragen sind: ClausSEN, Nikolaus von Verdun (zit. Anm. 6); R. Kroos, Zur Datierung des Dreikönigenschreins, in: Kunstchronik, 38, 1985, S. 290-298; A. und M. WERBKE, Theologie, Politik und Diplomatie am Dreikönigenschrein: Die Ikonographie der Frontseite, in: Wallraf-Richartz-Jahrbuch, 46, 1985, S. 7-73; J. PetersoHn, Der König ohne Krone und Mantel: Politische und kulturgeschichtliche Hintergründe der Darstellung Ottos IV. auf dem Kölner Dreikönigenschrein, in: DERS. (Hg.), Überlieferung - Frömmigkeit - Bildung als Leitthemen der Geschichtsforschung (Vorträge beim wissenschaftl. Kolloquium aus Anlass des 80. Geburtstags von Otto Meyer), Wiesbaden 1987, S. 43-76; V. N. TJAŽELov, Nikolaj Verdenskij i antikizirujuščee napravlenie v iskusstve okolo 1200 goda, in: I. E. DANILOVA (Hg.), Iz istorii zarubežnogo iskusstva (materialy naučnoj konferencii „Vipperovskie čtenija“ 21, 1988), Moskva 1991, S. 14-29; DAUTERT/LIND, Dreikönigenschrein (zit. Anm. 8); W. Telesko, Das theologische Programm des Kölner Dreikönigenschreins: Tradition und Innovation in der hochmittelalterlichen Ikonographie, in: Jahrbuch des Kölnischen Geschichtsvereins, 68, 1997, S. 25-50; J. FrTsCHEN, Die Goldschmiedeplastik des Marienschreins im Aachener Dom (Diss. Berlin 1997), Frankfurt a. M. 1998, S. 210-239. - Die Zuschreibung der Langseitenfiguren des Dreikönigenschreins an Nikolaus von Verdun ist jüngst von Jürgen Fitschen (ebenda, S. 213) wieder in Frage gestellt worden. Abgesehen vom Nachweis, daß in Köln teilweise dieselben Punzen wie in Klosterneuburg und Tournai verwendet worden sind (W. SCHULTEN, Stempelverwendung in der Goldschmiedewerkstatt des Nikolaus von Verdun, in: Kat. Rhein und Maas [zit. Anm. 5], Bd. I, S. 318f), läßt auch der enge stilistische Zusammenhang mit Klosterneuburg vor allem im Bereich der Physiognomien (siehe unten, S. 30f.) solchen Zweifeln keinen Raum mehr.

91) Vgl. Claussen, Zum Stil der Plastik (zit. Anm. 6), S. 12f; DERS., Nikolaus von Verdun (zit. Anm. 6), S. 447.

${ }^{92}$ ) Die übrigen Figuren der Apostelreihe, die aus dem ursprünglichen Bestand erhalten sind, unterscheiden sich durch ihre schmächtigeren Körper, die wenig gelöste, meist frontale Haltung und die ausdrucksloseren, glätteren $\mathrm{Ge}-$ 
Müssen wir deshalb eine erneute, intensive Beschäftigung mit antiker Kunst zwischen der Arbeit am Emailwerk und jener am Schrein annehmen? Claussen hat diese Frage zumindest in bezug auf Gewandstil und Bewegungsmotive verneint und vermutet, daß die in Klosterneuburg erprobten Werkstattgewohnheiten fortgesetzt wurden ${ }^{93}$. Birgit Bänsch hat versucht, die Kontinuität systematisch an bestimmten Haltungs- und Faltenschemata nachzuweisen ${ }^{94}$. Ihre Vergleichsbeispiele belegen jedoch eher das Gegenteil: Die wenigen Übereinstimmungen sind von so allgemeiner Art, daß man nicht von einer bewußten und systematischen Wiederholung von Mustern sprechen kann. Vor allem für die Grundstruktur der Schreinsfiguren sind nur sehr vereinzelt, etwa beim Propheten Amos ${ }^{95}$, Bezüge zu Klosterneuburg festzustellen. Vorbilder aus der heidnischen Antike können aber für diese „sprechenden“, d. h. auf ein imaginäres Gegenüber ausgerichteten Sitzfiguren kaum von Bedeutung gewesen sein; ihre Vorläufer sind vielmehr in der Tradition der bewegten Apostelreihen des 12. Jahrhunderts zu finden, für die der Heribertschrein ein gutes Beispiel liefert ${ }^{96}$.

Schwieriger zu beurteilen ist das Verhältnis zu Klosterneuburg beim Gewandstil. Grundsätzlich wird mit den gleichen ,antikisierenden“ Mitteln gearbeitet; bei den Schreinsfiguren ist aber die Drapierung insgesamt weicher und gleichmäßiger, der Stoff weniger gestrafft oder zu Wülsten geballt, die Falten sind feiner, die Mulden dazwischen wirken seicht und erweitern sich oft zu kleineren Flächen; bei manchen Figuren (so bei Moses oder, in geringerem Ausmaß, David, Abb. 39) bekommen die Gewänder fast etwas Organisches, Fließendes. Dieser Stilwandel ist zweifellos zu einem guten Teil durch das Medium der Treibarbeit bedingt, das eine weichere Formung der Stoffe erlaubt ${ }^{97}$. Ob ein erneutes Antikenstudium diese Entwicklung aber zusätzlich förderte, ist schwer zu beurteilen. Dem Gewandstil des Dreikönigenschreins näher als das Nicomacher-Symmacher-Diptychon oder der Jovinus-Sarkophag stehen frühkaiserzeitliche Steinskulpturen, aber auch qualitativ herausragende Werke der römischen Metallkunst wie eine Bronzefigur der Fortuna in Lyon (Abb. 36) oder ein - sogar in der gleichen Technik gearbeitetes Votivfigürchen einer Quellgöttin, auf das bereits Fillitz hingewiesen hat ${ }^{98}$; ähnliche Stücke mö-

sichter von der Prophetengruppe. - Ein großer Teil der Schreinsplastik ist abgebildet in SCHNITZLER, Rheinische Schatzkammer (zit. Anm. 20).

${ }^{93}$ ) Claussen, Zum Stil der Plastik (zit. Anm. 6), S. 31f. Interessant ist in diesem Zusammenhang sein Hinweis, daß die Brust- und Schulterpartie der Königin von Saba (Abb. 13) fast unverändert auf den Propheten Salomo übertragen worden ist (ebenda, S. 27). Frrschen, Goldschmiedeplastik (zit. Anm. 90), S. 225, hat dazu allerdings richtig beobachtet, daß das Draperieschema der Klosterneuburger Prudentia (im Zwickel zwischen den Szenen III/9 und III/10) jenem des Salomo noch näher ist.

94) BÄNSCH, Kölner Goldschmiedekunst (zit. Anm. 30), S. 112-115.

95) Vom Arm an abwärts stimmen Haltung, Drapierung des Gewandes und teilweise auch die Details der Faltenbildung relativ gut mit der Figur der Sarah aus der Beschneidung Isaaks (I/2) überein.

96) Vgl. Hamann-MacLean, Byzantinisches und Spätantikes (zit. Anm. 24), S. 244. Die Propheten Naum (Abb. 70) und Amos (Abb. bei Schnitzler, Rheinische Schatzkammer [zit. Anm. 20], Taf. 118) basieren im Prinzip auf denselben Figurenschemata wie Jakobus minor bzw. Andreas am Heribertschrein (Abb. ebenda, Taf. 84, vierte und fünfte Figur von links). Selbst bei den Faltenmustern gibt es Parallelen zum Heribertschrein, wo beispielsweise ebenfalls jene langen Faltenschlingen auftauchen, die die Unterschenkel in weitem Bogen umziehen. Die Nikolaus-Werkstatt setzte also nicht, wie BÄNSCH, Kölner Goldschmiedekunst (zit. Anm. 30), S. 145, meinte, jeweils „unabhängig von der auszuführenden Technik “ immer das gleiche Repertoire von Schemata ein; zumindest beim Typus der thronenden Figur existierten für die spezifischen Anforderungen des flachen Emails bzw. des Schreinreliefs zwei teilweise getrennt verlaufende Traditionsstränge.

97) Vgl. Claussen, Zum Stil der Plastik (zit. Anm. 6), S. 33.

${ }^{98}$ ) Filurtz, Nicolaus von Verdun (zit. Anm. 6), S. 284 und S. 286, Abb. 165. Das Silberfigürchen wurde 1902 bei 
gen Nikolaus zur Verfügung gestanden haben. Zwingend ist ein erneuter Impuls von außen bei dem schon in Klosterneuburg erreichten hohen Niveau des Gewandstils allerdings nicht ${ }^{99}$.

Eine eigentliche Antikenkopie machte Claussen an der Frontseite des Schreins aus: Im kontrapostisch ponderierten Engel mit Kelch und Patene links des Weltenrichters (Abb. 37) erkannte er eine dreidimensionale Umsetzung der Priesterin auf der Nicomacher-Tafel (Abb. 12); der gedrehte Stoffwulst des Himation auf Hüfthöhe sei der entscheidende Beweis für den $\mathrm{Zu}$ sammenhang ${ }^{100}$. Dieses Motiv bezeugt jedoch nur, daß die Figur tatsächlich ein antikes Vorbild rezipiert; ein Vergleich mit den eben erwähnten Statuetten der Fortuna (Abb. 36) und der Quellgöttin zeigt die gleichen Übereinstimmungen bis in die Einzelheiten des Faltenverlaufs und relativiert damit Claussens These, auch wenn wir die Kenntnis des Diptychons voraussetzen. Dem Gerichtsengel noch näher steht beispielsweise ein in Gallien sehr verbreiteter Typus der Göttin Hygieia; eine an sich unscheinbare Statuette im Museum von Dijon (Abb. 38) entspricht, von der groben Ausführung einmal abgesehen, dem Engel nicht nur in der Anlage der Bein- und Hüftpartie mit dem identischen Faltenverlauf und dem charakteristischen Gewandwulst, sondern auch in der Gestaltung des Oberkörpers mit dem straff gegürteten Chiton und der Haltung der Arme, die einst eine Schlange sowie vermutlich eine Schale hielten ${ }^{101}$. Wahrscheinlich kopierte also der Goldschmied eine solche Votivfigur von zweifellos höherer Qualität ziemlich genau, wobei er nur die Brust glätten und Schlange und Opferschale durch Kelch und Patene ersetzen mußte, um die heidnische Gottheit in einen christlichen Engel zu verwandeln. Es ist interessant zu beobachten, wie auch hier das Interesse für antike Ponderierung die Werkstatt und vermutlich sogar denselben Künstler nicht daran gehindert hat, beim rechten Engel nicht nur das Schüsselfaltenschema zwischen den Beinen, sondern auch das altertümlichere Standmotiv mit den leicht eingeknickten Beinen zu verwenden ${ }^{102}$.

Die herausragende Qualität der Plastik am Dreikönigenschrein erreicht ihren Höhepunkt in den berühmten Prophetenköpfen. In der Individualität, Lebendigkeit und Ausdruckskraft dieser Gesichter, die die gesamte Spannweite der menschlichen Psyche abzudecken scheinen, tritt das „epochensprengende" Genie ${ }^{103}$ des Nikolaus am deutlichsten zutage. Obwohl diese Charakterköpfe auf den ersten Blick wenig mit den Typen des Klosterneuburger Ambos zu tun haben, läßt sich die Werkstattkontinuität hier besser nachvollziehen als im Bereich von Haltungsmotiven und Gewandmustern.

der Kirche von Saint-Honoré-les-Bains im Departement Nièvre entdeckt (Les antiquités du Musée de Mariemont, Bruxelles 1952, Nr. F. 13, S. 170f.). - Vgl. auch Claussen, Zum Stil der Plastik (zit. Anm. 6), S. 32, der der Figur des Moses eine in Holland gefundene Bronzestatuette eines Genius gegenüberstellt.

${ }^{99}$ ) Krtzinger, Byzantine Contribution (zit. Anm. 4), S. 171, und Demus, Byzantine Art (zit. Anm. 4), S. 185, versuchten den plastischen Stil der Schreine in Köln und Tournai aus frühbyzantinischen Elfenbeinen der justinianischen Zeit abzuleiten. Die eher oberflächlichen Analogien zwischen den Reliefs am Marienschrein und den Evangelisten am Thron des Maximian in Ravenna sind aber kein Beleg für diese These, da sie das Pferd gleichsam beim Schwanz aufzäumen, und für die Eigenheiten des Faltenstils am Dreikönigenschrein kann die frühbyzantinische Kunst m. E. keine Erklärung liefern.

100) Claussen, Zum Stil der Plastik (zit. Anm. 6), S. 28.

101) Die Figur entspricht dem sogenannten Typus Broadlands. Zur Typologie der Hygieia-Darstellung siehe F. Croissant, Hygieia, in: Lexicon Iconographicum Mythologiae Classicae, V 1 , Zürich/München 1990, S. 554-572; dort weitere nahe verwandte Beispiele unter Nr. 63-68, 72, 80, 82, 85-86, 89.

${ }^{102}$ ) Vgl. Claussen, Zum Stil der Plastik (zit. Anm. 6), S. 28, der darauf hinweist, daß die Köpfe beider Figuren absolut identisch gebildet sind.

${ }^{103}$ ) Claussen, Nikolaus von Verdun (zit. Anm. 6), S. 447. 
Diesen Sachverhalt beobachteten schon von Falke, der unter anderem darauf hinwies, daß das unverwechselbare Stirnfaltenmuster der Emailköpfe auch bei den Schreinsfiguren vorkommt ${ }^{104}$, sowie Claussen ${ }^{105}$. Birgit Bänsch hat den Typenzusammenhang dann erstmals ausführlicher untersucht und festgestellt, daß den Köpfen in Klosterneuburg und in Köln im Prinzip der gleiche Mustervorrat zugrunde liegt ${ }^{106}$. Bei manchen getriebenen Figuren ist ein bestimmter Typus aus dem Emailwerk in allen Details zitiert: Das so charaktervolle königliche Haupt des David (Abb. 39) wiederholt beispielsweise den Kopf des Apostels zur Linken Christi im Abendmahl (Abb. 40); Jakobus maior ${ }^{107}$ den des Elias in der Szene seiner Himmelfahrt (Abb. 8); Andreas ${ }^{108}$ entspricht dem zweiten Apostel von links beim Abendmahl - die Liste ließe sich problemlos verlängern. Doch auch die meisten anderen Gesichter, besonders die älteren, bärtigen, sind mit den gleichen, schon bei den Emailköpfen angewandten Stilmitteln gestaltet: hohe, ausgeprägte Wangenknochen, schmale, leicht gebogene lange Nase, aufmerksam blickende Augen hinter markanter Brauenpartie, gefurchte Stirn und tiefe Falten, die sich von den Nasenflügeln zum Bart hinunterziehen ${ }^{109}$. Der Eindruck von höherer Vielfalt und Natürlichkeit wird zum einen durch die sorgfältigere Varïerung von Bart- und Haarformen erreicht; zum anderen bietet natürlich die Treibarbeit in Silber gegenüber den kleinen Kupferplättchen, wo die Köpfe nur mit wenigen Strichen charakterisiert werden konnten, ungleich größere Möglichkeiten zur Differenzierung der Figuren auch im Gesichtsausdruck.

$\mathrm{Daß}$ diese Möglichkeiten auch wahrgenommen wurden, bedarf aber einer Erklärung. Der Hinweis auf die mutmaßlichen byzantinischen Vorlagen der Emailköpfe reicht dazu nicht aus $^{110}$; aus solchen zweidimensionalen Vorbildern war die subtile plastische Durchbildung, der die Gesichter erst ihren Realismus, ihre Modernität verdanken, nicht zu erlernen ${ }^{111}$.

Die Forschung hat für diesen Qualitätssprung vor allem zwei mögliche Ursachen in Betracht gezogen: Naturstudium und Rezeption antiker Porträtskulptur. Anton Legner, der auf die

$\left.{ }^{104}\right)$ O. vON FALKE, Meister Nicolaus von Verdun und der Dreikönigenschrein im Kölner Domschatz, in: Zeitschrift für christliche Kunst, 18, 1905, Sp. 175f. Dazu erkannte von Falke gewisse Analogien bei der Haar- und Bartbildung, so die Ähnlichkeit zwischen dem hinteren Traubenträger und dem Propheten Habakuk, die wir nun mit der Verwendung desselben antiken Modells erklären können.

${ }^{105}$ ) Claussen, Zum Stil der Plastik (zit. Anm. 6), S. 33-35.

$\left.{ }^{106}\right)$ BäNSCH, Kölner Goldschmiedekunst (zit. Anm. 30), S. 98-101.

${ }^{107)}$ Abgebildet bei R. Hamann-MacLean, Der Dreikönigenschrein im Kölner Dom: Bemerkungen zur Rekonstruktion, Händescheidung und Apostelikonographie, in: Kölner Domblatt, 33/34, 1971, S. 64, Abb. 30.

${ }^{108)}$ Abgebildet ebenda, Abb. 33.

${ }^{109}$ ) BÄNSCH, Kölner Goldschmiedekunst (zit. Anm. 30), S. 99.

${ }^{110}$ ) Hamann-MacLean, Byzantinisches und Spätantikes (zit. Anm. 24), S. 263f, vermutete in den Heiligenbildnissen byzantinischer Handschriften, insbesondere in den Gesichtern der Propheten im Basileios-Menologium, die Vorbilder für die Prophetenköpfe. Als wichtige Quelle für die Kopftypen der Werkstatt wirken Muster dieser Art auch am Dreikönigenschrein nach; dies bedarf aber keiner erneuten Begründung mehr. Die „klassische“ Komponente ist zudem am Dreikönigenschrein eher stärker geworden. Bei genauerem Hinsehen haben nur zwei Propheten, Aaron und Abdias (Abb. 42, 44), jenen „gespannten, oft heftigen, drohenden, Zorn verhaltenden“ Ausdruck, den HamannMacLean in den Bildnissen im Basileios-Menologium wiederfand - und gerade ihre Köpfe sind, wie ich im folgenden darlegen möchte, in der Gesichtsbildung näher an antiken Typen.

111) Das gilt auch für die Werke der frühbyzantinischen Kunst, die KrrzıNGER, Byzantine Contribution (zit. Anm. 4), S. 41, als mögliche Vorbilder ins Spiel brachte. Die grimmigen Köpfe der Evangelisten auf dem Elfenbeinthron des Maximian in Ravenna zeigen keine „definite likeness“ (DEMUs, Byzantine Art [zit. Anm. 4], S. 185), sondern nur eine sehr allgemeine Geistesverwandtschaft mit einzelnen Propheten, die aber unabhängig von der physiognomischen Detailgestaltung ist. 
zweite Möglichkeit erstmals hingewiesen hatte ${ }^{112}$, ging sogar so weit zu behaupten, daß in allen Propheten „eindeutig das Vorbild ihrer jeweiligen antiken Bildnisstufe zu sehen“ sei113. Einzig Claussen hat aber diese These durch Vergleiche der Köpfe von Daniel und Amos mit Kaiser- und Philosophenporträts einer genaueren Prüfung unterzogen und aufgezeigt, daß die zunächst auffälligen Ähnlichkeiten letztlich auf Oberflächliches beschränkt bleiben ${ }^{114}$. Davon ausgehend haben zuletzt Ortrun Dautert und Christoph Lind behauptet, daß zwar einige der Prophetenköpfe „,in Anlehnung an antike Porträtplastik entstanden“ sein dürften, der „gesteigerte Ausdruck, die Spannung und die Beseeltheit“ sie aber "grundsätzlich von antiker Gestaltungsweise" abhebe ${ }^{115}$. Daß dies eine künstliche, von winckelmannschem Antikenverständnis geprägte Grenzziehung ist, vermag ein männlicher Porträtkopf aus der späten Kaiserzeit im Römisch-Germanischen Museum von Köln (Abb. 41) zu illustrieren. Wenn wir ihn neben den Kopf des Aaron (Abb. 42) stellen, zeigt sich, daß nicht nur Bart und Gesichtsschnitt (insbesondere die kontrahierten Brauen), sondern vor allem auch der Ausdruck von seelischer Anspannung und verhaltenem Zorn im römischen Bildnis recht genau vorweggenommen sind. Ein Abhängigkeitsverhältnis ist daraus schwerlich abzuleiten - der erst in der Neuzeit gefundene Kopf gibt keinen geläufigen Typus wieder, und vor allem in der Bildung der Haare bleiben recht große Unterschiede. Die Gegenüberstellung macht aber deutlich, daß antike Porträts gerade für die psychologische Belebung der Gesichter eine Rolle spielen konnten ${ }^{116}$.

Von ähnlich grimmigem Temperament ist auch der Prophet Abdias (Abb. 44) beseelt. Dessen Kopf, der auf keinem der Klosterneuburger Muster beruht und sich auch von der Gruppe der übrigen bärtigen Propheten abhebt, zeigt die gleichen physiognomischen Grundzüge wie antike Porträts des Diogenes ${ }^{117}$ : die fliehende Stirn, den kahlen Schädel, der von einem Kranz wilder Locken eingerahmt ist, den langen, spitz zulaufenden Bart, die etwas knollige Nase, die freiliegenden großen Ohrmuscheln. Die Büste des sogenannten Diogenes im Kapitolinischen Museum (Abb. 43) ${ }^{118}$ weist außerdem ebenfalls einen zweigeteilten, in dünnen Spitzen auslaufenden Bart auf und kommt dem Propheten vor allem im Gesichtsausdruck noch näher. Gewisse Differenzen, etwa in den Details von Haaren und Bart, bleiben auch hier bestehen; doch erscheint es nicht unwahrscheinlich, daß dem Goldschmied ein Philosophenkopf dieses oder eines verwandten Typus' als Vorlage diente.

${ }^{112}$ ) LeGNER, Rinderherde (zit. Anm. 56), S. 250, Anm. 43.

${ }^{113}$ ) Ders., Deutsche Kunst der Romanik, München 1982, S. 101. Auch W. SAuERLÄnder, Architecture and the Figurative Arts: The North, in: R. L. Benson, G. Constable (Hg.), Renaissance and Renewal in the Twelfth Century (from a conference commemorating the contribution by Charles Homer Haskins, Cambridge [Mass.], 26.-29. 11. 1977), Cambridge (Mass.) 1982, S. 682, nimmt „direct study of busts from the Roman imperial era“ an.

${ }^{114}$ ) Claussen, Zum Stil der Plastik (zit. Anm. 6), S. 35-38.

115 ) DAuTERT/Lind, Dreikönigenschrein (zit. Anm. 8), S. 90.

116) In den Mitteln, mit denen der erbitterte Gesichtsausdruck erzeugt wird, kommt dem Aaron auch der in mehreren Repliken überlieferte Typus des griechischen Philosophen Antisthenes sehr nahe (R. vON DEN Hoff, Philosophenporträts des Früh- und Hochhellenismus, München 1944, S. 136-150, Abb. 140-155). Man vergleiche insbesondere die gerunzelte Stirn über zusammengekniffenen Brauen und den leicht geöffneten Mund mit zurückweichender Unterlippe.

117) Für Abbildungen siehe vON DEN HoFf, Philosophenporträts (zit. Anm. 116), S. 129-135; vgl. besonders den Kopf in Aix-en-Provence, Musée Granet (ebenda, S. 130, Nr. 3, Abb. 135-136).

${ }^{118}$ ) Die traditionelle Identifikation mit dem Kyniker wird von der Forschung mehrheitlich zurückgewiesen. Vgl. W. HeLBIG, Führer durch die öffentlichen Sammlungen klassischer Altertümer in Rom, Leipzig 1912 ${ }^{3}$, Bd. I, S. 459f., Nr. 816. 
Falls diese Hypothese zutreffen sollte, dürfte es sich aber um einen Einzelfall gehandelt haben. Bei den übrigen Köpfen läßt sich der auf den ersten Blick so evident scheinende Zusammenhang mit antiker Porträtkunst kaum konkretisieren.

Deutlich zeigt sich die Problematik bei den vielen langbärtigen Figuren. Die Gesichtszüge von Moses, Joachim, Jeremias, Naum, Joel, Ezechiel gleichen vor allem in der Partie um Augen, Nase und Wangen Bildnissen griechischer Philosophen und Dichter (Abb. 45; vgl. besonders mit Moses, Naum [Abb. 35], Ezechiel) oder auch römischen Porträts des 2. und 3. Jahrhunderts, welche oft noch die gleiche schematisierte Zeichnung der Stirnfalten aufweisen (Abb. 46) ${ }^{119}$. Die wallenden Bärte lassen sich aber in keinem Fall auf antike Vorbilder zurückführen, während umgekehrt nirgendwo am Schrein die strähnigen, wilden Locken in Bart- und Haupthaar auftauchen, die etwa für die griechische Porträtkunst so charakteristisch sind. Keiner dieser Köpfe ist also eine Nachbildung eines bestimmten antiken Typus; die Goldschmiede haben sich höchstens ganz allgemein die plastischen Gestaltungsmittel antiker Porträtkunst zu eigen gemacht. Selbst im Falle des Jonas (Abb. 47), der doch die stärksten Assoziationen an römische Bildnisse „vielleicht spätrepublikanischer Zeit" ${ }^{120}$ auslöst, bringt die Suche nach antiken Vorlagen keine befriedigenden Ergebnisse - besonders wenn wir die im Falle des Kopfes vom Jovinus-Sarkophag erreichte Kopiergenauigkeit zum Maßstab nehmen. Zwar finden sich in der spätrepublikanischen Plastik tatsächlich vereinzelte Beispiele für bartlose, ältere Männerköpfe mit Glatze und Haarbüschel über der Stirn; doch der Vergleich mit einem Bildnis aus Senlis (Abb. 48) oder mit verwandten Stücken ${ }^{121}$ offenbart sofort den großen Abstand zum Verismus der römischen Porträts: Neben deren markanten, faltenzerfurchten Physiognomien, welche staatsmännische Gravitas zur Schau tragen, wirkt der etwas feiste Kopf des Jonas mit der relativ kleinen, ebenmäßigen Nase und dem schmalen Mund fast jungenhaft. Wenn der Goldschmied einen solchen römischen Kopf studiert hatte, so ist davon nur noch eine vage Erinnerung in sein Werk eingeflossen - gerade das Charakteristikum entsprechender spätrepublikanischer Bildnisse, die akzentuierten Alterszüge, fehlt dem Prophetenhaupt ${ }^{122}$.

Die Abhängigkeit von antiker Porträtplastik darf also nicht überbewertet werden; das Verhältnis dürfte dabei aber gerade umgekehrt sein, als Dautert und Lind vermuten: Antike Bildnistypen stellen nicht die Grundlage für die Propheten- und Apostelköpfe dar; vielmehr haben Nikolaus von Verdun und seine Mitarbeiter solchen Werken vor allem die differenzierte Modellierung der Gesichter und die damit verbundenen psychologischen Ausdrucksmöglichkeiten abgeschaut. Ohne die Porträtkunst auszuschließen, müssen dafür aber auch andere antike Quellen berücksichtigt werden.

Wie schon erwähnt, wurde für den Propheten Habakuk das Kopfmuster vom Jovinus-Sarkophag wiederverwertet (Abb. 25, 27). In diesem Fall interessierte nicht die dynamische Ex-

${ }^{119}$ ) Schon Claussen, Zum Stil der Plastik (zit. Anm. 6), S. 36, Anm. 76, verglich den Kopf des Naum mit Bildnissen des Antoninus Pius. Legner, Rinderherde (zit. Anm. 56), S. 250, Anm. 43, hatte für die Prophetenköpfe generell „das Vorbild römischer Marmorköpfe antoninischer Zeit" angenommen.

${ }^{120}$ ) Claussen, Zum Stil der Plastik (zit. Anm. 6), S. 38.

${ }^{121}$ ) Etwa das Porträt des Cicero in den Uffizien (B. ScHwerrzer, Die Bildniskunst der römischen Republik, Leipzig 1948, Abb. 147).

$\left.{ }^{122}\right)$ Zur Wirkungsabsicht römischer Porträts vgl. L. GiUlıanI, Bildnis und Botschaft: Hermeneutische Untersuchungen zur Bildniskunst der römischen Republik, Frankfurt a. M. 1986; zur Betonung des Alters in spätrepublikanischen Politikerbildnissen besonders S. 197. Die glatten, jugendlichen Züge des Jonas erinnern auf den ersten Blick eher an Bildnisse des julisch-claudischen Kaiserhauses; doch auch zu diesen bestehen nur oberflächliche Ähnlichkeiten. 
pressivität, d. h. die Pathognomie ${ }^{123}$ der antiken Vorlage, sondern deren Physiognomie. Während Haltung und Mimik nichts mehr mit dem Sarkophagrelief zu tun haben, hat sich der Künstler für die Detailgestaltung des Gesichts - die markante Adlernase mit den schmalen Nasenflügeln, die weit zurückgesetzten Augen, die Wangenpartie mit der langgestreckten Nasolabialfalte, die Barttracht mit dem in zwei Büschel geteilten Kinnbärtchen - eng an die Originalvorlage gehalten; nur die wilde, vom Wind durchpflügte Haarpracht wurde offenbar für eines Prophetenhauptes unwürdig befunden. Die Präzision der Rückübersetzung in die dritte Dimension bestätigt noch einmal, wie genau die ursprüngliche Musterzeichnung gewesen sein muß.

Schließlich könnte auch für die vollplastischen Prophetenköpfe antike Medaillonkunst eine Rolle gespielt haben. Das Profil des Daniel (Abb. 49) mit den gegenüber der kräftigen Nasenwurzel auffällig weit zurückversetzten Augen und der langen, leicht gebogenen Nase, deren steil ansteigende Kontur sich in gerader Linie in der Stirn fortsetzt, dürfte ein Beispiel dafür sein. Die ornamentalen Teile des Dreikönigenschreins wurden bekanntlich durch eine riesige Zahl von griechischen und römischen Gemmen und Kameen bereichert, die die Künstler also bei der Arbeit direkt vor Augen hatten ${ }^{124}$. Prunkstück dieses Schatzes war der sogenannte Ptolemäerkameo, dessen Profilköpfe den Goldschmied hier inspiriert haben könnten ${ }^{125}$. Noch überzeugender ist der Vergleich mit dem rechten Kopf auf einem Kameo-Fragment in Berlin (Abb. 50), das die gleiche lange Nase mit heruntergezogener Spitze sowie leicht abfallende Mundwinkel zeigt ${ }^{126}$.

In diesem Zusammenhang ist auch die Zierleiste auf der oberen Dachschräge der Salomonseite von Interesse, auf der eine Reihe von elf Kopfmedaillons in Grubenschmelz dargestellt ist (Abb. 51). Des öfteren ist auf die Nähe dieser Medaillons zu antiken Münzen oder Gemmen hingewiesen worden ${ }^{127}$, die vor allem bei den Profilansichten augenfällig ist. Gleichzeitig, auch

123) Der von Georg Christoph Lichtenberg geprägte Begriff der Pathognomik wird hier im Sinne seines Erfinders verwendet, welcher darunter „die ganze Semiotik der Affekte oder die Kenntnis der natürlichen Zeichen der Gemütsbewegungen " zusammenfaßte; ich folge damit GrulianI, Bildnis und Botschaft (zit. Anm. 122), besonders S. 49-51 (ebenda, S. 49, das Lichtenberg-Zitat).

124) Zum Gemmen- und Kameenschmuck des Dreikönigenschreins, der allerdings nur noch teilweise dem ursprünglichen Bestand entspricht, liegt jetzt die umfassende Publikation von Erika ZwIERLEIN-DiEHL vor: Die Gemmen und Kameen des Dreikönigenschreins (Der Dreikönigenschrein im Kölner Dom, I.1), Köln 1998.

${ }^{125}$ ) A. und M. WerbKe, Theologie, Politik und Diplomatie (zit. Anm. 90), S. 17f, sehen die Köpfe von Maria und Kind an der Stirnseite als Nachahmung der beiden Gesichter auf dem Kameo an. Für die Maria könnte dies zutreffen, das Profil des Jesuskopfes mit der kurzen Nase hat aber offenkundig nichts mit dem Kameo zu tun (vgl. die Aufnahme im Marburger Index, Blatt 1070, D10, Rhein. Bildarchiv 113'688). - Zum Ptolemäerkameo, seiner Rezeptionsgeschichte und seiner Position innerhalb des Schreinsprogramms siehe zuletzt ZwIERLEIN-DIEHL, Gemmen und Kameen (zit. Anm. 124), S. 50-61, 88-94 (mit Angabe der älteren Literatur).

126) Dazu W-R. Megow, Zu einigen Kameen späthellenistischer und frühaugusteischer Zeit, in: Jahrbuch des Deutschen Archäologischen Instituts, 100, 1985, S. 456-473, der es in die Jahre um 30 v. Chr. datiert und das dargestellte Herrscherpaar als Augustus und Livia identifiziert; der Stein könnte, so Megow (S. 459), aufgrund seiner Provenienz im Mittelalter einen Buchdeckel oder Schrein geschmückt haben. - Analogien zum Daniel bieten auch römische Gemmen und Münzen mit Bildnissen des jungen Oktavian; vgl. z. B. eine Gemme im Berliner Antiquarium, ca. 40-35 v. Chr., abgebildet bei M.-L. VollenweIDER, Die Porträtgemmen der römischen Republik, Mainz 1972, Taf. 150, Abb. 13. Unter den geschnittenen Steinen am Dreikönigenschrein vgl. außerdem die Kameen Kat. 18, 22 und den Intaglio Kat. 46 im Katalog von ZwierLeIN-DieHI, Gemmen und Kameen (zit. Anm. 124).

127) Wrrte, Tausend Jahre (zit. Anm. 90), S. 67; F. Mütherich, Die Ornamentik der rheinischen Goldschmiedekunst in der Stauferzeit (Diss. Berlin), Würzburg 1944, S. 54; Claussen, Zum Stil der Plastik (zit. Anm. 6), S. 34; SAUERLẢNDER, Architecture (zit. Anm. 113), S. 682. 
das wurde schon beobachtet, reproduzieren die Köpfe ziemlich genau die bereits aus Klosterneuburg bekannten Formen ${ }^{128}$. Um ein Beispiel herauszugreifen, sei auf den siebten Kopf von oben hingewiesen, der den Typus des im Profil gesehenen Apostels links im Pfingstwunder (II/15) wiederholt. Claussen hat seine seltsame Kopfbedeckung als Lorbeerkranz gedeutet ${ }^{129}$; wenn die Darstellung auch nicht eindeutig zu lesen ist - es scheint sich eher um eine Art Diadem oder Krone zu handeln -, so bezeugt dieses Detail doch zumindest, daß dem Kopf eine antike Münze oder Gemme mit einem Götter- oder Herrscherbildnis zugrunde liegt. Zugleich bestätigt sich damit die Vermutung, daß der Apostelkopf ebenfalls antike Wurzeln hat. Nicht zum Formenrepertoire von Klosterneuburg gehören dagegen die fast schlangenförmigen Locken, die den fünften und den zehnten Kopf von oben zieren: Sie sind offensichtlich direkt vom Medusenhaupt einer Gemme auf der Trapezplatte an der Stirnseite des Schreins (Abb. 53) abgeleitet.

Der Marienschrein in Tournai ist bis heute das Mauerblümchen im Nikolaus-CEuvre geblieben so sehr, daß man ihn zuweilen als reines Werkstattprodukt abqualifizieren wollte ${ }^{130}$. Tatsächlich liegen größere qualitative Schwankungen als am Klosterneuburger Ambo oder an den Langseiten des Dreikönigenschreins vor, welche auf eine stärkere Beteiligung der Werkstatt schließen lassen ${ }^{131}$.

Die Reliefs des Schreins sind denn auch nur sporadisch in die Diskussion um die Antikenrezeption miteinbezogen worden ${ }^{132}$; sie scheinen in dieser Beziehung unergiebig zu sein. Antikenstudium ist am Marienschrein offenbar meist nur noch indirekt eingeflossen; bei mehreren Gestalten sind dessen Spuren aber noch zu identifizieren. Der quer um die Hüften geschlungene dreieckige Mantelzipfel der Verkündigungsmaria (Abb. 52) geht unverkennbar auf eine ganz bestimmte Drapierung des Himation in der klassischen Kunst (Abb. 54) zurück, so antikenfern die Figur sonst auch wirken mag ${ }^{133}$. Der Oberkörper Christi in der Taufszene

${ }^{128}$ ) Weisgerber, Studien zu Nikolaus von Verdun (zit. Anm. 3), S. 102; Claussen, Zum Stil der Plastik (zit. Anm. 6), S. 34; BänSCH, Kölner Goldschmiedekunst (zit. Anm. 30), S. 96.

${ }^{129}$ ) Claussen, Zum Stil der Plastik (zit. Anm. 6), S. 34.

130) So Weisgerber, Studien zu Nikolaus von Verdun (zit. Anm. 3), S. 122; Hamann-MacLean, Byzantinisches und Spätantikes (zit. Anm. 24), S. 251f; B. FäTHKE, Die Meister des Klosterneuburger Altares (Diss. Marburg), Marburg/Lahn 1972, Kap. XIII. - Die einzige eingehende Untersuchung über den Marienschrein ist die Dissertation von Rebecca Price Gowen (Baltimore 1975), von der aber nur der erste Teil publiziert ist (R. PRICE GowEN, The Shrine of the Virgin in Tournai, I: Its Restorations and State of Conservation, in: Aachener Kunstblätter, 47, 1976-77, S. 111-176, mit erschöpfender Bibliographie).

131) Die offensichtlichsten Mängel betreffen die Engel- und Prophetenbüsten und die Dachreliefs. Eine Beteiligung der Werkstatt ist auch für die Reliefs der Flucht nach Ägypten und der Marienfigur in der Verkündigung anzunehmen, während besonders der thronende Christus an der Frontseite von höchster Qualität ist. (Die gesamte Plastik des Schreins ist abgebildet bei PrICE Gowen, Shrine of the Virgin (zit. Anm. 130).

${ }^{132}$ ) Am ehesten interessierte dabei noch die Figur des thronenden Christus an der Frontseite (Abb. bei PrICE GoWEN, Shrine of the Virgin [zit. Anm. 130], S. 119, Fig. 13): Claussen, Zum Stil der Plastik (zit. Anm. 6), S. 29, Anm. 71, verglich sie mit einer Skulptur der Phidias-Zeit. Auf der anderen Seite sah R. HAMANN-MacLEAN, Nikolaus von Verdun und seine Mitarbeiter, in: DERS., Stilwandel und Persönlichkeit, Stuttgart 1988, S. 263, am Marienschrein „die antikisierenden Elemente zur Formel erstarrt“ und TJAžFLov, Nikolaj Verdenskij (zit. Anm. 90), S. 25, die „Abkehr von den klassischen Idealen“ vollzogen.

${ }^{133}$ ) Genauso entspricht die Anordnung des Mantels beim linken Engel neben dem Maiestas-Christus (für Abb. vgl. Anm. 132) einem antiken Draperieschema, das etwa die Hygieia-Figuren vom Münchner Typ zeigen: Das schräg über die Brust gezogene Himation bedeckt Schultern und beide Arme, nur die rechte Hand bleibt frei. Vgl. CROISSANT, Hygieia (zit. Anm. 101), S. 566, Nr. 195-206; Taf. 393-394, Nr. 195, 198, 199. 
(Abb. 55) reflektiert ebenfalls noch die Vorbilder, die die Aktdarstellung am Klosterneuburger Ambo beeinflußt haben: Deutlich springt die Muskelpartie über der Hüfte vor, und der Brustkasten wirkt weniger ausgemergelt, da die Einzeichnung der Rippen fehlt; dafür ist die elegante Kontraposthaltung verschwunden - nur noch eine minimale Verschiebung des linken Fußes sorgt für die Andeutung des Spielbeins. Schließlich sind auch die auf die Kniekehle zulaufenden spitzen Falten etwa beim assistierenden Engel in derselben Darstellung gerade nicht, wie behauptet wurde, ein Beispiel für die Rückkehr zu Formengut des Heribertschreins ${ }^{134}$, sondern Zitat einer antiken Formel, die beispielsweise auf der Nicomacher-Tafel (Abb. 12) zu sehen ist.

Natürlich beruhen die meisten übrigen Figuren auf bewährten Mustern des 12. Jahrhunderts oder entstammen unmittelbar dem Repertoire der Werkstatt ${ }^{135}$. Doch gleichzeitig ist im Vergleich zum Klosterneuburger Ambo tendenziell das Aufgeben von gewissen altertümlichen Figurenrezepten zu beobachten. Jene unentschiedene Haltung zwischen Stehen und Schreiten, die auf den Emailplatten noch so verbreitet ist, kommt beispielsweise kaum mehr vor. Statt dessen ist - besonders wenn wir Price Gowens Rekonstruktionen der ursprünglichen Fußstellungen berücksichtigen ${ }^{136}$ - fast bei allen Figuren die Unterscheidung von Standbein und Spielbein wenigstens im Prinzip angelegt. Ebenfalls nur noch an einer Stelle (beim Engel rechts des thronenden Christus ${ }^{137}$ ) ist das Schüsselfaltenmotiv zwischen den Beinen zu finden.

Die Köpfe des Marienschreins führen im Prinzip die Formensprache des Dreikönigenschreins fort ${ }^{138}$; die charakteristischen Merkmale des Gesichtsschnitts, etwa die Zeichnung der gefurchten Stirn, kehren unverändert wieder. Der Kopf der Elisabeth (Abb. 56) nimmt den Typus der alten Hebamme aus der Geburt Samsons in Klosterneuburg (Abb. 33) auf, wobei aller Wahrscheinlichkeit nach noch einmal auf dasselbe antike Muster rekurriert wurde. Die Verwandtschaft mit dem zum Vergleich herangezogenen Sarkophagkopf (Abb. 34) ist unverkennbar, auch wenn das Kopftuch nun Haare und Ohren ganz zudeckt. Die Individualisierung und Naturnähe der Gesichter am Dreikönigenschrein wurde aber am Marienschrein offenbar nicht mehr im gleichen Maße gesucht. Die Forschung pflegt diese Akzentverschiebung mit Begriffen wie „Spiritualisierung “139 oder „espressione di profetica estasi “140 zu umschreiben. Diese expressive Wirkung hängt stark mit der Vergrößerung der Augenpartie zusammen: Die kugelig vorgewölbten, oft nach oben gerichteten Augen mit den überdimensionierten Tränensäcken assoziieren auf den ersten Blick alles andere als Antike. Vergleichbare Züge sind aber typisch für die spätantike Bild-

${ }^{134}$ ) So Hamann-MacLean, Nikolaus von Verdun (zit. Anm. 132), S. 263.

135) Die Gestalt des Simeon in der Darbringung (PRICE Gowen, Shrine of the Virgin [zit. Anm. 130], Fig. 37) wiederholt beispielsweise einen Typus, der auf dem Türsturz der Prioratskirche von La-Charité-sur-Loire zu sehen ist (Abb. in Sauerländer, Gotische Skulptur [zit. Anm. 5], Taf. 21). Der Figur des Täufers (Abb. 55) liegt hingegen, wie BäNsCH, Kölner Goldschmiedekunst (zit. Anm. 30), S. 111f, beobachtet hat, das nur leicht abgeänderte Figurenschema der Mutter Samsons in der Klosterneuburger Beschneidungsszene (III/3) zugrunde - selbst der nun funktionslos gewordene Ansatz des Kopftuches ist noch wie ein Schal um den Hals des Johannes geschlungen. Die Szene der Flucht nach Ägypten (Price Gowen, Shrine of the Virgin [zit. Anm. 130], Fig. 35) ist oft mit Moses' Reise nach Ägypten in Klosterneuburg (I/6) verglichen worden, auch wenn die tatsächlichen Übereinstimmungen eher banal sind.

136) Price Gowen, Shrine of the Virgin (zit. Anm. 130), S. 121.

137) Für die Abbildung vgl. Anm. 132.

138) BÄNsCH, Kölner Goldschmiedekunst (zit. Anm. 30), S. 99f, hat diesen Zusammenhang bei den Köpfen des Täufers und des Joseph auf der Flucht nach Ägypten nachgewiesen, welche vom Grundschema her jenen des Bartholomäus (mit etwas kürzerem Bart- und Haupthaar) und des Amos (ohne Locken) am Dreikönigenschrein entsprechen. Der Kopf des mittleren Königs auf der Rückseite des Marienschreins variiert den Typus des Apostels Philippus.

139) BuschHausen, Verduner Altar (zit. Anm. 14), S. 110; vgl. Lasko, Ars sacra (zit. Anm. 17), S. 243.

${ }^{140}$ ) Demus, Nicola da Verdun (zit. Anm. 90), Sp. 918. 
niskunst: Vor allem aus dem späten 2. und dem 3. Jahrhundert sind Porträts erhalten, die verblüffend ähnliche Augenformen aufweisen (Abb. 58); Verwandtes ist auch bei manchen Figuren am Jovinus-Sarkophag zu finden. Obwohl der Beweis schwer zu führen sein wird, kann man sich des Verdachts nicht erwehren, daß solche spätantike Köpfe hier vorbildlich waren.

Das erklärte Ziel dieser Untersuchung, den konkreten antiken Vorlagen des Nikolaus von Verdun auf die Spur zu kommen und so dem Goldschmied quasi bei der Arbeit über die Schulter zu schauen, konnte, wie zu befürchten war, nur ansatzweise erreicht werden. Zumindest ist aber der Nachweis erbracht, daß antike Kunst in der Nikolaus-Werkstatt tatsächlich aus erster Hand bekannt war. Dazu standen dem Künstler in seiner lothringischen Heimat sowie in der benachbarten Champagne genügend erstklassige römische Werke zur Verfügung, welche unter anderem auch die Voraussetzungen für den Muldenfaltenstil boten. Das unausgesprochene Dilemma der älteren Forschung, entweder Reisen ins Mittelmeergebiet oder eine indirekte Antikenrezeption annehmen zu müssen, wird damit obsolet. Zweifellos haben auch karolingische, ottonische und byzantinische Arbeiten eine wichtige Rolle bei der Genese des Nikolaus-Stils gespielt, wobei diese verschiedenen Komponenten sich zu einem erstaunlich homogenen Amalgam verbunden haben, dessen genaue Zusammensetzung wir nur noch in Ausnahmefällen entschlüsseln können. Es besteht aber kein Anlaß mehr, die Formensprache des Nikolaus als „Freilegung des antiken Kerns " ${ }^{\text {"141 }}$ von solchen nachantiken Vorlagen zu erklären.

Ihre Vorbilder fanden die Goldschmiede offenbar nicht nur in der Schatzkunst (Münzen, Gemmen, Elfenbeinschnitzereien, Bronze- und Silberstatuetten) oder in der Buchmalerei, sondern ebenso in Sarkophagreliefs und vermutlich auch in Monumentalskulptur und Porträtplastik. Die detailgetreue Umsetzung des Kopfes vom Jovinus-Sarkophag ins kleinformatige, lineare Email beweist, daß von einer durch die Arbeitstechnik bedingten „Bindung ans Metier“ sicher nicht gesprochen werden kann. Wenn, wie die statistische Auswertung der mutmaßlichen Vorlagen nach Gattungen andeutet, die Auseinandersetzung mit antiken Schatzkammerstücken besonders intensiv war, so hängt das wohl eher damit zusammen, daß dieser Bereich der griechisch-römischen Kunst für einen Goldschmied des 12. Jahrhunderts am leichtesten zugänglich war. Auf jeden Fall waren für den Faltenstil offensichtlich vor allem plastische Vorbilder maßgebend: Auch im Email sind die Draperien praktisch nie als lineare Formen, sondern immer räumlich gedacht, was in der maasländischen und vor allem kölnischen Schmelzkunst mitnichten die Regel ist ${ }^{142}$.

Als Übertragungsmedium dürften zumindest bei Vorbildern aus dem Bereich der Großplastik vor allem Zeichnungen gedient haben, im Falle von kleinformatigen Stücken wie Gemmen oder Bronzestatuetten auch Abgüsse und Wachsabdrücke. Die auffällige Tatsache, daß die mutmaßlichen Vorlagen von den Goldschmieden oft seitenverkehrt verwendet wurden - mit Sicherheit ist dies beim Kopf des Traubenträgers (Abb. 26) der Fall -, unterstreicht die wichtige Rolle von Pausen in der Werkstattpraxis jener Zeit: Mit Hilfe dieses Verfahrens konnte das Muster je nach den Erfordernissen des Darstellungszusammenhangs problemlos gespiegelt wer$\operatorname{den}^{143}$.

${ }^{141}$ ) Hamann-MacLean, Byzantinisches und Spätantikes (zit. Anm. 24), S. 250.

${ }^{142}$ ) Vgl. SHIKIDA, Bilddenken (zit. Anm. 8), S. 42.

${ }^{143}$ ) Dazu J. Springer, Gegenseitige Kopien von Miniaturen, in: Zeitschrift für Bücherfreunde, 10 (1906/7), S. 426f.; BäNsCH, Kölner Goldschmiedekunst (zit. Anm. 30), bes. S. 30-50. 
Angesichts der Vielfalt der Vorbilder, welche Nikolaus von Verdun studiert, überrascht die selektive Methode, mit der er sie für seine eigene Arbeit fruchtbar macht. Statt ein Werk wie den Jovinus-Sarkophag systematisch auszuwerten, wählt der Künstler aus dem großen Angebot an vorgeformten Typen ganz gezielt einzelne Motive aus, oft nur marginal erscheinende Details. Dieser selbstbewußte Umgang mit dem antiken Erbe ist in jener Epoche auch in anderen Bereichen zu beobachten; gemäß Hans Liebeschütz behandelte das 12. Jahrhundert das klassische Altertum „wie ein Schatzhaus von Gedanken und Formen, aus dem es die Stücke entnimmt, die unmittelbar in das Denken und Handeln seiner Gegenwart zu passen scheinen"144. Ähnlich wie Abt Wibald von Corvey die antiken Texte „nicht einem Deserteur und Überläufer gleich, sondern wie ein nach Beute trachtender Kundschafter (sicut explorator et spoliorum cupidus) “ durchforscht ${ }^{145}$, studiert Nikolaus von Verdun antike Kunst, um von ihr nur das zu übernehmen, was seinen Intentionen entgegenkommt. Was aber waren seine Intentionen, wonach suchte der Goldschmied?

Antikenrezeption war, so der Grundtenor der Forschung, für die Künstler der Zeit um 1200 in erster Linie Mittel zum Zweck: Die Kunst des Altertums bot ihnen ein Reservoir an ,vorgeformter Natur" und diente dadurch als Schrittmacher auf dem Weg zu lebensnäheren Darstellungsformen ${ }^{146}$. Dies gilt, wie alleine schon die Galerie der Prophetenköpfe am Dreikönigenschrein illustriert, sicher auch und in besonderem Maße für Nikolaus von Verdun. Die Antikenkopie ist bei ihm deshalb nicht ausschmückendes Zitat, sondern Hilfsmittel zur Formulierung eines naturnäheren Stils, einer neuen künstlerischen „Hochsprache“147. Weil diese Bemühungen jedoch nicht auf ein ,antikes Figurenideal“ ${ }^{\text {"148 }}$ abzielen, wird die klassische Kunst anders als für manche Vertreter der italienischen Frührenaissance oder auch der karolingischen Hofkunst nicht zur stilistischen Norm. Im Gegensatz zu jenen rezipiert der Goldschmied deshalb nur vereinzelt ganze Figurenschemata, und zwar vorzugsweise solche, die - wie gewisse Typen stehender weiblicher Gewandfiguren - in verwandter Form schon in der mittelalterlichen Tradition zu finden waren. Grundlage bleibt das romanische Motivrepertoire, das in seinem Erscheinungsbild (besonders durch den Faltenstil) modernisiert, aber nur punktuell erweitert wird. Vor diesem Hintergrund ist auch der Rückgang an direktem Antikenstudium vom Klosterneuburger Ambo über den Dreikönigenschrein zum Marienschrein zu sehen: Dem oft unvermittelten Nebeneinander von antiken und mittelalterlichen Figurenkonzepten am Emailwerk folgt eine konsequentere Integration der antiken Elemente am Kölner Schrein; dadurch verstärkt sich der Eindruck klassischen Formgefühls, obwohl sich nur wenige neue Antikenaufnahmen nachweisen lassen. Am Marienschrein haben diese ihre stilbildende Aufgabe erfüllt; der Verzicht auf neuerliches Antikenstudium geht deshalb einher mit einem Verzicht auf for-

144) H. Liebeschütz, Das zwölfte Jahrhundert und die Antike, in: Archiv für Kulturgeschichte, 35, 1953, S. 271.

${ }^{145)}$ Ego baec castra ingredior non tamquam desertor et transfuga, sed sicut explorator et spoliorum cupidus (zit. S. SETTIS, Continuità, distanza, conoscenza: Tre usi dell'antico, in: DERs. [Hg.], Memoria dell'antico nell'arte italiana, Bd. III, Torino 1986, S. 383f). Das Zitat aus dem bekannten Brief Wibalds an seinen Freund Manegold (vgl. dazu SETTIS, ebenda) geht auf eine Stelle in Senecas Briefen an Lucilius (I, $\left.2_{5}\right)$ zurück, die im Mittelalter in bezug auf die Lektüre heidnischer Autoren offensichtlich geradezu topisch verwendet wurde; für weitere Beispiele vgl. N. GRAMACCINI, Mirabilia: Das Nachleben antiker Statuen vor der Renaissance, Mainz 1996, S. 120.

146) Hamann-Maclean, Antikenstudium (zit. Anm. 10), S. 187; Sauerländer, Gotische Skulptur (zit. Anm. 5), S. 54; DERS., Architecture (zit. Anm. 113), S. 672, 684.

147) Vgl. P. C. CLAussen, Nikolaus von Verdun und die antikisierende Kleinskulptur (Referat am Internationalen Kolloquium des C.I.H.A. über Nikolaus von Verdun in Wien und Klosterneuburg, 25.-27. 9. 1995).

${ }^{148}$ ) So Filurtz/PIPPAL, Schatzkunst (zit. Anm. 13), S. 205. 
male Archaismen - das Ergebnis ist eine ausgesprochen homogene und ausgewogene Formensprache.

Die Funktion des Antikenstudiums im Werk des Goldschmieds läßt sich aber noch genauer analysieren. Dabei erweist sich das Beispiel des Jovinus-Sarkophags geradezu als Glücksfall. Während in den meisten nachweisbaren Fällen von Antikenkopien im Früh- und Hochmittelalter jeweils anonyme Künstler ihr Vorbild in toto (aber meist mit charakteristischen Abweichungen und Vereinfachungen) übernehmen ${ }^{149}$, werden hier nur wenige Elemente aus einem bestimmten Zusammenhang in einen anderen transferiert. Da wir sowohl den ursprünglichen Kontext als auch das CEuvre des Kopisten kennen, können wir für einmal sehr genau den Vorgang der Selektion eines Motivs aus einem gegebenen Angebot verfolgen und daraus die Auswahlkriterien und damit die Intentionen des Antikenstudiums erschließen.

$\mathrm{Daß}$ gerade die Gestalt des gestürzten Jagdgehilfen den Goldschmied interessierte, erscheint auf den ersten Blick nicht weiter bemerkenswert - sie hat wenige Jahrzehnte später auch den Bildhauer des Reimser Chorkapitells in ihren Bann geschlagen. Den Grund könnte man zunächst einfach darin suchen, daß der Sarkophag schon im 12. Jahrhundert erhöht aufgestellt und diese Figur so am besten zu sehen war ${ }^{150}$. Vor allem jedoch ist der liegende Barbar die dramatischste und wildeste Gestalt des Reliefs; und die Faszination für die „Wildheit“ der antiken Skulptur ist im Hochmittelalter auch literarisch bezeugt. So zeigt sich beispielsweise Fulcoius von Beauvais (gest. nach 1083) in seinem berühmten Brief an Hugo von Cluny, in dem er die Entdeckung eines antiken Marskopfes schildert, zugleich beeindruckt und abgestoßen von dessen horror und feritas ${ }^{151}$. Gefördert durch die Dämonisierung der heidnischen Idole ${ }^{152}$, scheint das Konzept der feritas im Antikenverständnis jener Epoche neben Begriffen wie Schönheit und Lebendigkeit ${ }^{153}$ ein zentraler Topos gewesen zu sein - in der romanischen Skulptur wurde die antike Überlieferung denn auch ganz besonders für die Darstellung von Fabeltieren und Ungeheuern benutzt ${ }^{154}$. Vor diesem Hintergrund ist die Idee, den gefallenen Jäger in ein solches Mischwesen zu verwandeln, nicht so bizarr, wie es zunächst scheinen mag, sondern geradezu charakteristisch für einen bestimmten Zugang zur Antike ${ }^{155}$.

Ein ganz anderer, sagen wir mal, fortschrittlicherer Ansatz liegt dagegen der Verwendung desselben Vorbildes in Klosterneuburg zugrunde: Nur noch der Kopf der Figur interessiert, doch nicht nur wegen seiner besonderen physiognomischen, sondern auch wegen seiner pathognomischen Merkmale - daher sind Haltung und mimischer Gestus so getreu wie möglich wiederholt. Während beim Reimser Kapitell das tertium comparationis zur Sarkophaggruppe in der äußeren Situation des Kampfes liegt, so geht es dem Goldschmied um die innere Dramatik

${ }^{149}$ ) Vgl. die Analyse der bekannten Beispiele aus Oviedo, Frómista, Pisa, Modena, Bourges etc. bei SeTris, Continuità, distanza, conoscenza [zit. Anm. 145], S. 399-410; dazu auch DERS., Von auctoritas zu vetustas: Die antike Kunst in mittelalterlicher Sicht, in: Zeitschrift für Kunstgeschichte, 51, 1988, S. 157-179.

$\left.{ }^{150}\right)$ Siehe oben, Anm. 75. Auf eine erhöhte Lage deutet auch die Profilansicht am Klosterneuburger Ambo hin, die man bei ebenerdiger Anordnung nur haben kann, wenn man unmittelbar vor dem Sarkophag auf dem Boden kauert.

${ }^{151}$ ) Horrendum caput et tamen boc horrore decorum, / Lumine terrifico, terror et ipse decet: / Rictibus, ore fero, feritate sua speciosum, / Deformis formae forma quod apta foret (zit. A. BoUtÉMY/F. VERCAUTEREN, Foulcoie de Beauvais et l'intérêt pour l'archéologie antique au XI'e et au XII' siècle, in: Latomus, 1, 1937, S. 179).

152) Dazu zuletzt Gramaccrni, Mirabilia (zit. Anm. 145).

${ }^{153)}$ Siehe unten, S. 40f.

154) Vgl. ADHÉMAR, Influences antiques (zit. Anm. 56), S. 160f, 179-189.

155) Noch in Castel del Monte, im protohumanistischen Klima unter Friedrich II., ist im Prinzip derselbe Mechanismus wirksam, wenn ein antiker Barbarentypus für eine groteske Maske adaptiert wird. 
der Figur: Der Ausdruck des gestürzten Jägers, der sich verzweifelt des anstürmenden Löwen zu erwehren sucht, schien ihm offensichtlich das geeignete Vorbild für die verwandte Situation des Mannes, der das Gewicht der Traube aus dem Gelobten Land kaum zu tragen vermag. Wir haben es also hier mit einer „Pathosformel“ im Warburgschen Sinne zu tun; wenn Domenico Ghirlandaio für die von Furcht ergriffenen römischen Soldaten in der Auferstehungsszene der Cappella Tornabuoni Köpfe aus Studien nach der Trajanssäule verwendet ${ }^{156}$, so ist das im Grunde genommen derselbe Vorgang.

Dieses Beispiel, aber auch der Kopf des Abdias am Dreikönigenschrein (falls er wirklich ein antikes Vorbild wiedergibt) sind Indizien dafür, daß die Goldschmiede gerade die Dramatik und die psychologische Dimension der antiken Kunst interessierte. Daß der Kopf des Kundschafters dann als besonders gelungenes Exemplar auf der Zierleiste am Dreikönigenschrein wiederkehrt, illustriert die Wichtigkeit, die man ihm in der Werkstatt als Ausdrucksstudie beimaß. Spätestens zu diesem Zeitpunkt wird das Muster dann aber zur weiteren Verwertung in seine Einzelteile aufgespalten: Während auf der Emailleiste nur noch Mimik und Kopfwendung beibehalten sind, kehren die physiognomischen Merkmale am Kopf des Habakuk wieder, nun völlig losgelöst vom ursprünglichen Ausdrucksgehalt der Vorlage. Auch dieses Baukastenprinzip ist ein Charakteristikum der Antikenrezeption des Nikolaus von Verdun.

Die Rolle der antiken Kunst als „Naturersatz“ kann also im Falle des Goldschmieds noch differenzierter beschrieben werden. Es ging dabei einerseits, wie schon zur Genüge herausgearbeitet worden ist ${ }^{157}$, um die organische Gestaltung des Körpers, um die Unterscheidung von Körper und darüberliegendem Gewand, um natürliche Haltungen und Faltenwurf - als Beispiele wären das Studium des Nicomacher-Symmacher-Diptychons und eines Sarkophagreliefs in der Art des Kopenhagener Stücks zu nennen. Kennzeichnend für die Antikenrezeption des Nikolaus von Verdun im Unterschied zu der seiner Zeitgenossen ist aber, daß er ganz besonders für die Darstellung von charakteristischen Physiognomien und die Differenzierung des Mienenspiels auf das Instrumentarium der griechisch-römischen Kunst zurückgriff; hierin liegt das Innovationspotential seines Ansatzes, der bereits auf das Antikenstudium eines Nicola Pisano ${ }^{158}$ vorausweist. Ziel ist damit letztlich die Aneignung jener Lebendigkeit und Ausdruckskraft, die ein Autor des frühen 13. Jahrhunderts wie Magister Gregorius an römischen Kunstwerken bewundert ${ }^{159}$.

Die vielleicht naheliegendste Qualität, die die klassische Kunst außerdem vermitteln konnte, ist körperliche Schönheit. Das christliche Mittelalter zerstörte die heidnischen Idole nicht in ästhetischer Ignoranz, sondern gerade auch weil es sich ihrer äußerlichen Vollendung und da-

156) E. H. Gomвrich, Aby Warburg: Eine intellektuelle Biographie, Frankfurt a. M. 1984 (19701), S. 232.

${ }^{157}$ ) Fim.rrz, Zu Nikolaus von Verdun (zit. Anm. 6), S. 280f.; DERS., Nicolaus von Verdun (zit. Anm. 6), S. 281-287; Filurtz/ Pippal, Schatzkunst (zit. Anm. 13), S. 205.

${ }^{158}$ ) Vgl. dazu M. SEIDEL, Studien zur Antikenrezeption Nicola Pisanos, in: Mitteilungen des kunsthistorischen Instituts in Florenz, 19, 1975, besonders S. 328.

${ }^{159}$ ) Vgl. seine Beschreibung der Fragmente einer Kolossalstatue (moturo et locuturo simillimum), der Schlachtendarstellungen am archus triumphali Augusti (vera bella videre existimes) und die vielzitierte Passage über die Venusstatue (Videturque comminus aspicientibus in niveo ore ymaginis sanguinem natare; zit. MAGISTER GREGORIUS, Narracio de mirabilibus urbis Romae [Textus minores, 42], hg. von R. B. C. HuYgens, Leiden 1970, S. 18, S. 24, S. 20; zur Kontroverse um die Datierung des Textes vgl. I. HerkLotz, Der Campus Lateranensis im Mittelalter, in: Römisches Jahrbuch für Kunstgeschichte, 22, 1985, S. 19, Anm. 99 [mit Angabe der älteren Literatur], welcher ihn in die Zeit Gregors IX., 1227-1241, setzt). Es ist in diesem Zusammenhang nicht unbedingt relevant, ob es sich dabei um eine wirklich selber empfundene Lebendigkeit oder um einen literarischen Topos handelt. 
mit ihres Verführungspotentials bewußt war ${ }^{160}$. Exemplarisch hat Guibert de Nogent in seiner zu Beginn des 12. Jahrhunderts geschriebenen Autobiographie diesen Zwiespalt zwischen Ablehnung und Bewunderung in Worte gefaßt:

Laudatur itaque in idolo cujuslibet materiei, partibus propriis forma conveniens et, licet idolum ab Apostolo, quantum spectat ad fidem, nibil appelletur, nec quippiam profanius habeatur, tamen illa membrorum apta diductio non ab re laudatur. ${ }^{161}$

Wenn der Goldschmied den Christus in der Klosterneuburger Taufszene nach dem Modell einer römischen Bronzestatuette gestaltet, so zieht er gleichsam die praktische Konsequenz aus dieser Erkenntnis: Er trennt die schöne Form von ihrem heidnischen Inhalt und unterzieht sie einer Interpretatio christiana bzw. macht sie der Verherrlichung Gottes nutzbar. Dieser Vorgang kommt dem einen Aspekt jenes Phänomens gleich, welches Panofsky als „Disjunktionsprinzip “ der mittelalterlichen Kunst beschrieben hat ${ }^{162}$. Gerade in diesem Fall stellt die Vereinnahmung antiker Schönheit aber eine Gratwanderung dar, die von der Kühnheit des Nikolaus von Verdun zeugt; denn wo immer im 12. Jahrhundert nackte Götterfiguren mit ihrer Kontraposthaltung sonst imitiert wurden, dienten sie, wie beispielsweise in einem Glasfenster in Canterbury ${ }^{163}$, der Denunziation des Götzenkultes. Zumindest im Urteil des heutigen Betrachters vermag das Resultat dieser heiklen Vermählung von christlichem Inhalt und normalerweise heidnisch konnotierter Körperschönheit zu überzeugen ${ }^{164}$; auch bei der Königin von Saba erscheint die antikennahe Darstellung zur Charakterisierung der Person gerechtfertigt. Die üppigen Formen der trauernden Maria unter dem Kreuz dagegen wirken im Angesicht des leidenden Christus selbst für unser Auge deplaziert. Hier scheint das Antikenstudium übers Ziel hinauszuschießen, zum künstlerischen Selbstzweck zu werden - oder jedenfalls einem rein ästhetischen Schönheitsempfinden zu folgen, das keine Rücksicht mehr auf die inhaltliche Angemessenheit nimmt.

${ }^{160}$ ) Zu dieser Problematik zuletzt GramaccinI, Mirabilia (zit. Anm. 145), besonders S. 33-41.

161) De vita sua, sive monodiae, I; zit. GUIBERT DE NOGENT, Autobiographie (Les classiques de l'histoire de France au Moyen Âge, 34), hg. von E.-R. LABANDE, Paris 1981, S. 12f. Deutsche Übersetzung nach F. von BezolD, Das Fortleben der antiken Götter im mittelalterlichen Humanismus, Bonn/Leipzig 1922, S. 43:

„So lobt man daher an einem Idol irgendwelchen Stoffes die in allen Teilen harmonische Form, und obwohl das Idol von dem Apostel, soweit es den Glauben angeht, als ein Nichts bezeichnet und für unheiliger als irgendetwas anderes gehalten wird, so wird doch jene passende Anordnung der Glieder mit Recht gelobt.“

${ }^{162}$ ) Auf der anderen Seite wird, so Panofsky, für die Darstellung antiker, heidnischer Themen in der Regel eine nichtantike Formensprache verwendet (E. PANOFSKY, Renaissance and Renascences in Western Art, Stockholm 1960, bes. S. $83 \mathrm{ff})$.

163) Dazu CAvinEss, Early Stained Glass (zit. Anm. 19), S. 58, Abb. 37, 40, die annimmt, daß der Glasmaler bei der Darstellung des Idols ebenfalls eine römische Bronzestatuette vor Augen oder wenigstens im Kopf hatte. Vgl. auch die stürzenden Götterbilder in den Mosaiken von Monreale (Martyrium der hll. Castus und Castrensis; E. KrTzINGER, I mosaici di Monreale, Palermo 1960, Abb. 43) und San Marco in Venedig (Martyrium des hl. Philippus; O. Demus, The Mosaics of San Marco in Venice, Chicago/London 1984, Bd. I 2 , Abb. 365).

164) Wie brisant diese künstlerische Lösung aber im 12. Jahrhundert sein mußte, belegt die Kritik Abaelards - der doch gerne als Vorläufer des neuzeitlichen Denkens gefeiert wird - an der Darstellung des Göttlichen im Gewande menschlicher Schönheit (nach dem Vorbild heidnischer Idole), welche in der rhetorischen Frage gipfelt: Numquid amare potest ut Juppiter idola Christus, / Aut sculpi ut Vesta nostra Maria volet? (zit. von BEzOLD, Fortleben [zit. Anm. 161], S. 44). 
In ähnlicher Weise der Faszination des antiken Kunstwerks erlegen ist wohl auch der Goldschmied, der an der Frontseite des Dreikönigenschreins die Figur des Täufers ausführte und dabei dessen härenes Gewand kurioserweise dem Venus-Schleier auf der großen Gemme an der Trapezplatte gleich oberhalb nachempfand ${ }^{165}$. Allein die Aura des antiken Objekts, die auf seiner Seltenheit, seiner magischen Kraft, seinem Alter gründet, rechtfertigte hier vermutlich die Verwendung als Vorlage ${ }^{166}$, ungeachtet des inhaltlich ebenso wie ästhetisch eher bizarren Resultats. Diese Johannes-Figur hat direkt sicher nichts mehr mit Nikolaus von Verdun zu tun, wohl nicht einmal mehr mit seiner Werkstatt; man könnte die eigenartige Antikenrezeption deshalb als mißverstandene Aneignung seiner Praktiken durch einen Kölner Epigonen erklären und wird damit vermutlich nicht ganz falsch liegen. Doch selbst in der Szene des Roten Meeres am Klosterneuburger Ambo, wo der Einbezug von Sarkophagmotiven den Realismus der Darstellung steigern sollte, war die Autorität des antiken Vorbildes offensichtlich so groß, daß auch die Nacktheit der Kinder aus dem dionysischen Kontext übernommen wurde, obwohl dafür in der biblischen Szene jede inhaltliche Berechtigung fehlt.

Gerade solche weder ikonographisch noch formalästhetisch ausreichend motivierte Rezeptionen lassen die Frage nach einer zeichenhaften Funktion antikisierender Formen auch bei Nikolaus von Verdun berechtigt erscheinen. Bereits Floridus Röhrig hatte beobachtet, daß am Klosterneuburger Ambo vor allem Figuren „aus der mittleren, neutestamentlichen Zone, denen der Künstler größere Weihe verleihen wollte“, an antike Statuen erinnern ${ }^{167}$. Daraus ließe sich die These entwickeln, daß die auctoritas der antiken Form gezielt zur Auszeichnung bestimmter Figuren oder des ganzen Heilsgeschehens eingesetzt wurde - in diesem Fall, um den in der Inschrift angesprochenen decor des sub gratia-Zeitalters zu unterstreichen und so das gnadenhafte Geschehen des Neuen Testaments gegen die alttestamentarischen Typen abzusetzen. In diesem Lichte könnte sich das oben geäußerte Unbehagen über die Gestaltung der Marienfigur in der Kreuzigung als ein modernes Mißverständnis erweisen: Gerade antike Schönheit erschien dem Goldschmied möglicherweise als adäquates Mittel, um die Würde der Gottesmutter im Moment des größten Schmerzes zum Ausdruck zu bringen. Ebenso wie beim Christus in der Taufe wäre dann der kontrapostische Stand eine besondere Art der Nobilitierung, ein Zeichen für äußere wie innere Schönheit und Erhabenheit.

Man wird jedoch mit einem solchen Deutungsansatz rasch in Verlegenheit kommen bei der Frage, warum diese Option dann im Falle der Verkündigungsmaria beispielsweise nicht wahrgenommen wurde. In bezug auf das Maß an eingebrachter Antike ist zudem eine Privilegierung der mittleren Reihe des Ambos schwerlich zu belegen. Die Ungereimtheiten häufen sich erst recht, sobald wir über Klosterneuburg hinaus schauen: Wenn von den beiden Engeln zu seiten Christi an der Stirnseite des Dreikönigenschreins (Abb. 37) der eine einen antiken, der andere einen mittelalterlichen Figurentypus aufweist, obwohl sie auf derselben Hierarchiestufe stehen, dann konnten diese beiden Gestaltungsweisen offenbar wahlweise, womöglich nur um der Variation willen nebeneinander verwendet werden. Für diese Probleme kann es keine einfache Lösung geben; wir müssen fallweise mit der Möglichkeit eines solchen demonstrativ-nobilitierenden Einsatzes von antiker Form rechnen, der in der Nikolaus-Werkstatt aber mit Sicherheit kein

${ }^{165}$ ) Claussen, Zum Stil der Plastik (zit. Anm. 6), S. 30f. Die Seltsamkeit dieser Ableitung wird dadurch nicht gemildert, daß die Venusfigur im 12. Jahrhundert vermutlich als Maria gedeutet wurde (vgl. ZwIERLEIN-DIEHL, Gemmen und Kameen [zit. Anm. 124], S. 94f.).

166) Vgl. SETTIS, Continuità, distanza, conoscenza (zit. Anm. 145), S. 480.

${ }^{167}$ ) F. RÖHRIG, Der Verduner Altar, Wien $1955^{2}$, S. 36. 
systematisch verfolgtes Konzept darstellte - allein schon die Rezeption des Kopfes vom Jovinus-Sarkophag zeugt von einem ganz anderen, pragmatischen Umgang mit römischer Kunst.

Claussen hat dagegen den antiken- und naturnahen Figurenstil am Dreikönigenschrein als Streben nach Authentizität interpretiert; der Künstler habe versucht, „den legendären Königen, die ja Zeitgenossen des Augustus gewesen sein mußten, ein Gehäuse zu schaffen, in das sein Wissen von antiker Form und natürlich ein Höchstmaß an substantieller Antike in Gestalt von geschliffenen Steinen Eingang gefunden hat ${ }^{\text {"168. }}$. Eine historisierende Rekonstruktion war dabei zweifellos nicht intendiert; Gemmen und antikennahe Formen waren nur geeignet, dem Betrachter ganz allgemein verehrungswürdiges Alter der Reliquien und ihres kostbaren Behälters zu suggerieren. Leider stößt diese Deutung ausgerechnet in der Szene der Epiphanie auf Schwierigkeiten, wo nicht nur Otto IV., sondern auch die drei „antiken“ Könige und Maria mit dem Kind in mittelalterliche Herrschertracht gekleidet sind ${ }^{169}$.

Weitergehende Thesen, die die antikisierende Formensprache mit der Reichs- und Kaiserideologie in Verbindung bringen ${ }^{170}$, sind erst recht problematisch - schon deshalb, weil es keine Anzeichen dafür gibt, daß die Dreikönigsreliquien für die Sakralisierung des staufischen Herrschertums in Anspruch genommen wurden ${ }^{171}$; selbst die politische Funktion der Stiftung Ottos IV. darf nicht überbewertet werden ${ }^{172}$. Eine Verbindung zum antiken Kaisertum bietet das Schreinsprogramm ohnehin nicht. Wenn irgendwo Antikenstudium in diesem Sinne hätte eingesetzt werden müssen, dann am Aachener Karlsschrein; doch gerade dort sticht die antikenferne Gestaltung ins Auge.

Es ist klar, daß sich die Existenz einer semantischen Ebene von antiken Formen mit ähnlichen Argumenten und Gegenargumenten weder beweisen noch widerlegen läßt; die Diskussion um inhaltliche Deutungen wird immer Spiegelfechterei bleiben, solange wir uns ausschließlich auf die Bildquellen stützen können. Es ist zweifellos möglich, daß antikennaher Darstellung etwa auch von der Auftraggeberseite her eine ideologische Bedeutung zugemessen wurde; diese

${ }^{168}$ ) Claussen, Nikolaus von Verdun (zit. Anm. 6), S. 448.

${ }^{169}$ ) Zur Gewandung der Anbetungsgruppe siehe PETERSOHN, Der König ohne Krone (zit. Anm. 90), S. 49f und Abb.1.

170) TJAžELov, Nikolaj Verdenskij (zit. Anm. 90), S. 24, erwägt die Möglichkeit, daß die antike Einkleidung der Propheten die Kontinuität zwischen der Herrschaft der römischen Cäsaren und jener der deutschen Kaiser unterstreichen sollte (wobei er fälschlicherweise Friedrich Barbarossa als Stifter nicht der Reliquien, sondern des Reliquiars bezeichnet), begegnet der These aber selbst mit großer Skepsis. Eigenartigerweise will er diesen Gedanken bei Claussen gelesen haben.

171) Dazu H. StehкÄmper, Könige und Heilige Drei Könige, in: Kat. Die Heiligen Drei Könige, Köln 1982, S. 37-39, 45; WerbKe, Theologie, Politik und Diplomatie (zit. Anm. 90), S. 33f; Petersohn, Der König ohne Krone (zit. Anm. 90), S. 65-72. Die ältere Forschungsmeinung z. B. bei J. TonsY, Achthundert Jahre Dreikönigenverehrung in Köln, in: Kölner Domblatt, 23/24, 1964, S. 27-30; sie wurde zuletzt noch von H. P. HilGER, Sacrum Imperium: Insignien und Denkmale, in: Kat. Ornamenta Ecclesiae (zit. Anm. 6), Bd. III, S. 187f, vertreten. Auch die Anspielung auf die wisen bei Walther von der Vogelweide (1. Philippston Nr. 3) zielt nicht auf eine Parallele zwischen dem staufischen König und seinen biblischen Vorläufern ab, sondern zwischen deren Huldigung und damit Offenbarung Christi und jener der thüringischen und sächsischen Fürsten an den staufischen König; die Drei Könige werden also nicht mit Philipp verglichen, sondern mit den deutschen Fürsten (vgl. dazu P. WAPNEwsKr, Die Weisen aus dem Morgenland auf der Magdeburger Weihnacht, in: Lebende Antike [Symposion für Rudolf Sühnel], hg. von H. MELLER, H.-J. ZIMMERMANN, Berlin 1968, S. 74-94).

172) PETERSOHN, Der König ohne Krone (zit. Anm. 90), S. 65-72. Eine neue Deutung der Darstellung Ottos IV. auf der Stirnseite bietet L. GoMpF, Der Kölner Dom, die Heiligen Drei Könige und der Apostel Thomas, in: Kölner Domblatt, 61, 1996, S. 99-122, indem er sie mit einer in Köln um 1200 aufgekommenen Prophezeiung in Verbindung bringt, wonach Otto dereinst als Nachfolger der Drei Könige das heidnisch gewordene Morgenland neu missionieren werde. 
muß aber im Falle des Nikolaus von Verdun insofern sekundär gewesen sein, als sie etwa in Köln nicht die Ursache für die Stilbildung sein konnte, sondern nur bei der Entscheidung für eine „antikisierende“ Werkstatt den Ausschlag gegeben haben kann.

Ich bin der Frage des Naturstudiums, so sehr sie auch mit jener der Antikenrezeption verknüpft ist und daher im Gang der Argumentation immer wieder anklang, bisher sorgfältig ausgewichen. Der Grund liegt darin, daß der Nachweis von Naturbeobachtung für diese Zeit, aus der keine Entwurfszeichnungen und Studien erhalten sind, auf praktisch unüberwindliche methodische Schwierigkeiten stößt. Die Forschung hat das Thema denn auch selten angegangen und war dabei weitgehend auf Mutmaßungen angewiesen ${ }^{173}$. Da aber die bisherigen Ergebnisse auch gewisse Folgerungen für das Problem Naturstudium zulassen, soll es in einem kurzen Exkurs doch noch zur Sprache kommen.

Am dringendsten stellt sich die Frage bei den Kölner Prophetenköpfen, die so „unmittelbar aus dem Leben gegriffen " 174 scheinen. Claussen grenzt vom antiken oder antik wirkenden Grundtypus der Köpfe einen an der Natur geschulten Realismus des physiognomischen Details und des Mienenspiels ab, der diese Gesichter letztlich erst „zu ihrem außerordentlichen Ausdruck befähigt" ${ }^{175}$. Zweifellos wären diese Leistungen ohne eine gute Beobachtungsgabe und einen wachen Sinn für die menschliche Physiognomie nicht denkbar gewesen. Wie weit sich aber der Goldschmied bei der konkreten Arbeit auf am lebenden Menschen Gesehenes abstützte, ist eine andere Frage. Claussen räumt selbst ein, daß „systematische Modellstudien im Atelier" nicht anzunehmen sind ${ }^{176}$. Ich würde noch weiter gehen und behaupten, daß die Goldschmiede überhaupt keine zeichnerischen Vorlagen nach der Natur benützten. Denn wie anders wäre es zu erklären, daß die Stirnfalten bei fast allen Köpfen der Langseiten dasselbe Muster zeigen? In dieser Beziehung ist gerade der Vergleich mit den sicher nach dem Modell gearbeiteten römischen Bildnissen aus spätrepublikanischer Zeit aufschlußreich, welche eine unabsehbare Vielfalt an individuell beobachteten Faltenformen aufweisen ${ }^{177}$. In der NikolausWerkstatt wird dagegen ein Rezept eingesetzt, das aller Wahrscheinlichkeit nach nicht Naturbeobachtung, sondern dem Studium älterer Kunst zu verdanken ist (vgl. Abb. 18, 46 und Anm. 50), aber eben ein befriedigendes $\mathrm{Maß}$ an Natürlichkeit garantiert ${ }^{178}$. Wie zurückhaltend man mit dem Prädikat „Naturstudium“ umgehen muß, sehen wir daran, daß auch der Kopf des Habakuk, der doch zunächst „keinerlei Assoziationen antiker Skulptur erweckt ${ }^{\text {“179, }}$, ausgerechnet einer solchen seine Individualität verdankt.

173) Vgl. z. B.: Griessmaier, Nikolaus von Verdun (zit. Anm. 4), S. 40-42; BuschHausen, Verduner Altar (zit. Anm. 14), S. 110 (beide zum Klosterneuburger Ambo); Claussen, Zum Stil der Plastik (zit. Anm. 6), S. $38-41$ (zu den Prophetenfiguren am Dreikönigenschrein).

174) VON FALKE, Dreikönigenschrein (zit. Anm. 89), S. 8.

${ }^{175}$ ) Claussen, Zum Stil der Plastik (zit. Anm. 6), S. 38.

176) Ebenda.

177) Vgl. das reiche Abbildungsmaterial in SCHwErrzer, Bildniskunst (zit. Anm. 121).

${ }^{178}$ ) Ein solches Werkstattrezept ist vermutlich auch der von Claussen, Zum Stil der Plastik (zit. Anm. 6), S. 38, beobachtete Übergang von der faltigen Stirn zur glatt gespannten Kopfhaut - am Klosterneuburger Ambo zeigt z. B. die Stirnglatze des hintersten Mannes im Durchzug durch das Rote Meer (Abb. 22) dasselbe Gestaltungsprinzip in graphischer Umsetzung; daß die Künstler diese physiognomische Kenntnis nun zuallererst Naturerfahrung verdankten ist nicht zwingend - auch antike Porträts konnten sie ihnen vermitteln (Abb. 48).

${ }^{179}$ ) Claussen, Zum Stil der Plastik (zit. Anm. 6), S. 38. 
Bleibt noch der Bereich von Mienenspiel und Gesichtsausdruck. Natur- oder besser Lebenserfahrung hat hier sicher eine Rolle gespielt - nur diese konnte überhaupt das Interesse dafür wecken. Doch ob sich die Künstler dann für ihre Arbeit nicht doch vorzugsweise an bereits vorgeprägten Wendungen der antiken oder byzantinischen Kunst orientierten, erscheint zumindest fraglich. Welche Rolle die antike Kunst für Nikolaus von Verdun auch als Repertoire von Ausdrucksstudien spielte, deutet die Kopie des Kopfes vom Jovinus-Sarkophag am Klosterneuburger Ambo an.

Das Arbeiten mit übernommenen (oder selbst entwickelten) Schemata hat in diesem Fall mit Stilisierung nichts zu tun; es ist vielmehr ein Versuch, als naturnah empfundene Details in Formeln zu fixieren, die dem Betrachter Natürlichkeit suggerieren sollen. Dies ist gerade deshalb notwendig, weil die Naturnähe eben nicht jedesmal durch Modellstudium automatisch garantiert ist, sondern durch Kompilation von Mustern sozusagen systematisch erarbeitet werden muß.

Auf welche Weise in der Nikolaus-Werkstatt aus der Auseinandersetzung mit älteren Vorlagen eigenständige, auf Naturnähe abzielende Lösungen entwickelt wurden, läßt sich vielleicht am besten an einem Beispiel vom Klosterneuburger Ambo analysieren. Wie bereits beobachtet worden ist, war für die Figur des Petrus in der Himmelfahrt Christi (Abb. 5) vermutlich ein Werk in der Art jenes karolingischen oder ottonischen Elfenbeinreliefs in Cambridge vorbildlich, das eine Messe mit einem ebenfalls von hinten gesehenen singenden Priester mit erhobenen Händen darstellt ${ }^{180}$; für die Idee des perspektivisch verkürzten Gesichts dürfte eine ottonische Vorlage wie das Diptychon mit dem Thomas-Wunder (Abb. 57) den Anstoß gegeben haben ${ }^{181}$. Der Goldschmied hat nun diese plastischen Muster in die Fläche transponiert, dabei aber die Einzelheiten der Gesichtszeichnung nicht kopiert, sondern den werkstatteigenen Typus in analoger Weise in Verkürzung darzustellen versucht. Daß ihm die Anordnung der üblichen Faltenlinien nicht ganz gelungen ist (die Furchen links und rechts der Nase, die offenbar die Nasolabialfalten vorstellen sollen, dürften gar nicht zu sehen sein), bezeugt, daß er nicht direkt nach der Natur zeichnete - und ist doch gleichzeitig ein Indiz dafür, daß er auch nicht einfach ein Vorbild repetierte. Das Beispiel ist sehr bezeichnend für die Arbeitsweise der Nikolaus-Werkstatt: Man experimentiert zwar mit naturnahen Darstellungsformen und beschreitet damit neue Wege, Ausgangspunkt ist aber immer der sichere Boden des bereits Erprobten ${ }^{182}$.

Wenn wir die Rolle des Naturstudiums für die Kunst des Nikolaus von Verdun relativieren, so steht das mit dem in Einklang, was die jüngere Forschung über die künstlerische Praxis in der Werkstatt festgestellt hat: Arbeiten mit einem festen Repertoire an Mustern, serielle Re-

${ }^{180}$ ) M.-M. Gauthier, Emaux du moyen âge occidental, Fribourg 1972, S. 173. Abb. bei Goldschmidt, Elfenbeinskulpturen (zit. Anm. 40), Bd. I, Taf. LIII, Nr. 120. Zur Datierungsfrage siehe SurmanN, Studien zur ottonischen Elfenbeinplastik (zit. Anm. 35), S. 22-107.

$\left.{ }^{181}\right)$ Vgl. auch ein allerdings qualitativ minderwertiges Relief mit der Himmelfahrt Christi in der Eremitage, wo gleich mehrere solcher Köpfe zu sehen sind (GolDSCHMIDT, Elfenbeinskulpturen [zit. Anm. 40], Bd. I, Taf. LIX, Nr. 138).

182) Sehr ähnlich liegt der Fall beim verlorenen Profil des Apostels im Pfingstwunder (II/15). Dieser Typus ist ebenfalls keine Neuerfindung Nikolaus', sondern existiert zuvor bereits am Heribertschrein (in einer der Darstellungen des Kampfes zwischen Tugenden und Lastern, abgebildet bei SCHNITZLER, Rheinische Schatzkammer [zit. Anm. 20], Taf. 93, untere Abb., oben rechts) oder auf einem Emailplättchen im Wiener Diözesanmuseum (FrLLrTz/PIPPAL, Schatzkunst [zit. Anm. 13], Abb. 46.4). Doch erneut geht der Künstler zugleich eigene Wege, indem er die Gesichtslosigkeit seiner Vorbilder mit der perspektivisch richtigen Einzeichnung der Stirnfalten zu überwinden sucht; auch in diesem Fall stützte er sich aber nicht auf direkte Naturbeobachtung, denn andernfalls müßte zumindest noch die Nasenspitze zu sehen sein. 
produktion mittels Pausen, Anlehnung an Vorbilder auch dort, wo kein bindendes ikonographisches Schema existierte ${ }^{183}$. Dies impliziert kein negatives Qualitätsurteil - im Gegenteil. Die Bindung an die Tradition betrifft nur die Methode, nicht die Intentionen und Ziele der künstlerischen Arbeit. Der unbestreitbare Eindruck von Lebensnähe, der sich vor den Propheten des Dreikönigenschreins einstellt, bleibt ja bestehen. Daß derart innovative Resultate weitgehend mit den scheinbar inadäquaten Mitteln ihrer Zeit erreicht worden sind, macht die Leistung der Werkstatt um so bemerkenswerter. Problematisch daran ist, daß wir jener Komponente des Werks, die mit kunstwissenschaftlicher Analyse nicht mehr zu fassen ist und eben nur noch dem „Genie“ des Künstlers zugeschrieben werden kann, noch größeres Gewicht zugestehen müssen. Das Phänomen Nikolaus von Verdun läßt sich aber auf diese Weise besser aus seinem historischen Kontext verstehen. Erklärt ist es damit freilich noch nicht: Mag das wissenschaftliche Interesse für die Natur des Menschen, seine äußere Erscheinung wie seine Psyche, um 1200 qualitativ und quantitativ neue Dimensionen angenommen haben ${ }^{184}$ - in der bildenden Kunst jener Zeit bleibt das realistische Menschenbild, das uns an den Langseiten des Dreikönigenschreins entgegentritt, ein isoliertes Ereignis.

${ }^{183}$ ) Vgl. BÄNSCH, Kölner Goldschmiedekunst (zit. Anm. 30), und DAHM, Studien zur Ikonographie (zit. Anm. 8).

184) Claussen, Zum Stil der Plastik (zit. Anm. 6), S. $40 f$.

Abbildungsnachweis: Abb. 1: nach Il menologio di Basilio II (zit. Anm. 24), - Abb. 2: nach Buschhausen (zit. Anm. 14). - Abb. 3: nach Lowden (zit. Anm. 26). - Abb. 4, 5, 8, 10, 19, 22, 26, 31, 33, 40: Institut für Kunstgeschichte, Universität Wien. - Abb. 6, 57: nach Swarzensky (zit. Anm. 50). - Abb. 7: nach Kat. Ornamenta Ecclesiae (zit. Anm. 6). - Abb. 9: nach Goldschmidt (zit. Anm. 40). - Abb. 11, 13, 16, 24, 34, 39: Bildarchiv Foto Marburg. - Abb. 12: nach Claussen (zit. Anm. 48). - Abb. 14: nach V. Kockel, Porträtreliefs stadtrömischer Grabbauten, Mainz 1993. - Abb. 15: London, Victoria and Albert Museum. - Abb. 17, 23, 43, 46, 54, 58: Archiv des Autors. - Abb. 18: Firenze, Biblioteca Medicea Laurenziana. Mit Genehmigung des Ministero per i beni e la attività culturali; jegliche weitere Reproduktion ist untersagt. - Abb. 20: nach Boucher (zit. Anm. 58). - Abb. 21: Kopenhagen, Ny Carlsberg Glyptotek. - Abb. 25: nach Andreae (zit. Anm. 72). - Abb. 27: nach E. Stephany, Wunderwelt der Schreine, Frankfurt a. M. 1959. - Abb. 28: nach Panofsky (zit. Anm. 76). - Abb. 29: nach Pace (zit. Anm. 77). - Abb. 30, 32: nach M.-L. Vollenweider, Die Steinschneidekunst und ihre Künstler in spätrepublikanischer und augusteischer Zeit, Baden-Baden 1966. - Abb. 35, 37, 42, 44, 47, 49, 51, 53: Rheinisches Bildarchiv Köln. - Abb. 36, 38, 48: nach Espérandieu (zit. Anm. 62). - Abb. 41: nach H. Borger, Das Römisch-Germanische Museum in Köln, München 1977. - Abb. 45: nach Richter (zit. Anm. 116). Abb. 50: nach A. Furtwängler, Die antiken Gemmen, Leipzig/Berlin 1900. - Abb. 52, 55, 56: nach Price Gowen (zit. Anm. 130). 


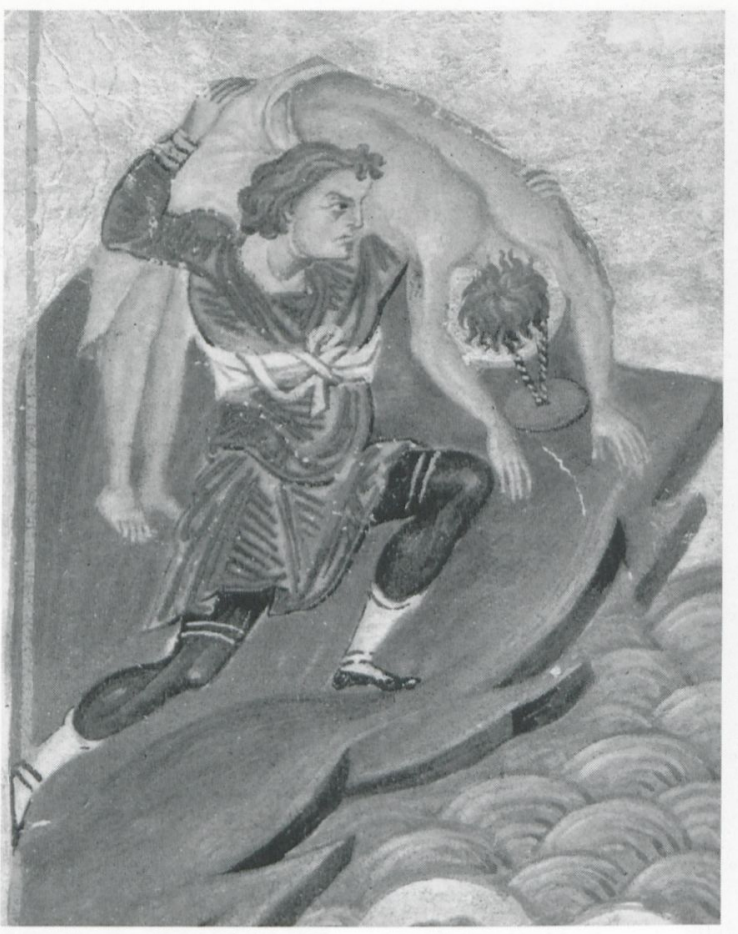

1. Sog. Menologium Basileios' II., Das Martyrium der Christen von Nikomedia, um 985 (Detail).

Rom, Biblioteca Vaticana, Vat. gr. 1613, S. 280

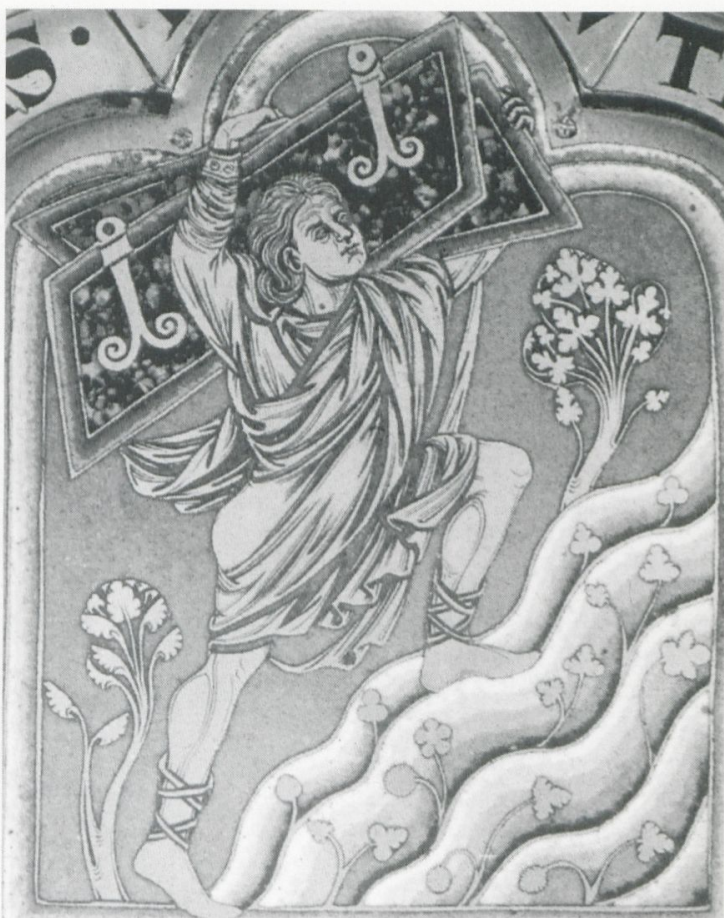

2. Klosterneuburger Altar, Samson trägt die Tore von Gaza, 1181 vollendet. Klosterneuburg, Augustinerchorherrenstift

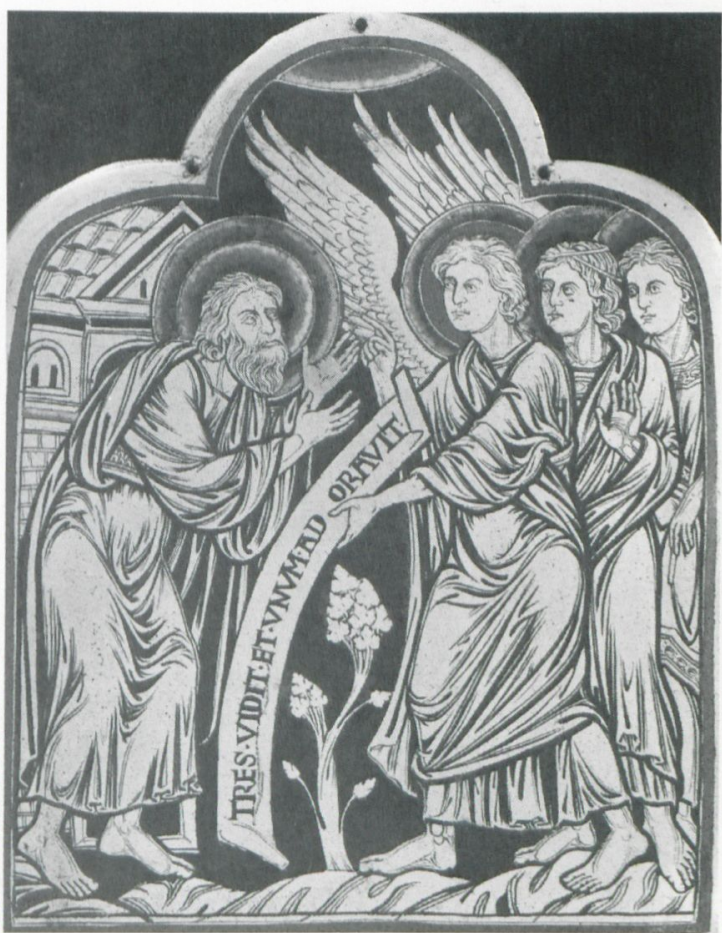

4. Klosterneuburger Altar, Verkündigung Isaaks

3. Codex der Prophetien des Jesaias, Gebet des Jesaias, erste Hälfte 11. Jh. (Detail). Rom, Biblioteca Vaticana, 


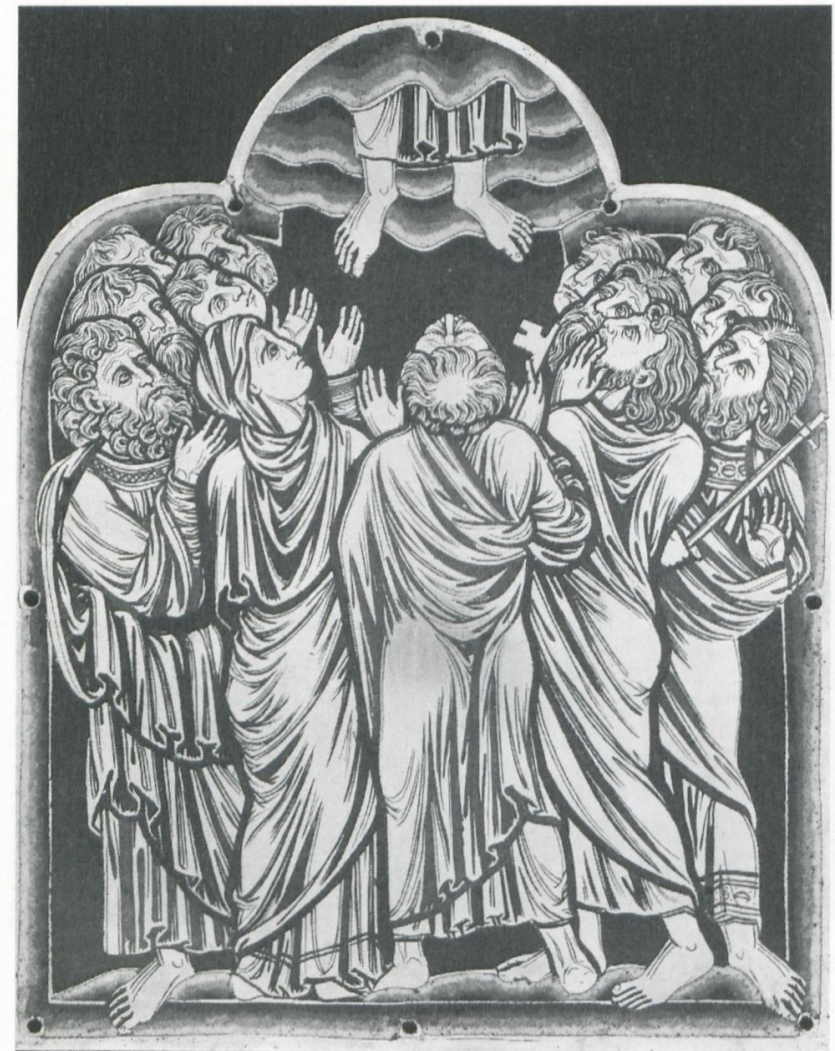

5. Klosterneuburger

Altar, Himmelfahrt

Christi

6. Heribertschrein,

Prophet Amos, um

1160-70. Köln-

Deutz, St. Heribert
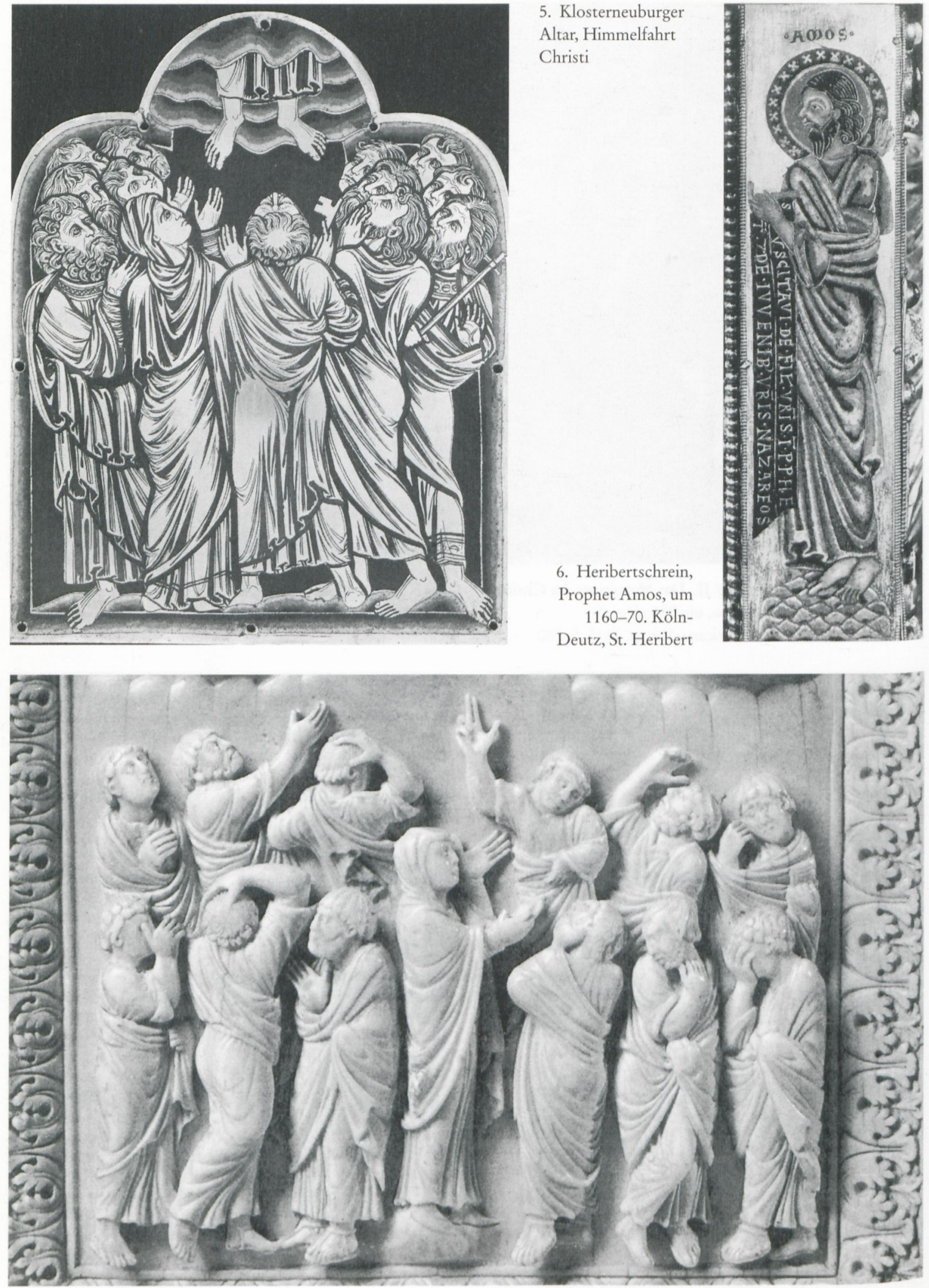

7. Buchdeckel mit der Himmelfahrt Christi, spätes 9. oder 10. Jh. (Detail). Wien, Kunsthistorisches Museum 


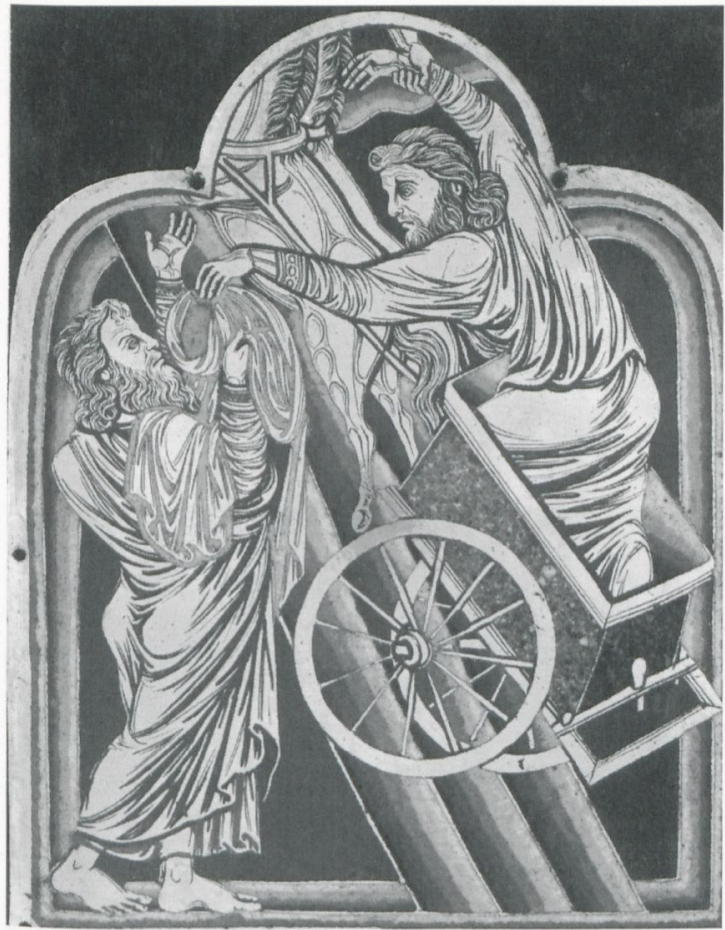

8. Klosterneuburger Altar, Himmelfahrt des Elias

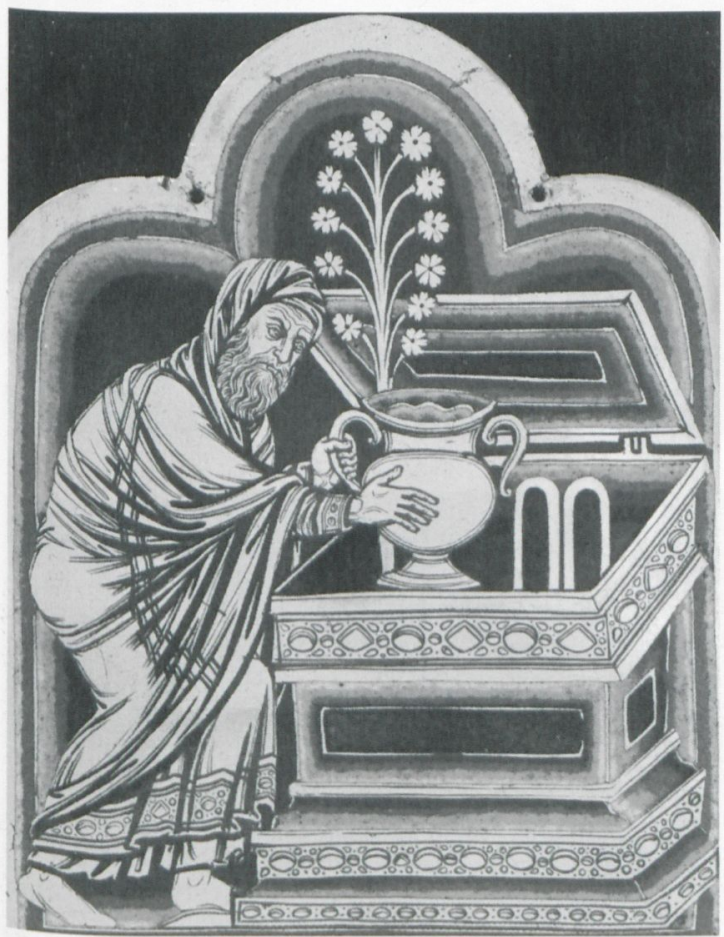

10. Klosterneuburger Altar, Aaron mit dem Manna

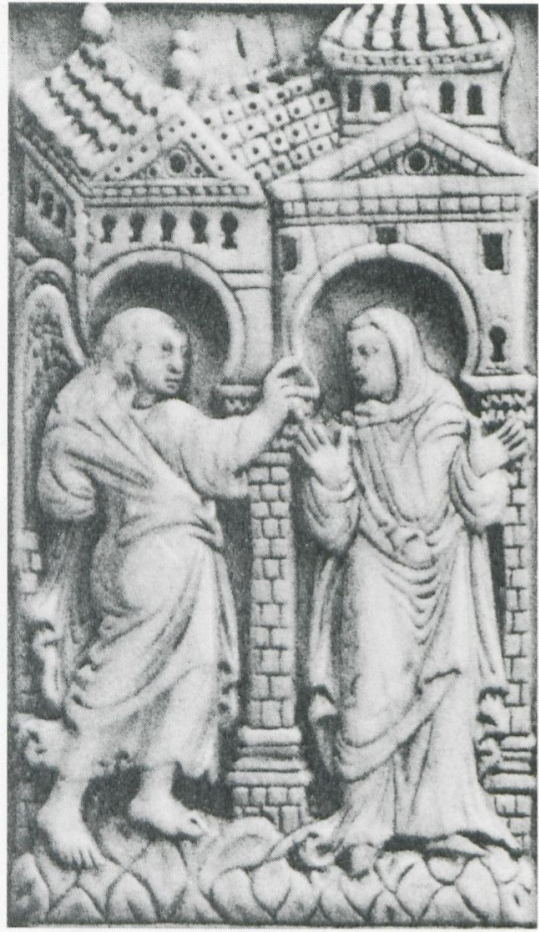

9. Buchdeckel mit der Verkündigung Christi, spätes 9 . oder 10. Jh. Ehemals Berlin, Kaiser-Friedrich Museum

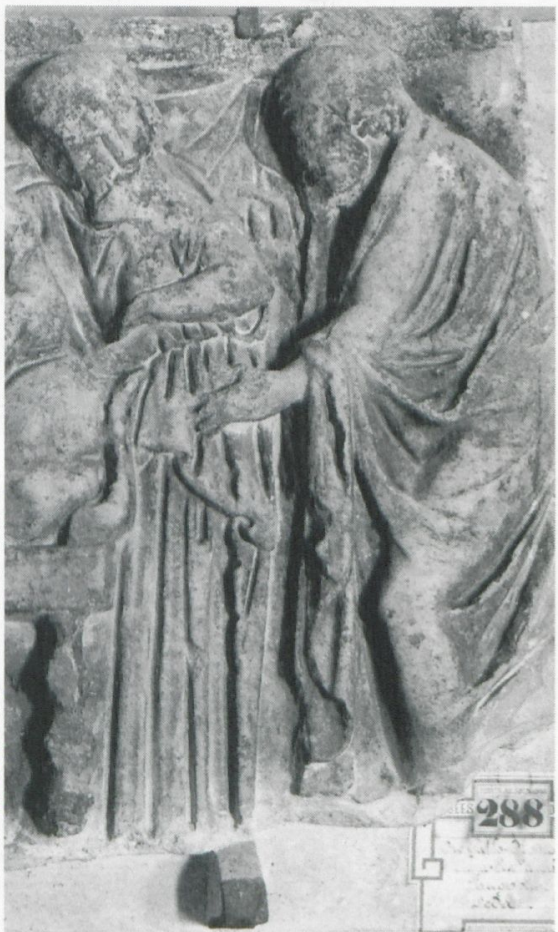

11. Sarkophagfragment mit Leda-Mythos, 3. Jh. n. Chr. (Detail). Aix-en-Provence, Musée Granet 

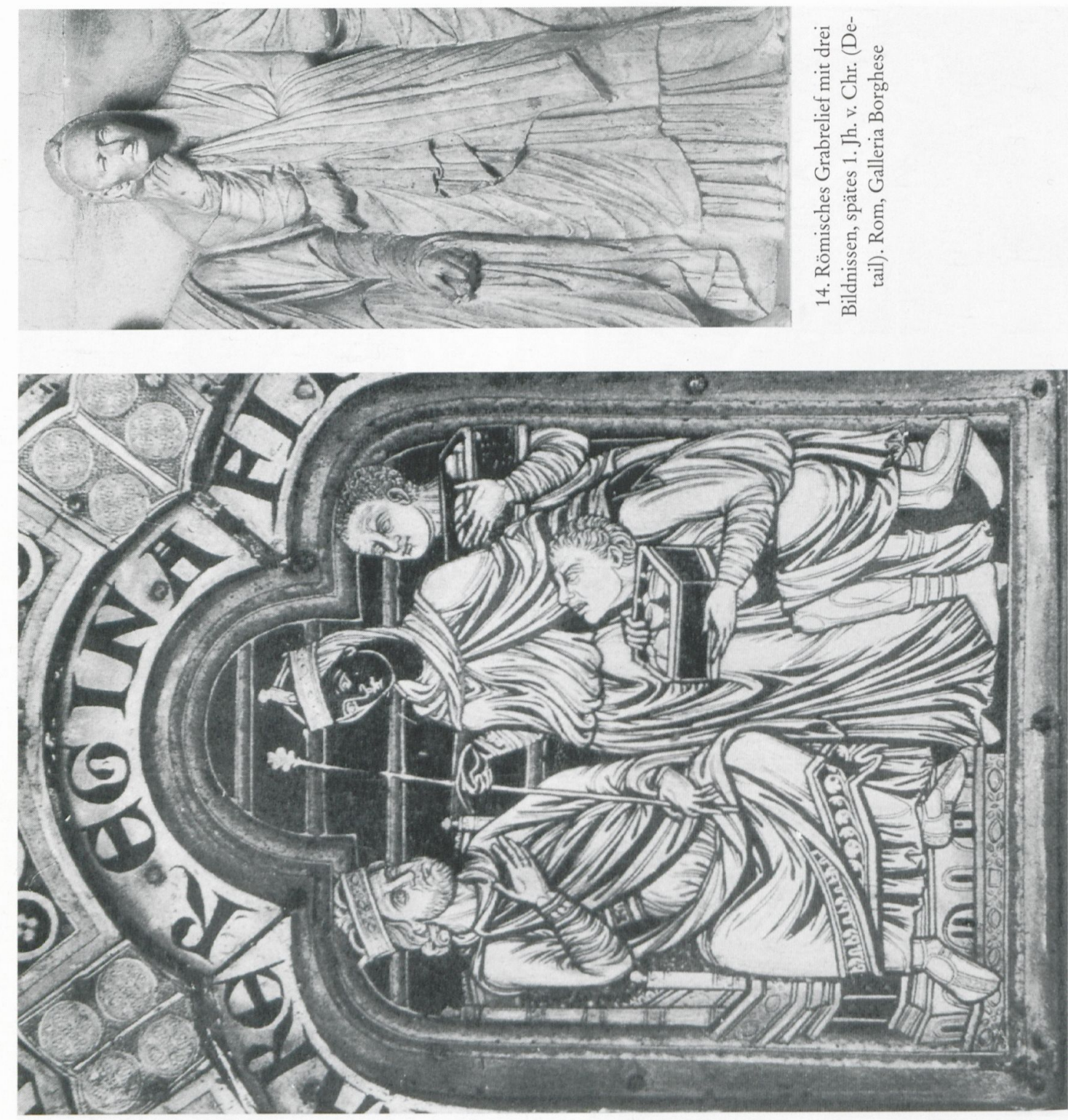



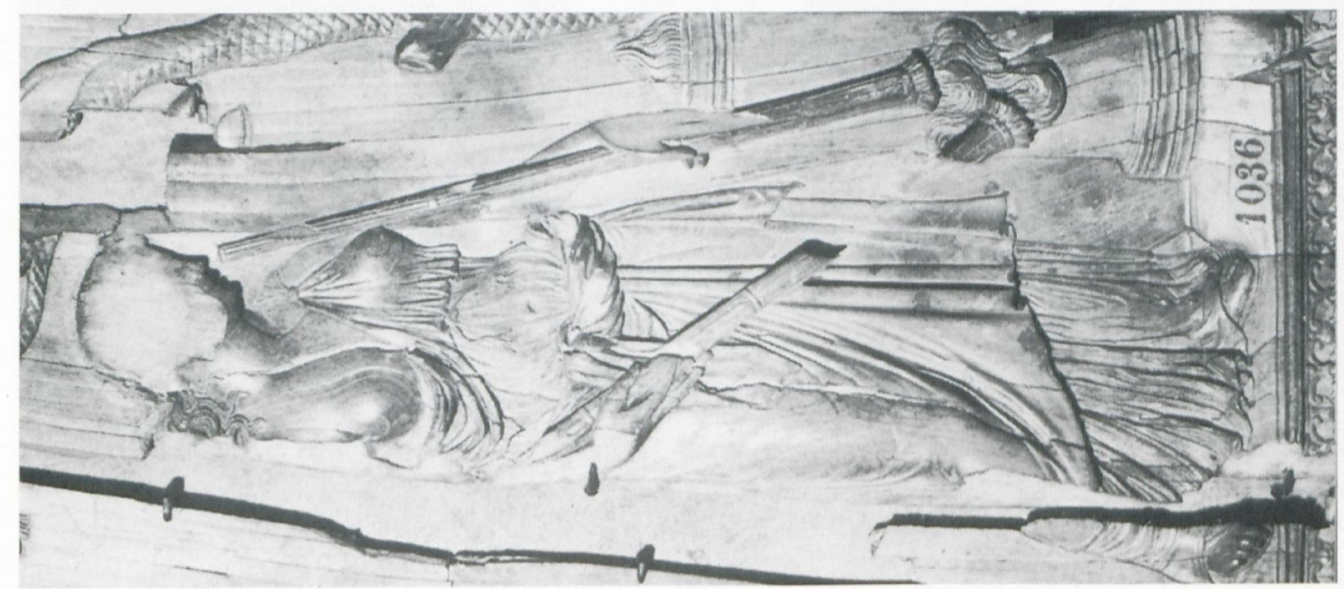



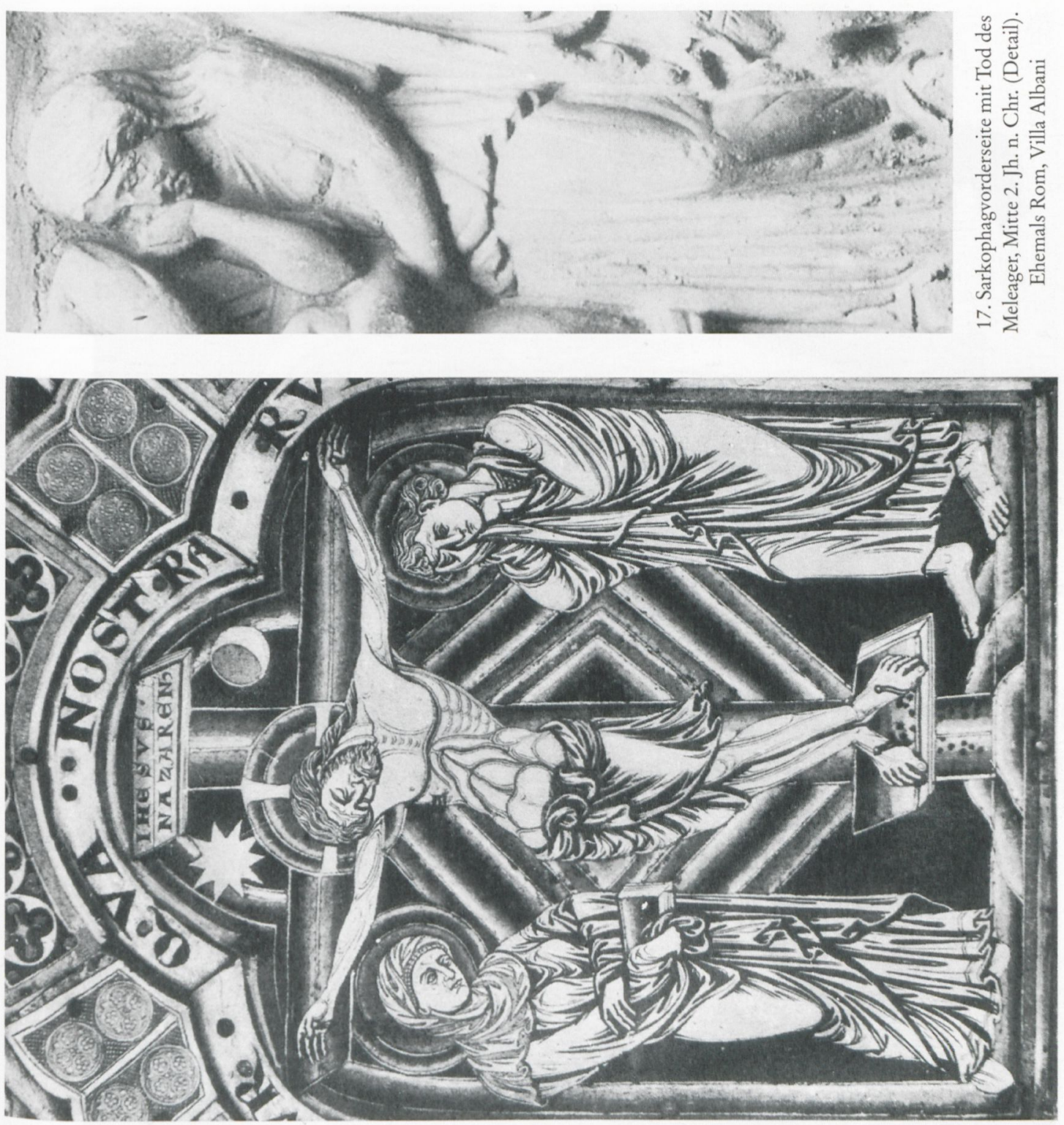

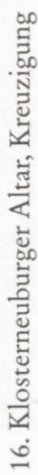

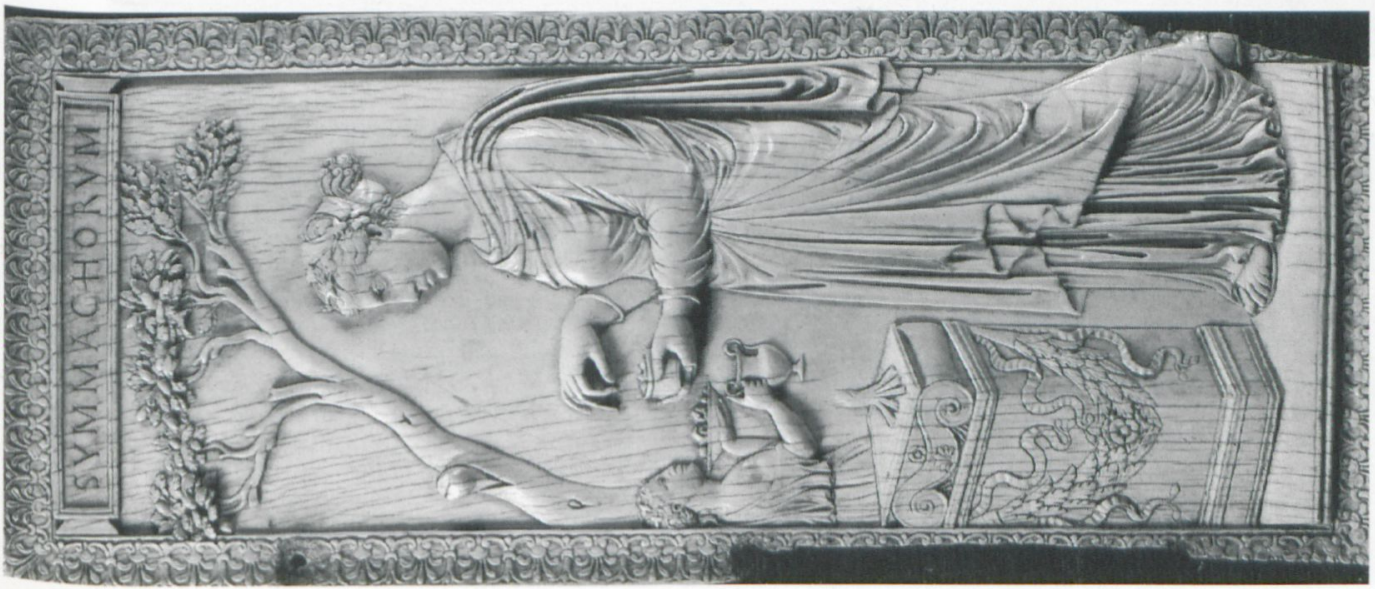

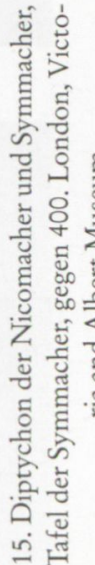



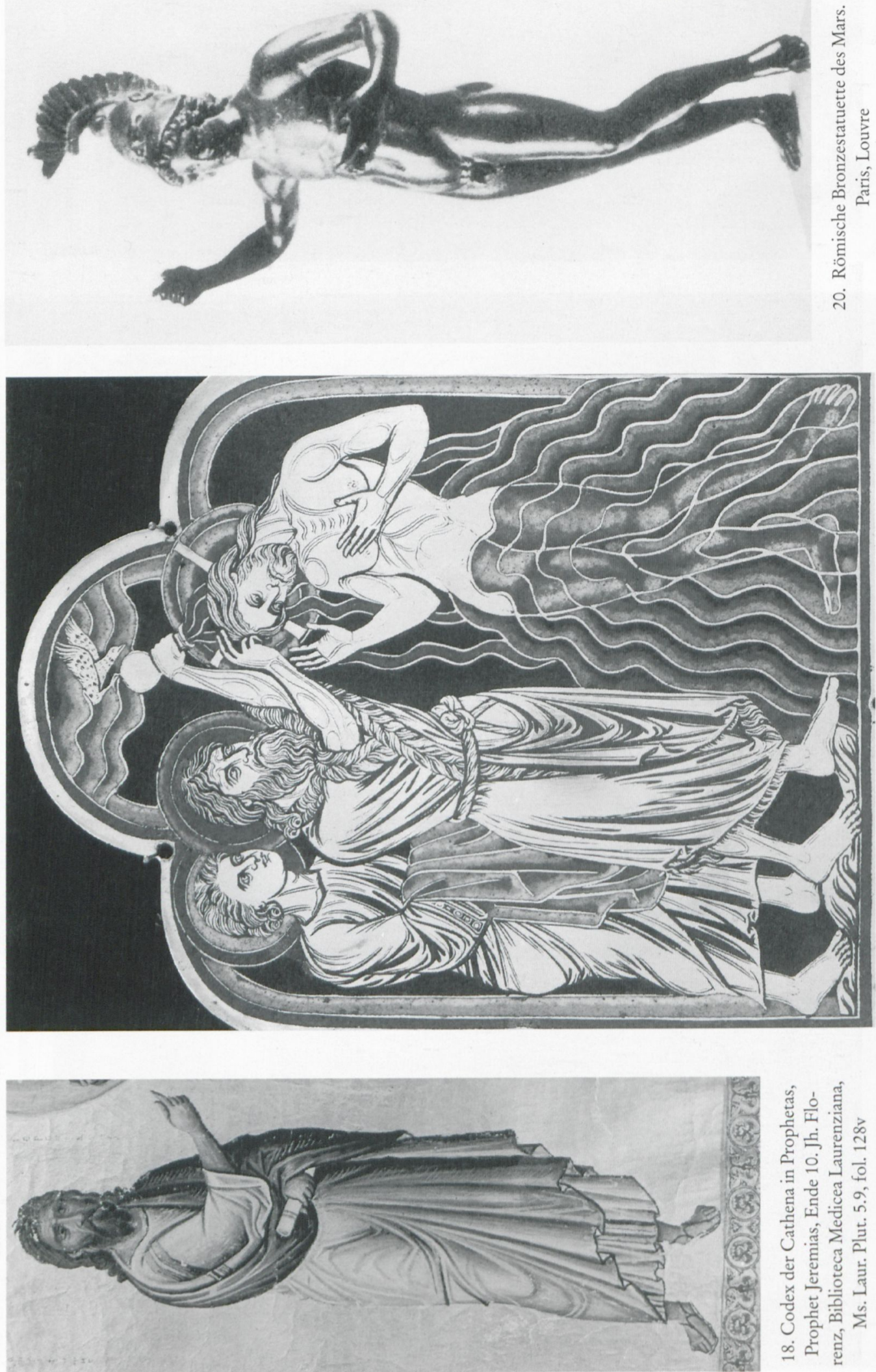

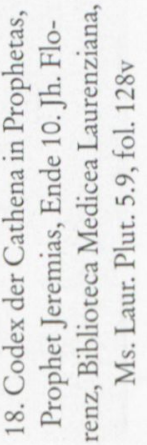



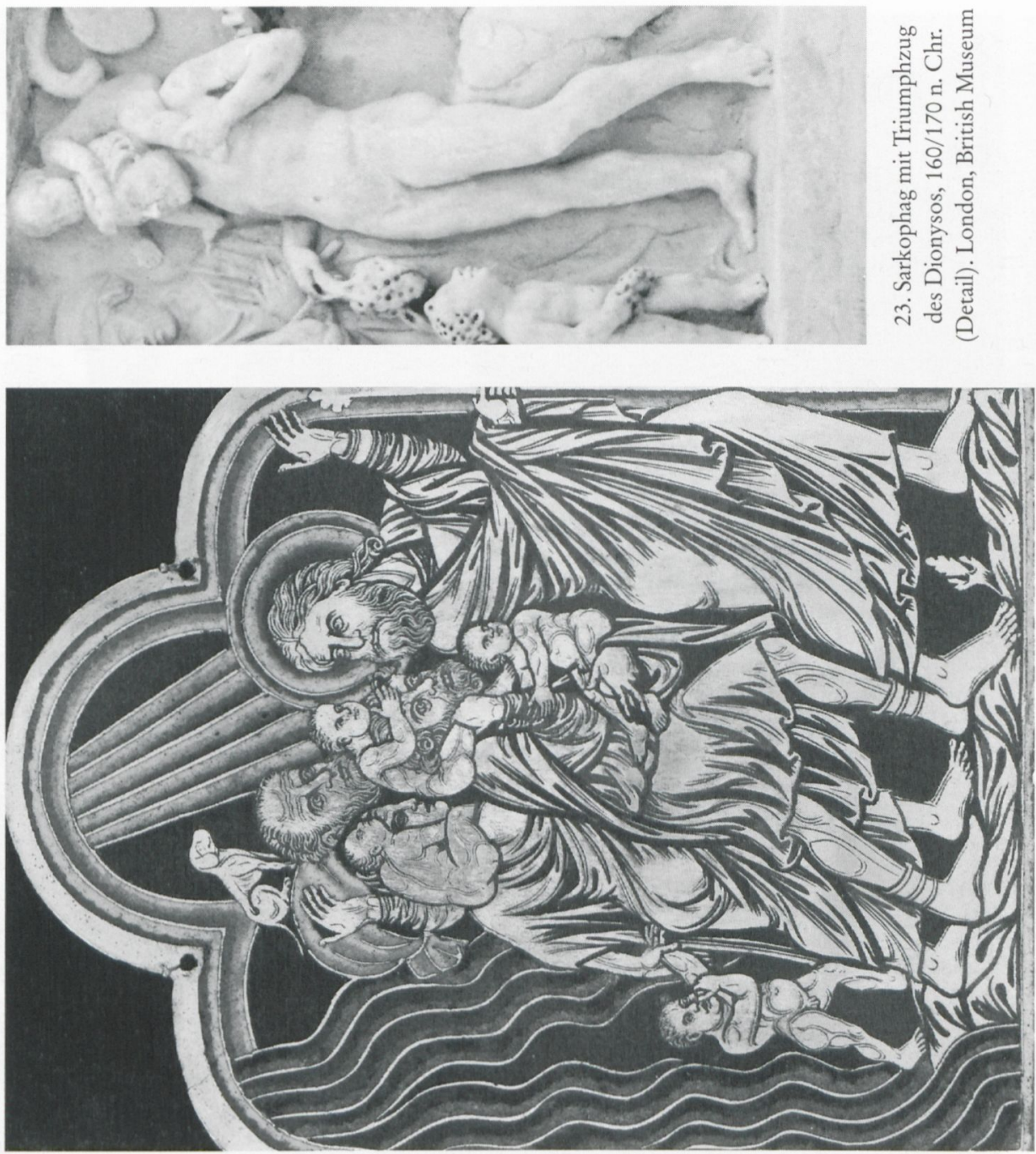

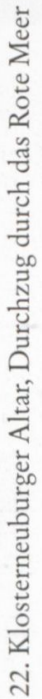
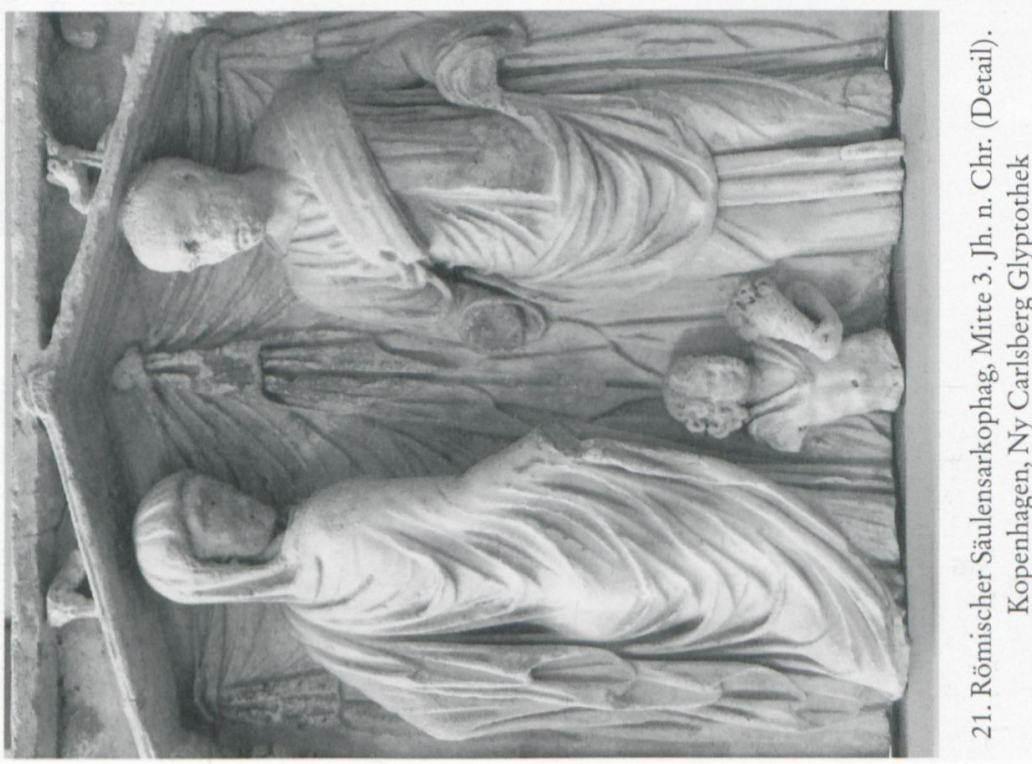


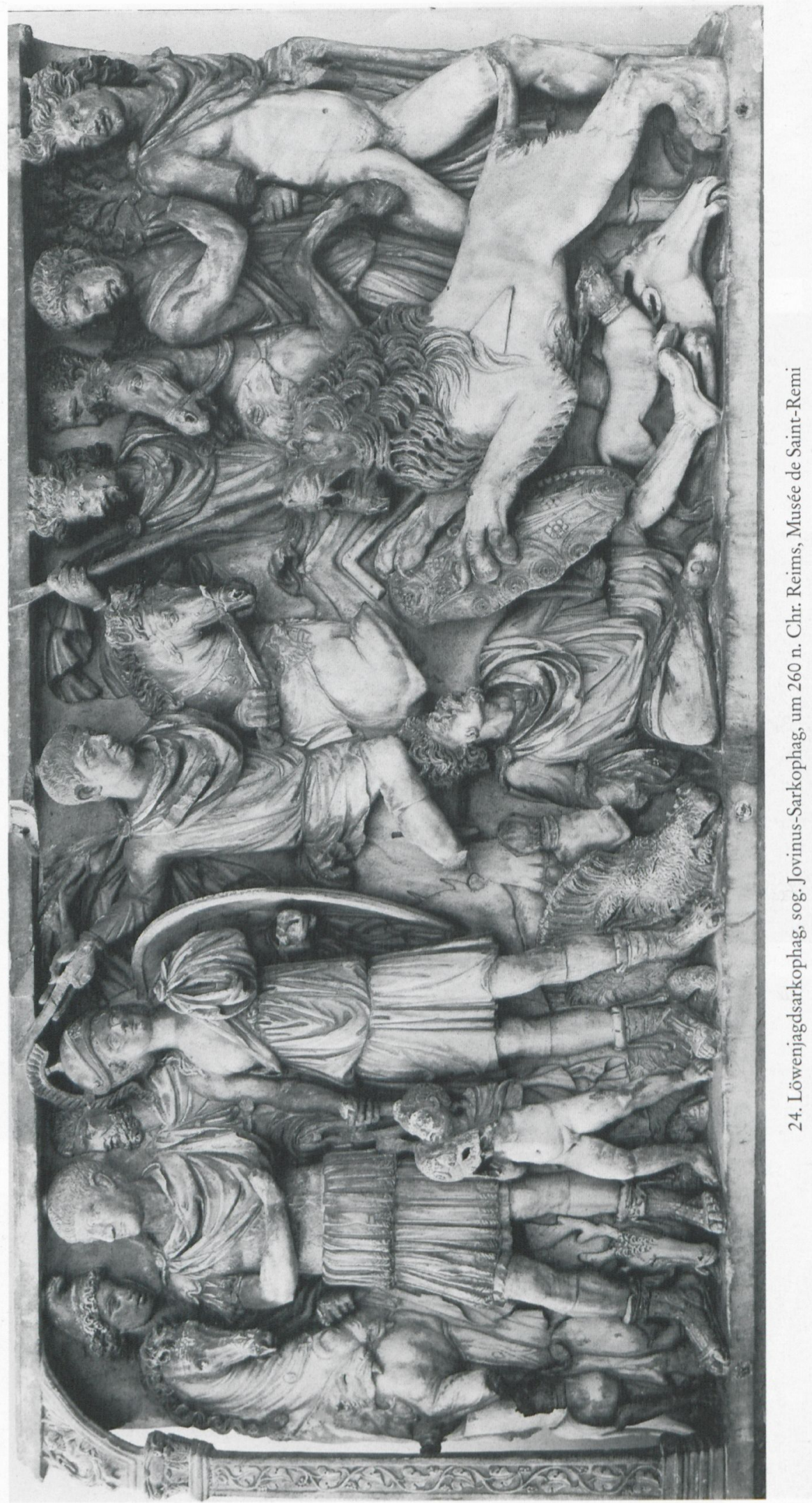



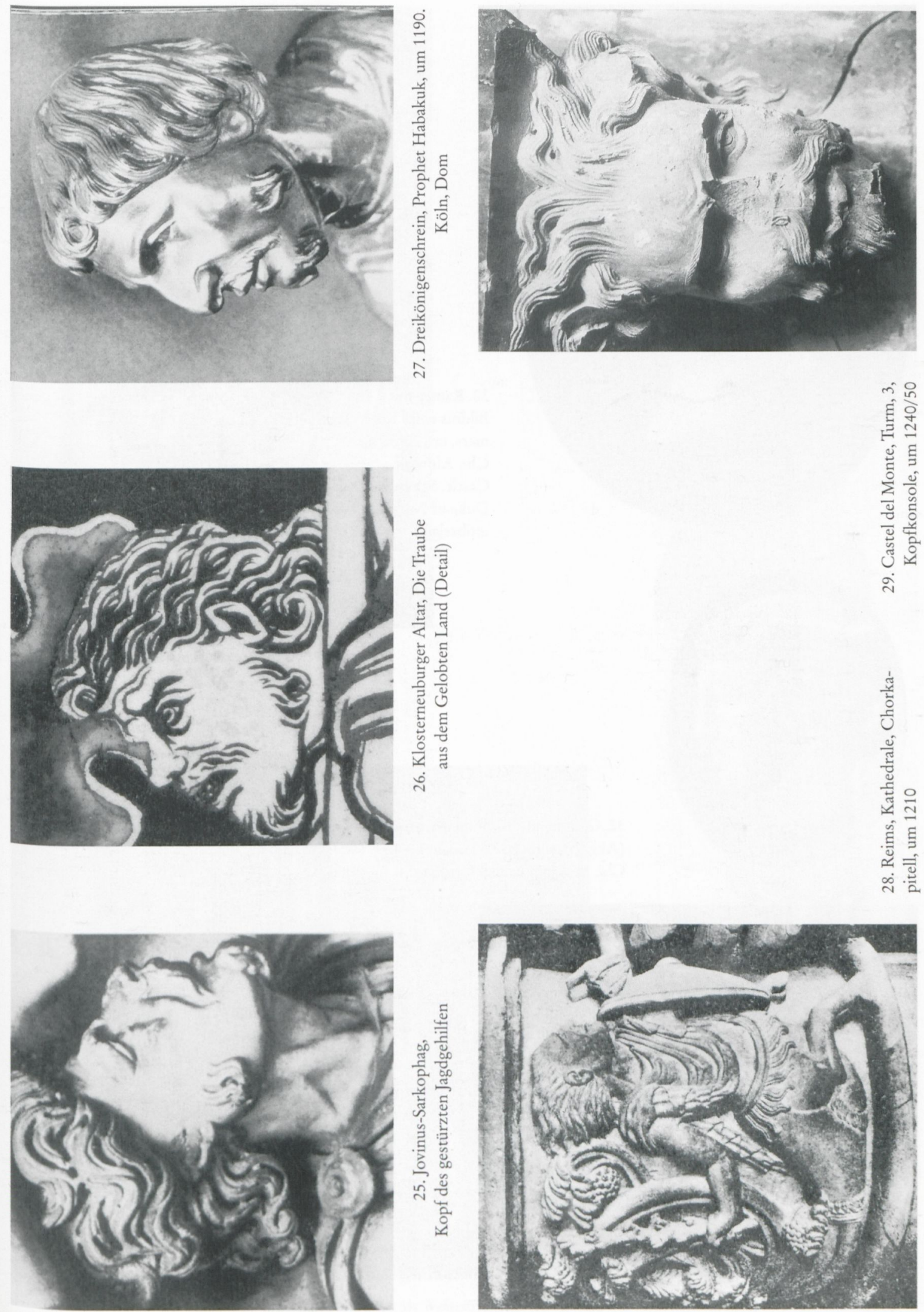


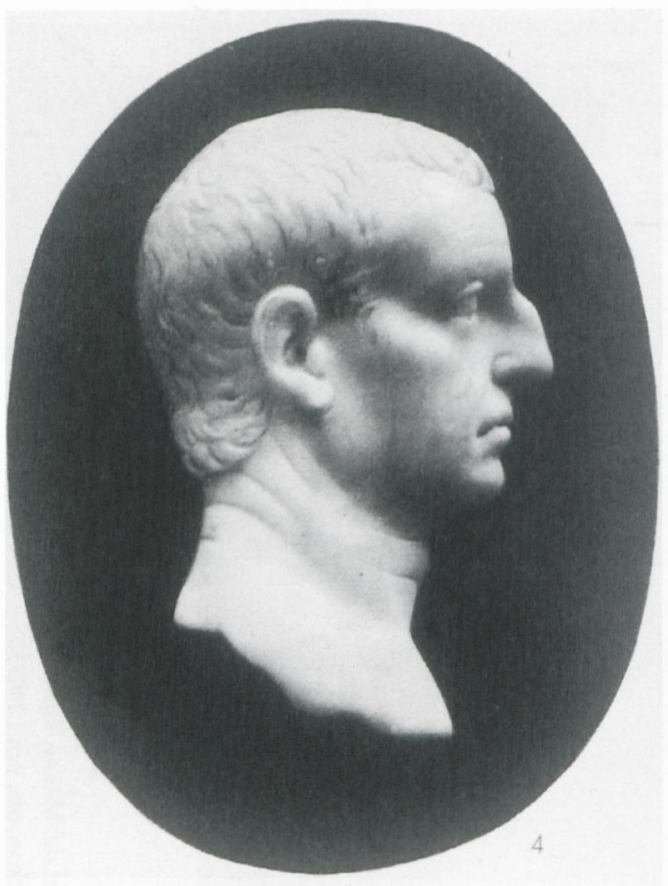

30. Kamee mit Bildnis eines Römers, um 20/30 n. Chr. Alnwick Castle, Sammlung Duke of Northumberland

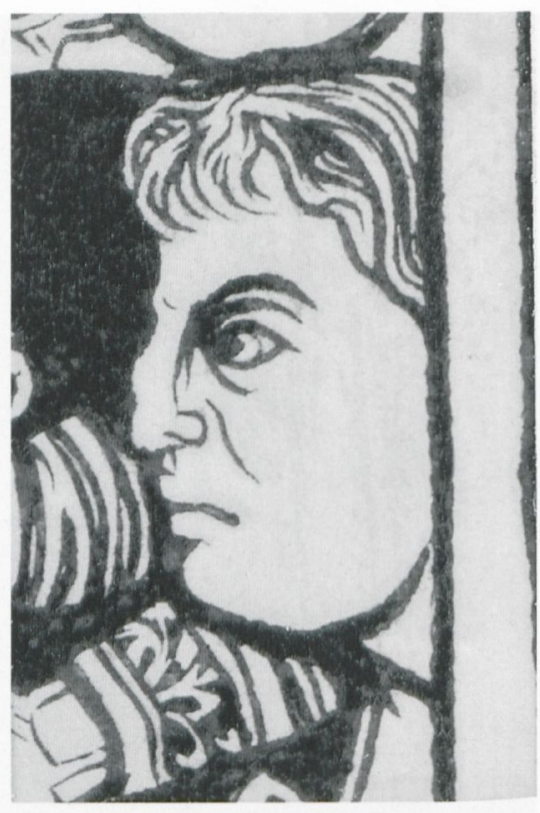

31. Klosterneuburger Altar, Einzug in Jerusalem (Detail)

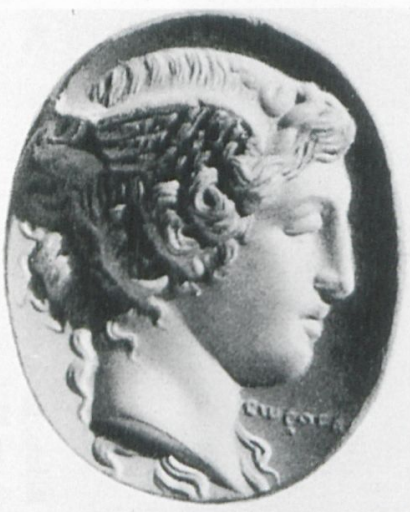

32. Gemme mit Kopf der Medusa (Abguß), sign. Sosokles, um 50/40 v. Chr. London, British Museum

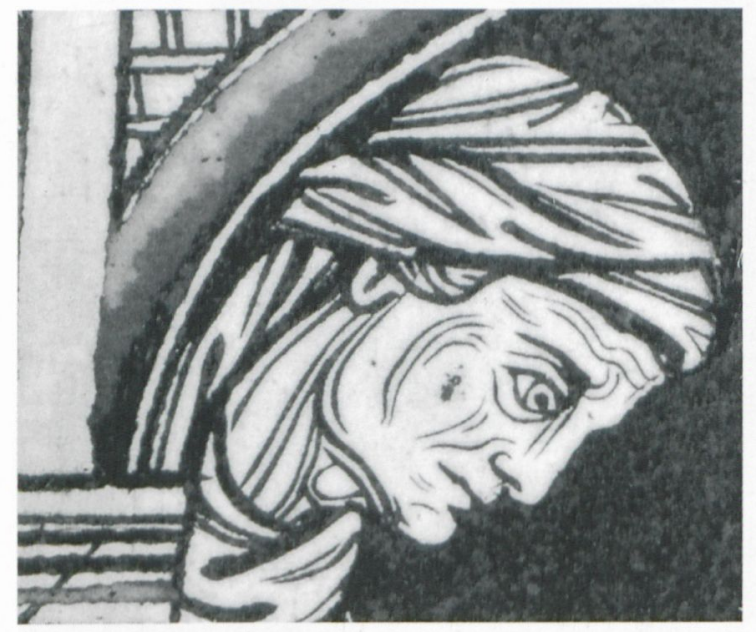

33. Klosterneuburger Altar, Geburt Samsons (Detail)

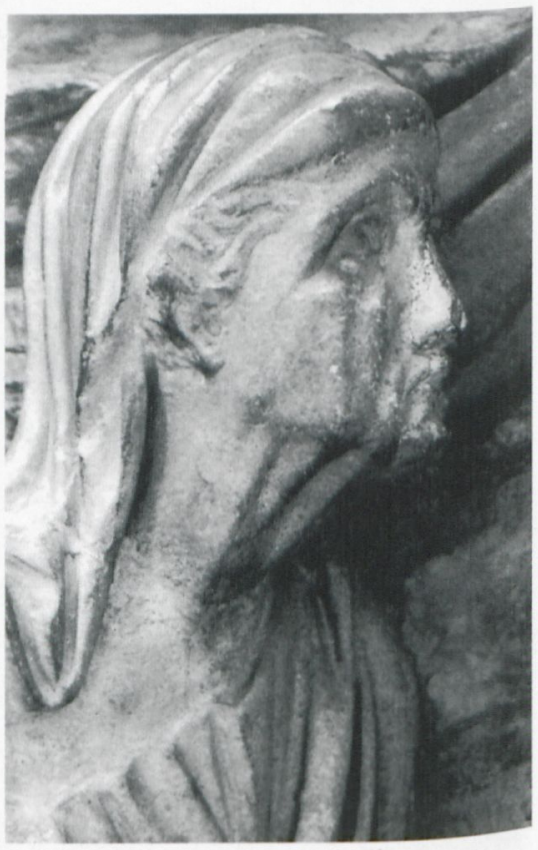

34. Hippolytos-Sarkophag, gegen 290 n. Chr. (Detail). Paris, Louvre 


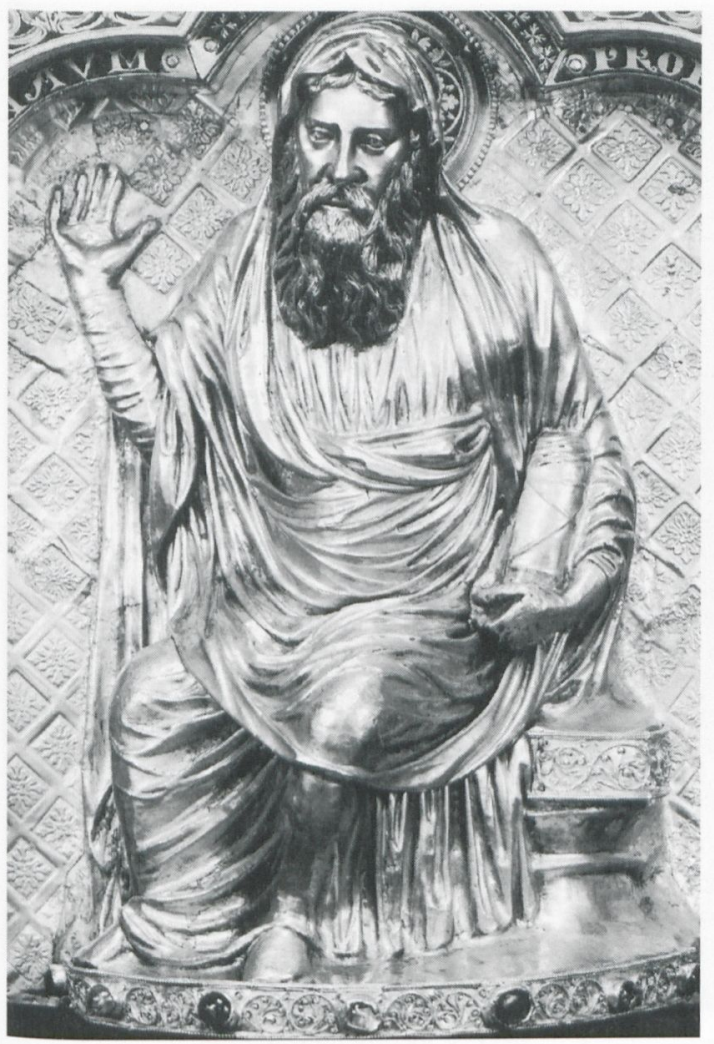

35. Dreikönigenschrein, Prophet Naum

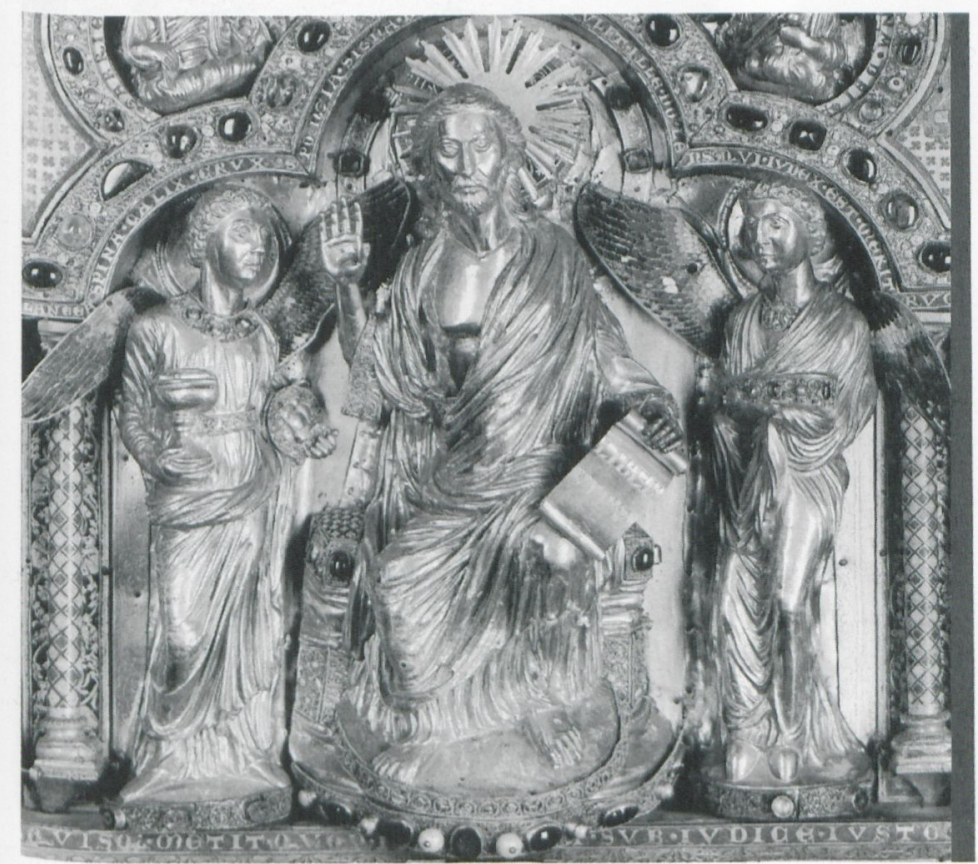

37. Dreikönigenschrein, Stirnseite, Christus als Weltenrichter

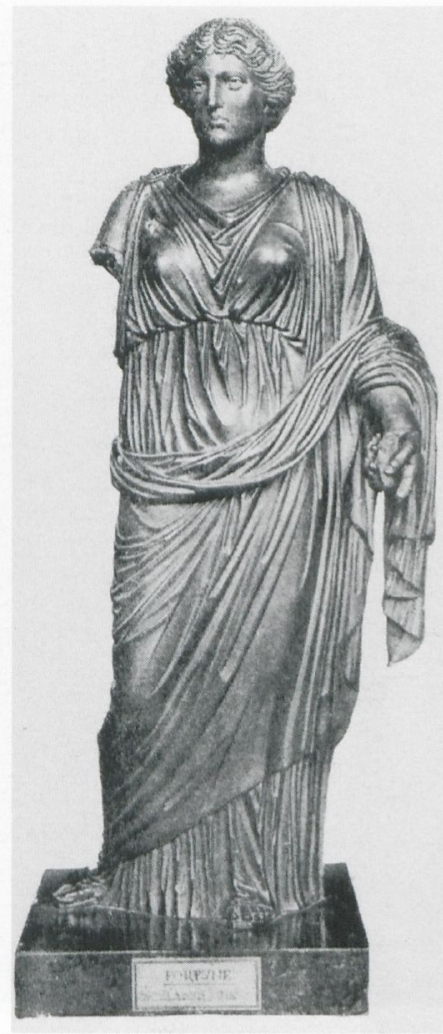

36. Bronzestatuette der Fortuna, röm. Kopie nach griech. Original des 5. Jh. v. Chr. Lyon, Musée des Beaux-Arts

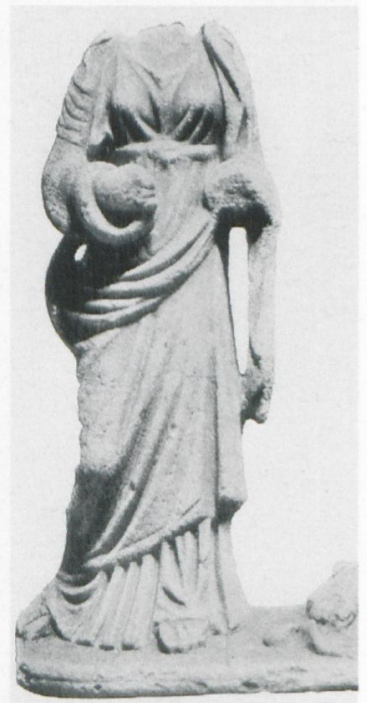

38. Statuette der Hygieia (Fragment einer Hygieia-Aeskulap-Gruppe), provinzialrömisch. Beaune, Musée Marey et des Beaux-Arts 


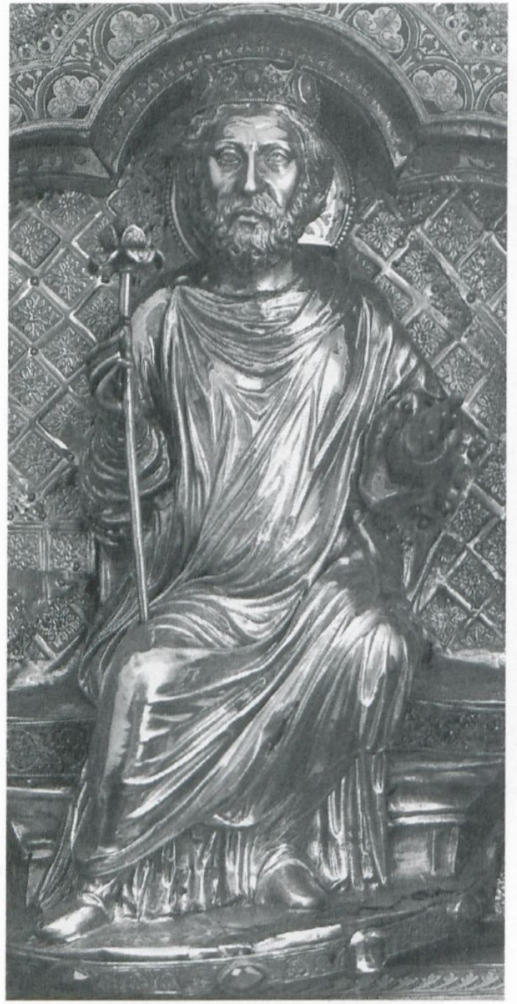

39. Dreikönigenschrein, König David

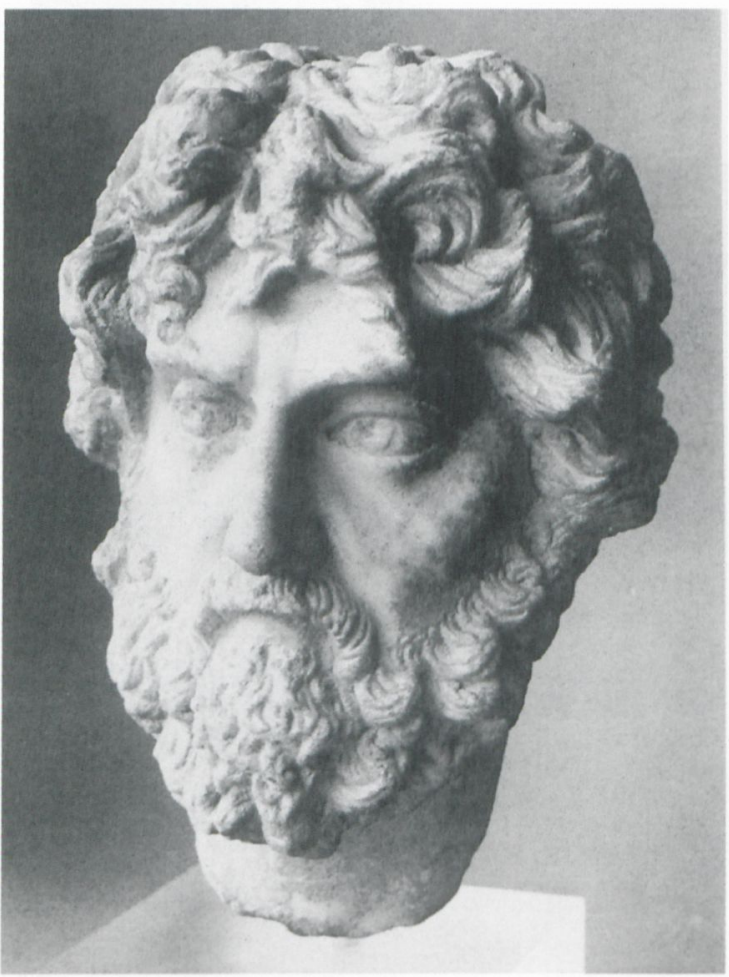

41. Männlicher Porträtkopf, 2. Jh. n. Chr. Köln, Römisch-Germanisches Museum

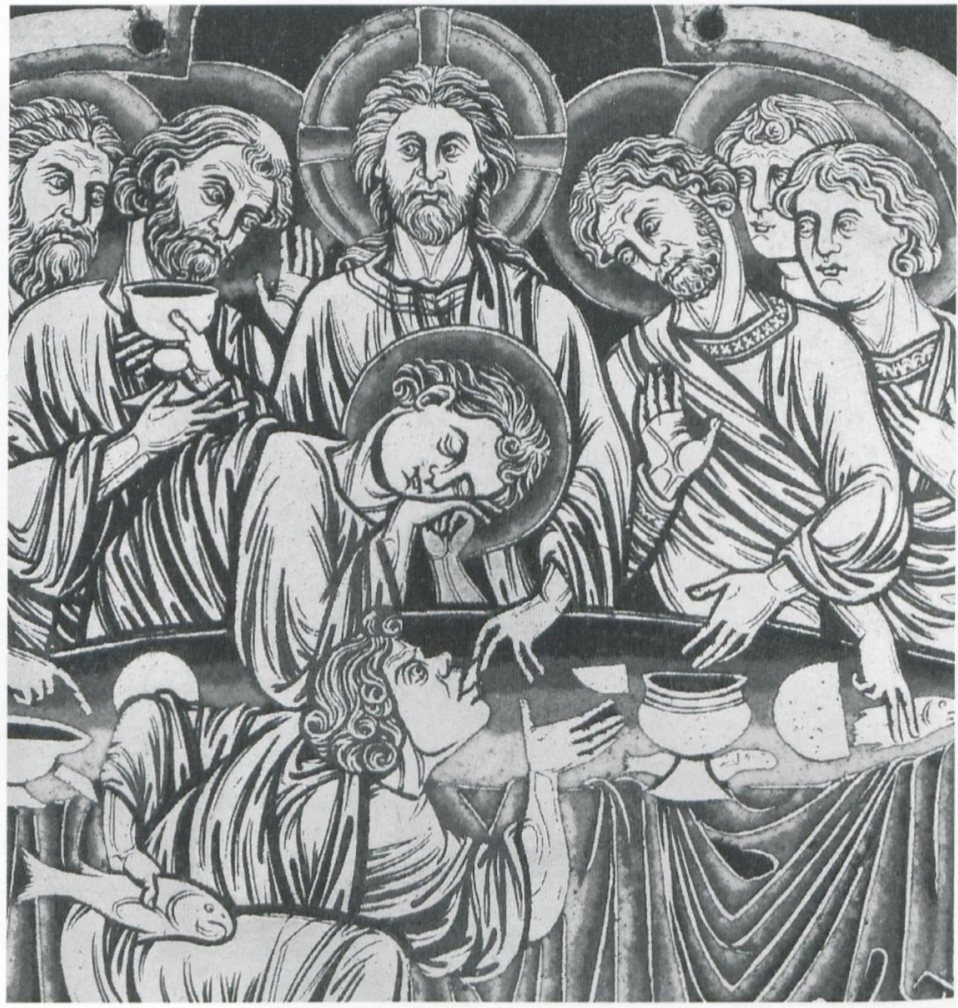

40. Klosterneuburger Altar, Abendmahl (Detail)

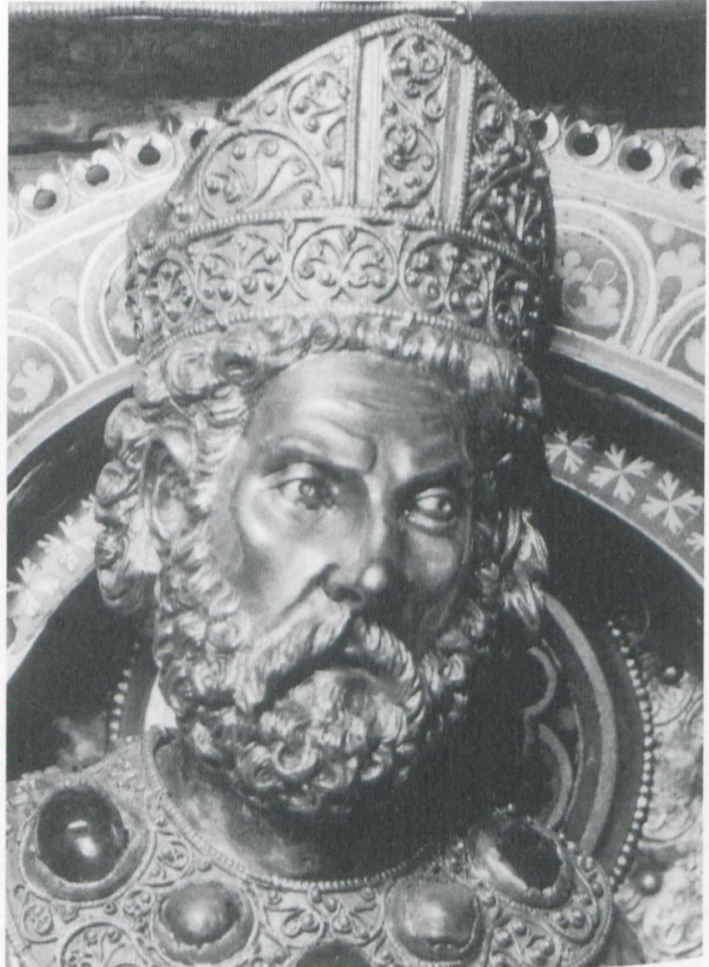

42. Dreikönigenschrein, Prophet Aaron 


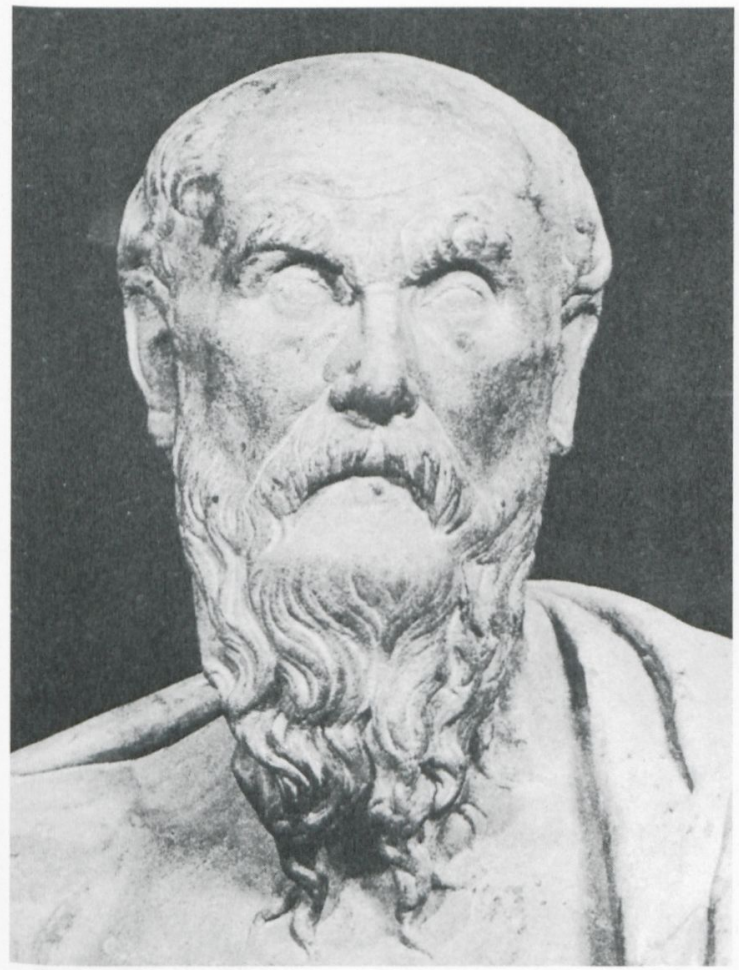

43. Sog. Büste des Diogenes, röm. Kopie nach griech. Original. Rom, Kapitolinische Museen

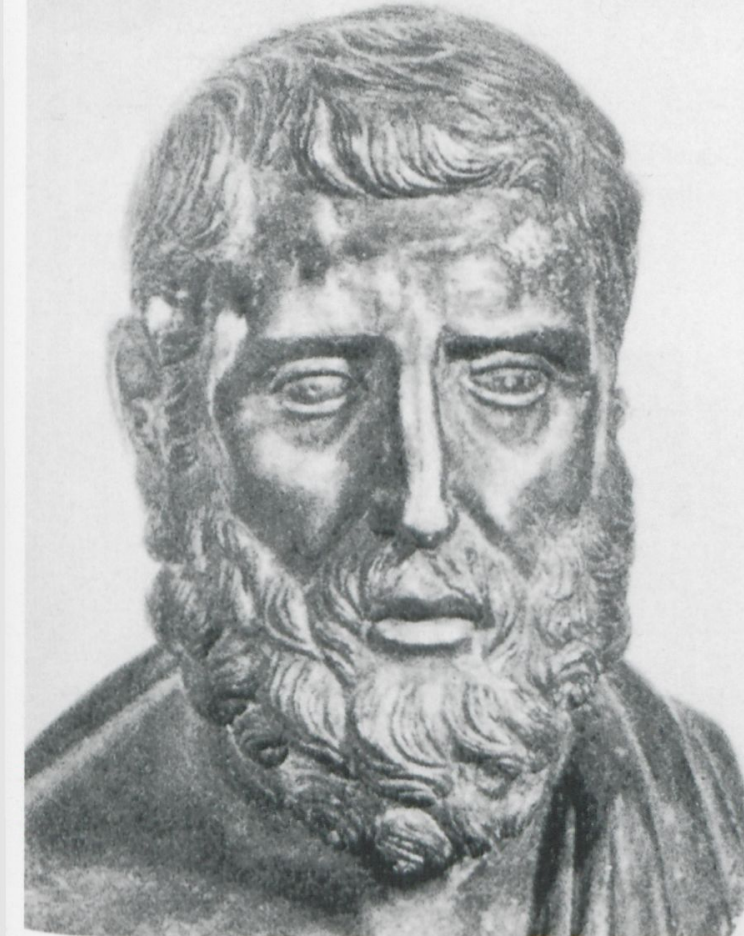

45. Bronzebüste des Hermarchos, röm. Kopie nach griech. Original d. 3. Jh. v. Chr. Neapel, Museo Nazionale

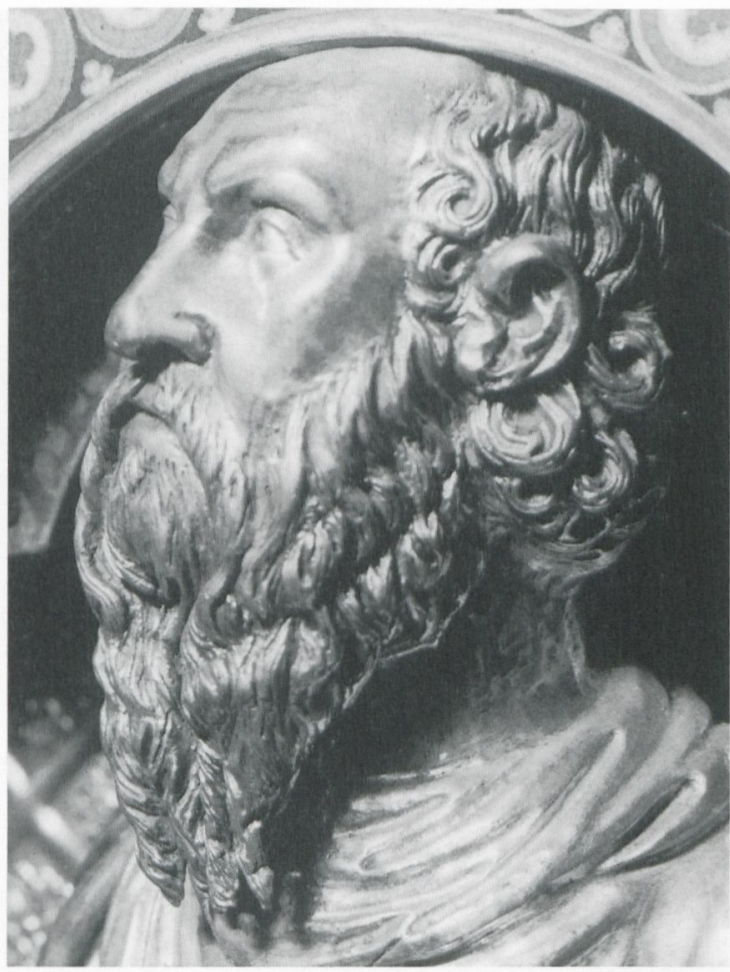

44. Dreikönigenschrein, Prophet Abdias

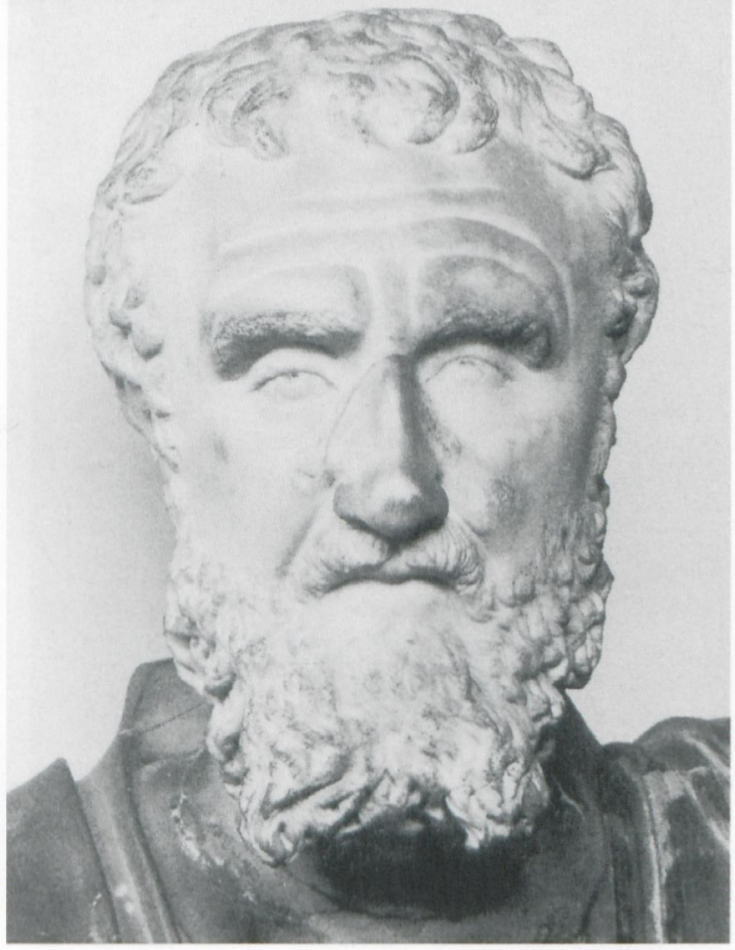

46. Männlicher Porträtkopf (Didius Iulianus?), Ende 2. Jh. n. Chr. Rom, Villa Albani 


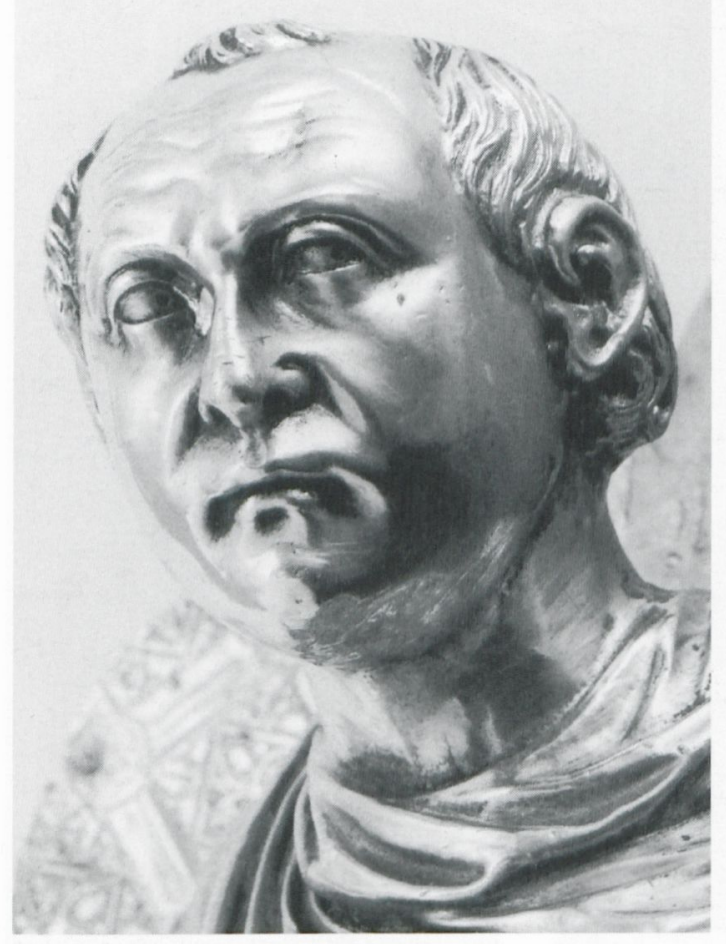

47. Dreikönigenschrein, Prophet Jonas

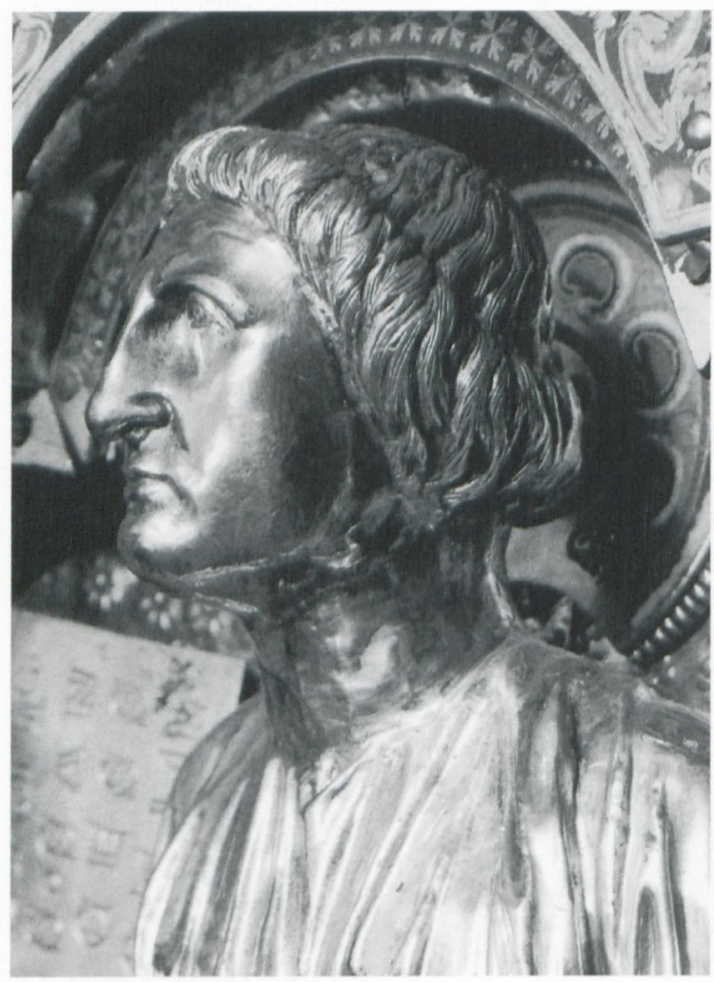

49. Dreikönigenschrein, Prophet Daniel

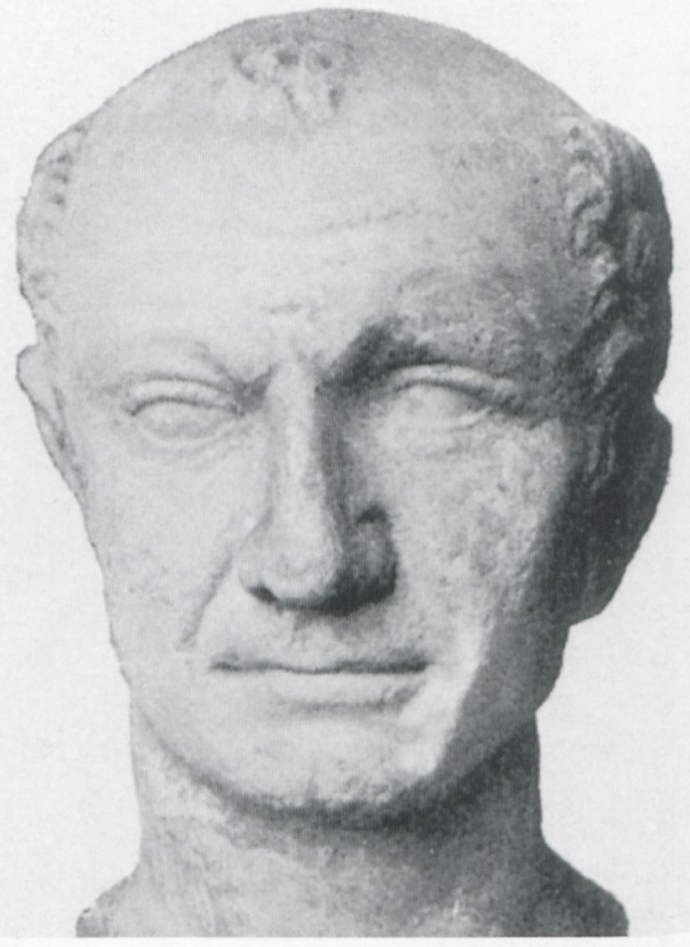

48. Römischer Porträtkopf (sogen. Julius Cäsar), 1. Jh. v. Chr. Senlis, Musée d'Art et d'Archéologie

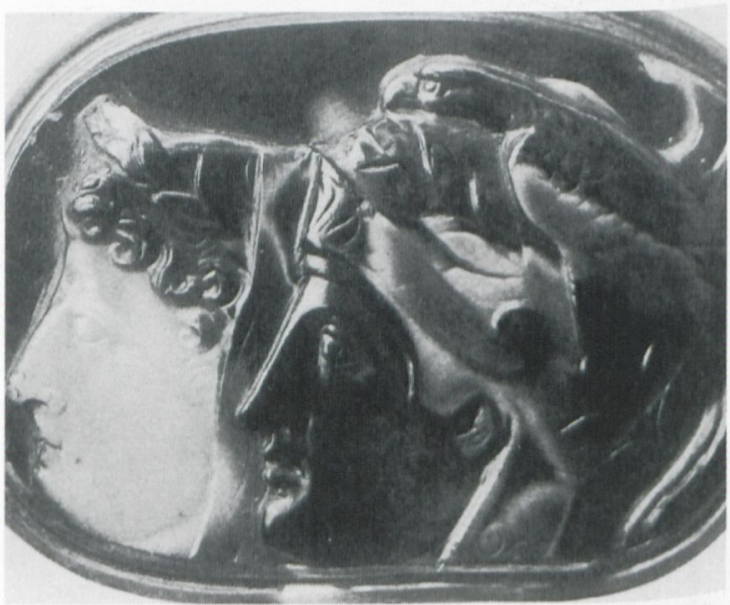

50. Kameo mit Porträt eines Herrscherpaares, um 30 v. Chr. Berlin, Antikenmuseum 

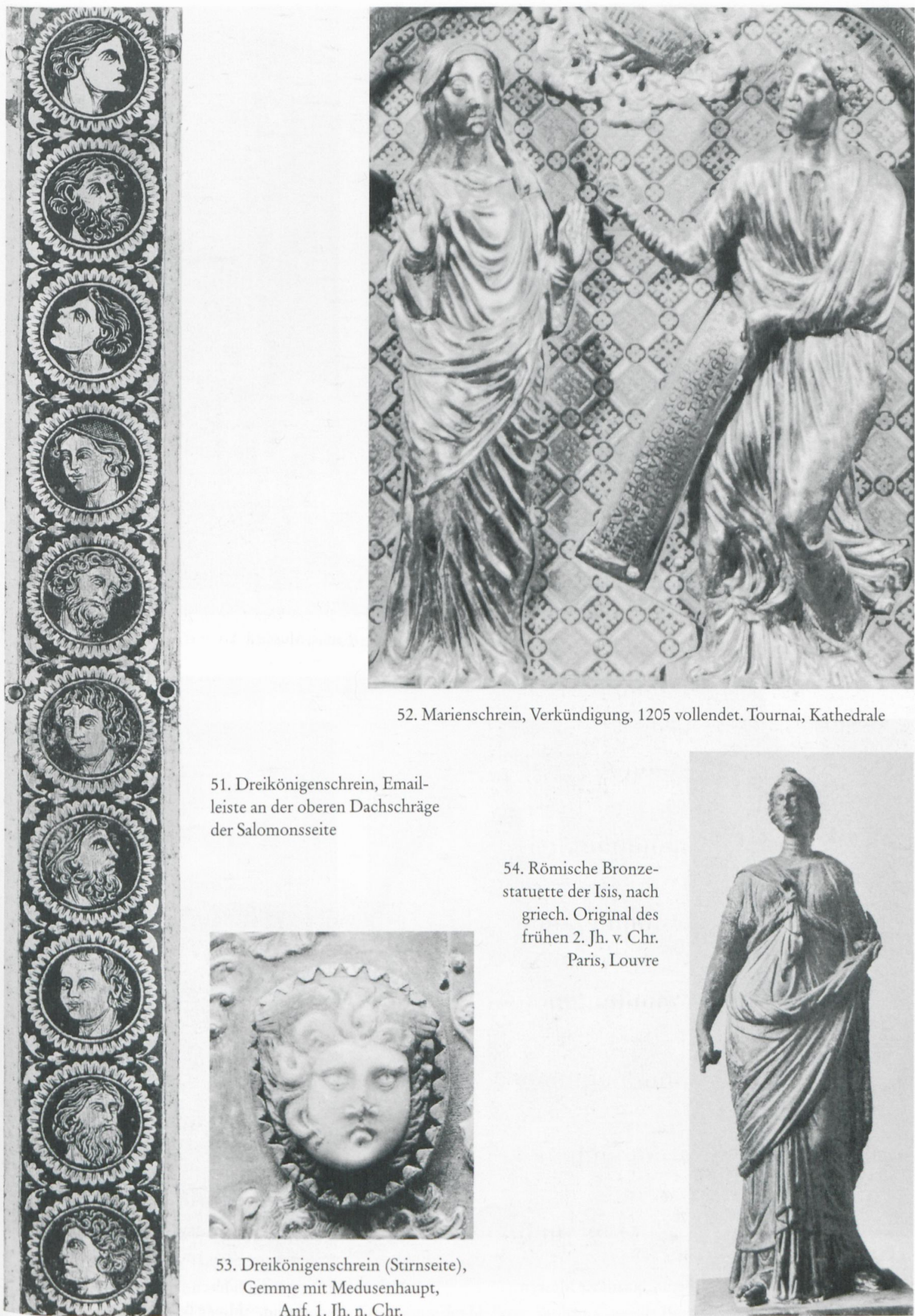

52. Marienschrein, Verkündigung, 1205 vollendet. Tournai, Kathedrale

51. Dreikönigenschrein, Emailleiste an der oberen Dachschräge der Salomonsseite

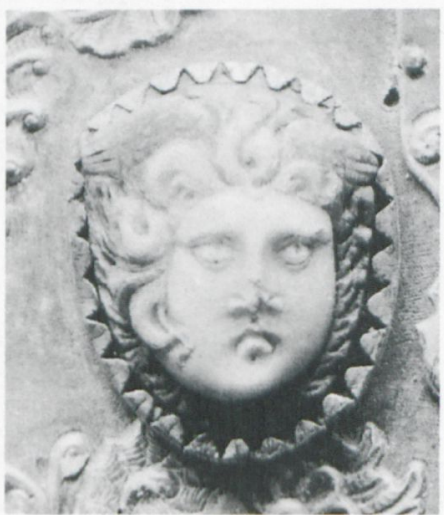

53. Dreikönigenschrein (Stirnseite), Gemme mit Medusenhaupt, Anf. 1. Jh. n. Chr.

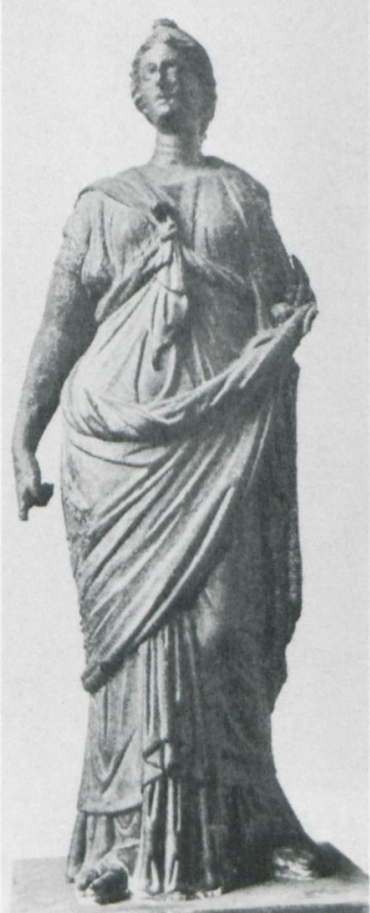




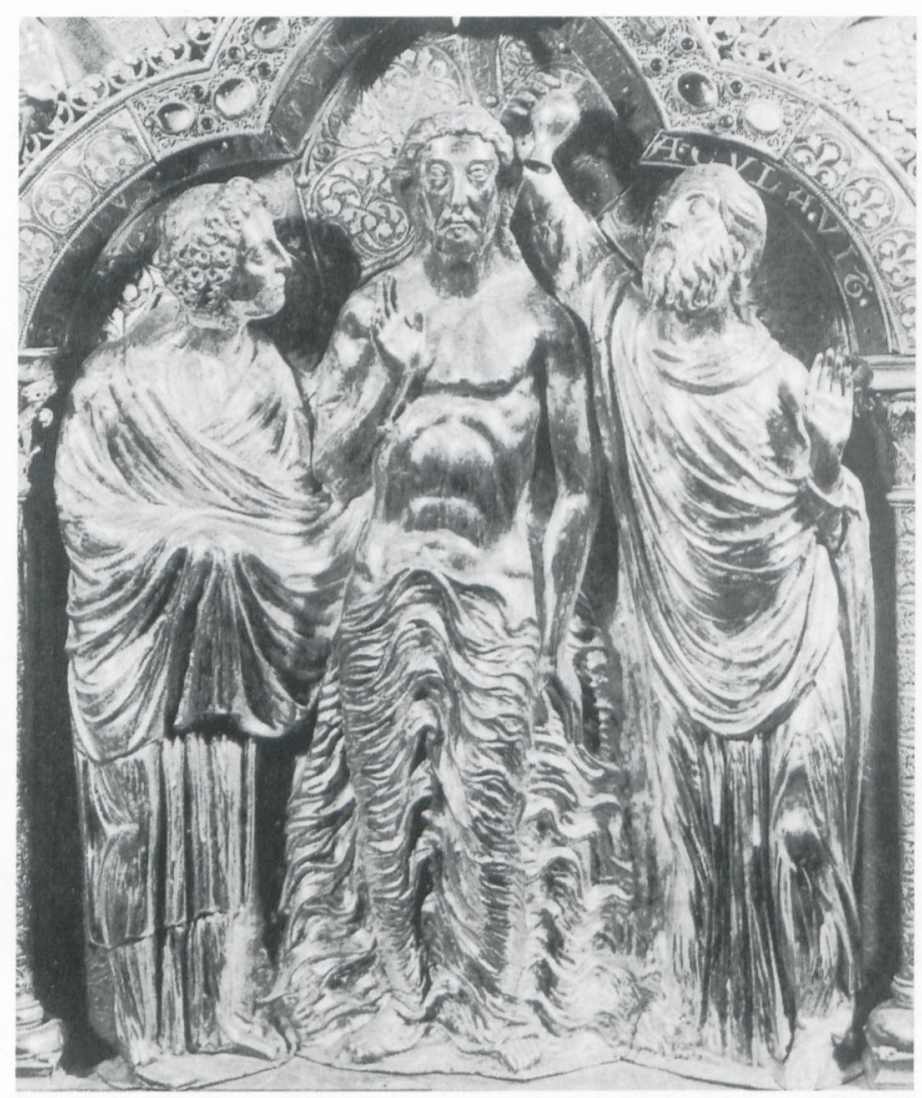

55. Marienschrein, Taufe Christi

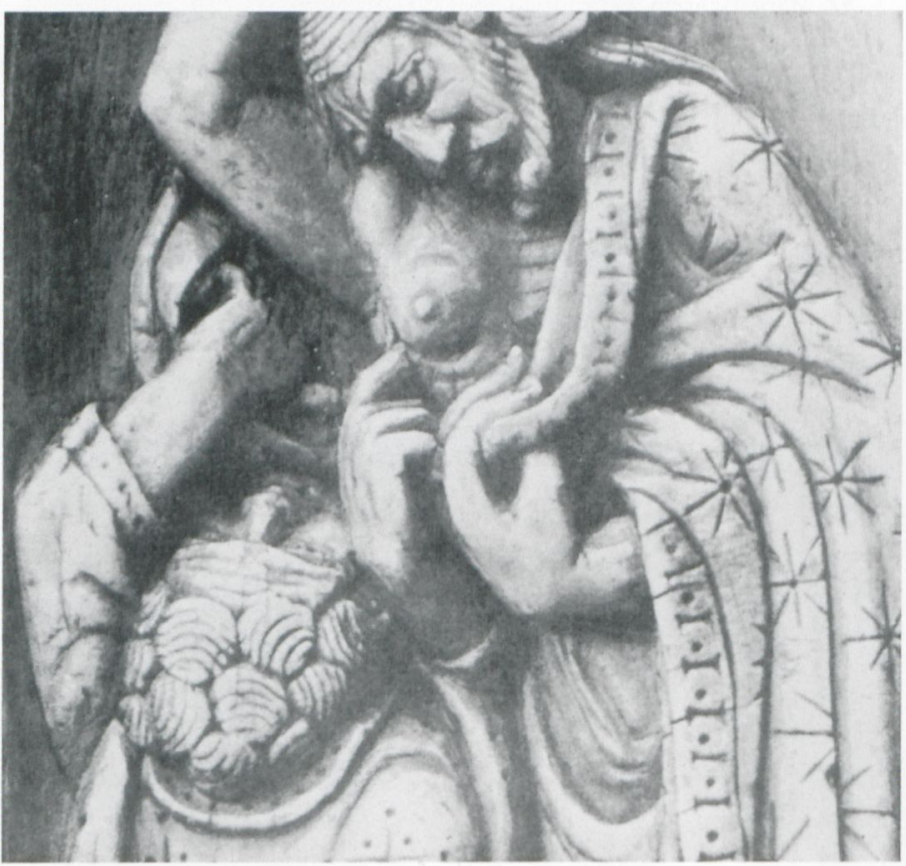

57. Tafel eines Diptychons mit dem ungläubigen Thomas, 2. Viertel d. 11. Jh. (Detail). Berlin, Staatliche Museen

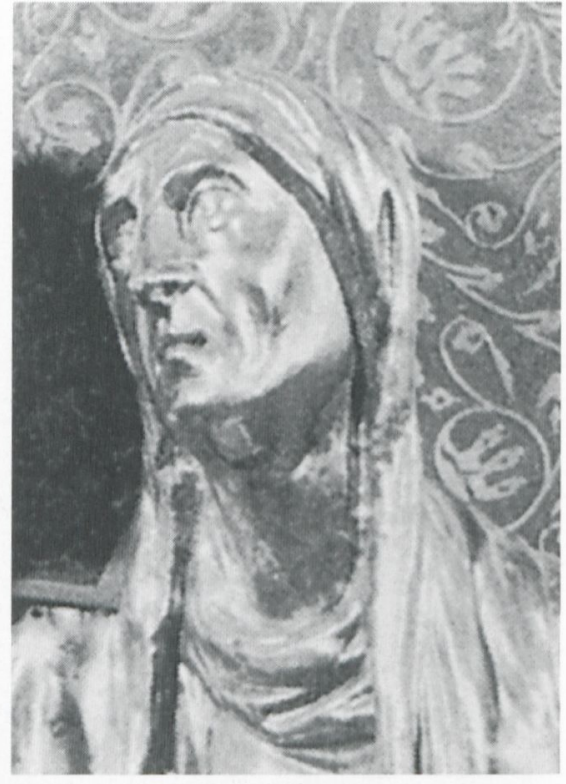

56. Marienschrein, Heimsuchung (Detail)

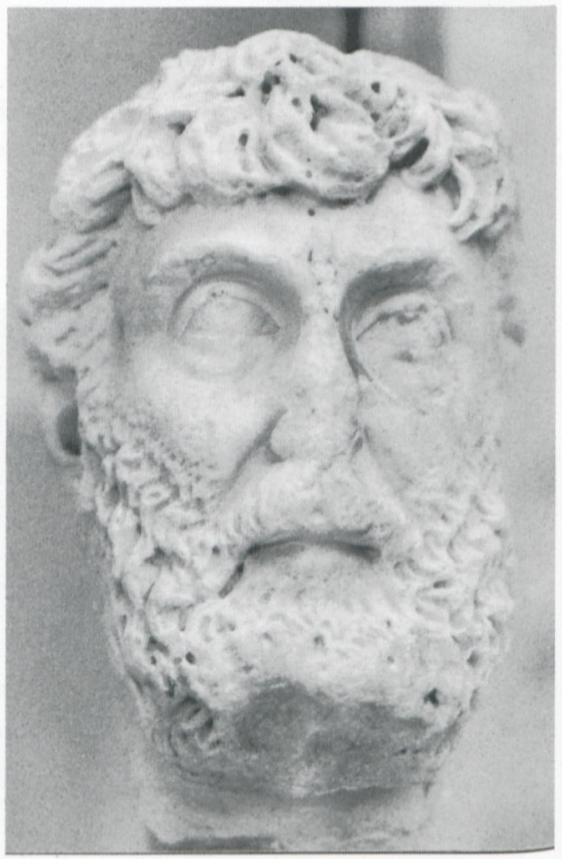

58. Männlicher Porträtkopf, spätantoninisch-frühseverisch. Reims, Musée de Saint-Rémi 